\title{
The decline of silky lacewings and morphological diversity of long-nosed antlion larvae through time
}

\author{
Gideon T. Haug, Carolin Haug, Paula G. Pazinato, Florian Braig, \\ Vincent Perrichot, Carsten Gröhn, Patrick Müller, and Joachim T. Haug
}

\begin{abstract}
Psychopsidae (silky lacewings) is a species-poor ingroup of Neuroptera. Silky lacewings show a distinct relic distribution, indicating that the group was more speciesrich and diverse in the past. Silky lacewings have distinct larvae that resemble antlion larvae but differ from these in lacking teeth on their mouth parts, and in having a projecting labrum, which makes them "long-nosed antlion larvae". These larvae are well known from Myanmar amber (about 100 mya) and Baltic amber (mostly 34-38 mya, possibly 23-48 mya), as well as from the extant fauna. We report and figure numerous additional specimens from both amber types and from ca. 100 mya old French Charentese amber, expanding the known record of well-illustrated extant and fossil specimens from 26 to 52 specimens. We compare the diversity of head shape among these larvae through time by outline analysis. Results indicate that morphological diversity was pronouncedly higher in the Cretaceous, even after sample size correction. Eocene representatives are more diverse than modern representatives, but less diverse than Cretaceous ones, in one shape aspect that explains most of the overall variation $(55.7 \%)$. Eocene representatives are less diverse in another shape aspect that explains the second-most variation $(26.9 \%)$, but this might reflect a lack of first larval stage specimens. There seems to be no strong correlation between size and shape. This type of analysis enables a test for the loss of diversity over time, based on morphological diversity as a proxy, without the requirement of identifying fossil larvae down to a narrow taxonomical range.
\end{abstract}

Gideon T. Haug. Ludwig-Maximilians-Universität München, Biocenter, Großhaderner Str. 2, 82152 Planegg-Martinsried, Germany. gideon.haug@palaeo-evo-devo.info Carolin Haug. Ludwig-Maximilians-Universität München, Biocenter, Großhaderner Str. 2, 82152 PlaneggMartinsried, Germany and GeoBio-Center at LMU, Richard-Wagner-Str. 10, 80333 München, Germany. carolin.haug@palaeo-evo-devo.info

Paula G. Pazinato. Ludwig-Maximilians-Universität München, Biocenter, Großhaderner Str. 2, 82152

Haug, Gideon T., Haug, Carolin, Pazinato, Paula G., Braig, Florian, Perrichot, Vincent, Gröhn, Carsten, Müller, Patrick, and Haug, Joachim T. 2020. The decline of silky lacewings and morphological diversity of long-nosed antlion larvae through time. Palaeontologia Electronica, 23(2):a39. https://doi.org/10.26879/1029 palaeo-electronica.org/content/2020/3113-long-nosed-antlion-diversity

Copyright: August 2020 Palaeontological Association.

This is an open access article distributed under the terms of Attribution-NonCommercial-ShareAlike 4.0 International (CC BY-NC-SA 4.0), which permits users to copy and redistribute the material in any medium or format, provided it is not used for commercial purposes and the original author and source are credited, with indications if any changes are made.

creativecommons.org/licenses/by-nc-sa/4.0/ 
Planegg-Martinsried, Germany. paula.pazinato@palaeo-evo-devo.info Florian Braig. Ludwig-Maximilians-Universität München, Biocenter, Großhaderner Str. 2, 82152 PlaneggMartinsried, Germany. florianbraig@t-online.de Vincent Perrichot. Univ. Rennes, CNRS, Géosciences Rennes, UMR 611835000 Rennes, France. florianbraig@t-online.de

Carsten Gröhn. Bünebüttler Weg 7, 21509 Glinde, Germany. vincent.perrichot@univ-rennes1.fr Patrick Müller. Friedhofstr. 9, 66894 Käshofen, Germany. pat14789@web.de Joachim T. Haug. Ludwig-Maximilians-Universität München, Biocenter, Großhaderner Str. 2, 82152 Planegg-Martinsried, Germany and GeoBio-Center at LMU, Richard-Wagner-Str. 10, 80333 München, Germany. joachim.haug@palaeo-evo-devo.info

Keywords: Psychopsidae; Neuroptera; Baltic Amber; Burmese Amber; French Amber; elliptic Fourier transformation

Submission: 15 September 2019. Acceptance: 20 July 2020

\section{INTRODUCTION}

Our terrestrial ecosystem is dominated by the myriad forms of the group Insecta. In recent years there has been a frightening decline of diversity in this group (e.g., Dunn, 2005; Hallmann et al., 2017), which begs the question: what is the cause behind this decline? To improve our understanding of possible causes we should consider the processes behind such declines. One approach is to observe comparable processes back in time, i.e., look at past cases of decline in diversity, as documented by the fossil record.

At first, we should know how the diversity of the group Insecta is structured. There is a distinct taxonomic pattern: most of the true species richness is concentrated in the group Holometabola (sometimes also referred to as Endopterygota), the species richness of which is concentrated among four major ingroups: 1) Diptera - flies, gnats, midges and mosquitoes; 2) Lepidoptera - butterflies and moths; 3) Coleoptera - beetles and weevils; and 4) Hymenoptera - wasps, bees and ants. Each of these four ingroups includes more than 100,000 species. It has been suggested that at least part of the reason for the evolutionary success of Holometabola is the differentiation of lifestyles in larvae and corresponding adults. Besides the highly successful four major ingroups, there are also further ingroups of Holometabola with fewer species. One of these is the group of lacewings, Neuroptera.

Adult lacewings roughly resemble butterflies or dragonflies in many aspects of their morphology, but lacewing larvae look very different from larvae of other groups (and from their corresponding adults). Most lacewing larvae have an elongate body with six locomotory appendages, but are unique in having long, prominent and forward projecting mouth parts. The most prominent mouth parts, mandibles and maxillae, form a pair of functional stylets with a central channel. Most larval lacewings are ambush predators and use their stylets for injecting venom into their prey. The venom partly predigests the prey, and the liquefied innards are sucked out through the stylets (e.g., Cover and Bogan, 2015). The larvae have a blind ending gut, which might be coupled to the exclusively liquid food.

Currently, relationships within Neuroptera are not reliably resolved (cf. Winterton et al., 2010, 2018; Aspöck et al., 2012; Engel et al., 2018), but one large ingroup is very stable, Myrmeleontiformia. This group includes all groups which are closely related to antlions, the most famous lacewings, with their iconic pit-building larvae. One of the ingroups of Myrmeleontiformia is Psychopsidae, the group of silky lacewings. Psychopsidae includes only 28 extant species (Makarkin, 2018), which have an exclusive distribution in Southeast Asia, Southern Africa and Australia (Oswald, 1993; Bakkes et al., 2017); this is a typical case of a relic distribution, i.e., in ancient times the group had a larger distribution than today. This observation is supported by fossils in European ambers although silky lacewings no longer occur in Europe.

Larvae of silky lacewings resemble antlion larvae in overall appearance. Yet, they differ in certain aspects (Makarkin, 2018): 1) the labrum is prominent and forward projecting, 2) a prominent long seta arises at the distal end of the antenna, 3) the mandibles are smooth and toothless, and 4) the walking legs bear prominent trumpet-shaped empodia (attachment structures) at their distal end. The prominent labrum in silky lacewing larvae 
imparts a long-nosed appearance. Similar to larvae of Crocinae (ingroup of Nemopteridae), which are often called "long-necked antlions" due to the elongate neck region, larvae of silky lacewings could thus be called "long-nosed antlions" because of the prominent labrum.

Psychopsidae appear to have been more diverse in the past and have since seen a decline in diversity. Their larvae, as for all holometabolans, play a central role in the ecological impact of silky lacewings. To improve our understanding of processes in diversity declines, we 1) review all available specimens of silky lacewing larvae from the literature, fossil and extant, 2) report numerous new fossil specimens and 3) analyse the changes in diversity of larval morphology of Psychopsidae over time in this study.

\section{MATERIAL AND METHODS}

\section{Material}

Material for this study came from different collections: one specimen deposited in the Museum of Comparative Zoology (MCZ) Harvard (PALE 18004), one in the Natural History Museum (Museum für Naturkunde) Berlin (MBI 5648) and one in the collections of the University of Rennes (IGR.ARC-205.2). Three specimens come from the collection of one of the authors (collection Gröhn 2994, 7507, 7639). Four specimens come from the collection of one of the other authors (collection Müller BUB 3179, 3356, 3386, 3389; see the discussion herein for remarks on the availability of these specimens). Eighteen specimens are deposited in the collection of the Palaeo-Evo-Devo Research Group Collection of Arthropods, LudwigMaximilians-Universität München (PED 0039, 0045, 0051, 0055, 0060, 0063, 0080, 0082, 0100, 0109, 0125, 0127, 0128, 0131, 0133, 0137, 0153, 0205). The PED specimens were purchased on ebay.com by various traders (burmite-miner; burmite-researcher; burmitefossil; cretaceous-burmite; macro-cretaceous; mi2leon). Additional photographs of in total four specimens were kindly provided by Jonas Damzen (amberinclusions.eu) and Marius Veta (ambertreasure4u.com).

\section{Documentation Methods}

Documentation of most specimens was performed on a Keyence VHX 6000 digital microscope, namely of all specimens from the collections Gröhn, Müller and PED, as well as those from the University of Rennes and the Museum in Berlin. We photographed each speci- men from both sides (if accessible), once illuminated by coaxial cross-polarised light (Haug et al., 2013a) and once by unpolarised ring light, under both illuminations with a white and a black background. The images providing the best contrast were used.

The specimen from the collection of the MCZ was photographed with a Canon EOS Rebel T3i equipped with a MP-E $65 \mathrm{~mm}$ super-macro lens. Illumination was provided by flashes equipped with polarisers, together with a perpendicular filter in front of the lens, providing cross-polarised light.

Some details were also documented on a Keyence BZ 9000 fluorescence microscope. Different illuminations with UV (DAPI), blue (GFP), green light (TRITC) and white light (bright field) were used. Each image was documented as a composite (Haug et al., 2008, 2011). Every image detail was documented by a stack of images of varying focus; several adjacent images details were recorded covering the entire specimen. Each image was documented under several exposure times to resolve also darker structures (Haug et al., 2013b).

\section{Image Processing}

Images recorded on the Keyence VHX 6000 were processed automatically by the built-in software. Images recorded on the Keyence BZ 9000 were processed with external software. Stacks of images were fused with Combine ZP to receive sharp images. Adjacent image details were stitched with Adobe Photoshop Elements 11. Adobe Photoshop CS2 and CS3 were used for optimising all images (histograms, saturation, sharpness).

\section{Presentation}

All visible structures of the fossils were colourmarked to provide an interpretation of the structures. Adobe Illustrator CS2 was used to redraw silky-lacewing larvae from images in the literature. The drawings were slightly simplified; corresponding structures were given the same colours.

\section{Shape Analysis}

A comparative statistical analysis of the morphology of the specimens was conducted by a Principal Component Analysis (PCA) of the results of an Elliptic Fourier analysis. All accessible heads (head capsules), in total 45, were redrawn by hand in Adobe Illustrator CS2. Hereby, the better-preserved half of the head was drawn and mirrored. The resulting image was checked against the origi- 
nal to reduce possible artefacts. Dorsal and ventral views were used although there are slight differences, but the important criterion was a wellaccessible posterior rim of the head capsule.

Redrawn images were analysed in SHAPE (C) National Agricultural Research Organization of Japan), a free software providing the tools to perform Elliptic Fourier and PCA analysis. The software transforms the outlines of the head reconstruction drawings into a vectorized object, also called chain code. To achieve this, the program uses a vector-based step-by-step approximation of an ellipse to the outline of the head. The vectorized shapes (chain codes) are represented by numeric values, which are then transformed into normalized Elliptic Fourier Descriptors (EFDs). This method represents a variation of the wellknown Fourier transformation, practically applied on shapes of natural objects. The 45 EFDs were finally analysed with a Principal Component Analysis (PCA) that resulted in the most important characters for morphological diversity in the data set. The entire procedure including the PCA was applied following Iwata and Ukai (2002) and Braig et al. (2019). The results of the PCA were finally visualized using Microsoft Excel. The first two and, therefore, most important dimensions (Principal Components) were plotted against each other.

\section{Morphospace Occupation}

We compared the diversity of head shape for three time slices: Cretaceous, Eocene (most probably, but see Sadowski et al., 2017 for possibilities of younger age) and extant. For each, the range of occupation of the dominating assembled dimensions (principle components) was plotted and compared. Principal Component values for each individual of each group (time slice) were plotted for the first two Principal Components. An exception was the group of Cretaceous specimens. Here, sample-size-corrected maximum and minimum values were also plotted. In this way, the diversity of head shape for each time slice was depicted and compared for the first two PCs, and diversity of head shape was taken as an indicator proxy for overall variation.

\section{Sample Size Correction}

Sample sizes are different for each time slice, which may affect the comparison results. We therefore needed a correction for sample size differences. To achieve this, we selected the smallest sample size (10 of both Eocene and modern specimens) as a baseline. In order to adapt the 25 Cre- taceous specimens to this sample size, we randomly selected 10 specimens from the Cretaceous, then took the largest and smallest value for every PC and saved them. This process was repeated for a thousand times, and the means of these thousand maximum and minimum values were calculated. This process was conducted using the R-statistics environment 3.4.3 (R Core Team, 2018).

\section{RESULTS}

\section{Extant Larval Representatives of Psychopsidae Depicted in the Literature}

All depictions of extant larval representatives in the literature are listed chronologically. Cases in which the same specimen has been re-figured are also included chronologically with reference to the original occurrence. While this includes a certain redundancy, it should represent the most complete way of cross-referencing, avoiding interpreting the same specimen as two independent occurrences.

1) Froggatt (1907) provided the drawing of a larva of Psychopsis mimica (his fig. 33) in dorsal view (specimen 1; Figure 1A). The drawing is symmetrical and not very detailed, indicating a certain degree of idealisation. Still the drawing appears to be based on an actual specimen (see discussion in MacLeod, 1964). No indication of size was provided.

2) Tillyard (1918) provided the so far only complete post-embryonic development of a species of Psychopsidae (all instars as drawings). The first depiction was that of an instar 1 (specimen 2; Figure 1B; Tillyard, 1918, his text-fig. 2a) including detail of distal region of walking appendages (his text fig. 2b). Based on some sizes given in the text we can estimate the overall size to have been about $2.7 \mathrm{~mm}$. Tillyard's plate LXXIX fig. 2 shows another instar 1 specimen; yet it remains unclear whether it is the same individual. According to the text, Tillyard appears to have had numerous specimens. Yet, due to the uncertainty we do not further consider the second drawing. Another individual is likewise an instar 1 , yet well fed, probably several months old, and with a much larger trunk (Tillyard, 1918, his plate LXXIX fig. 3). Estimated size is about $4.3 \mathrm{~mm}$. It is further considered here, although it may represent the same individual (indicated in the figure legend "The same larva", yet this might refer also to the 'same species'), as it represents clearly another developmental state (therefore treated as a separate entity of information, hence specimen 3; Figure 1C). Also two fur- 


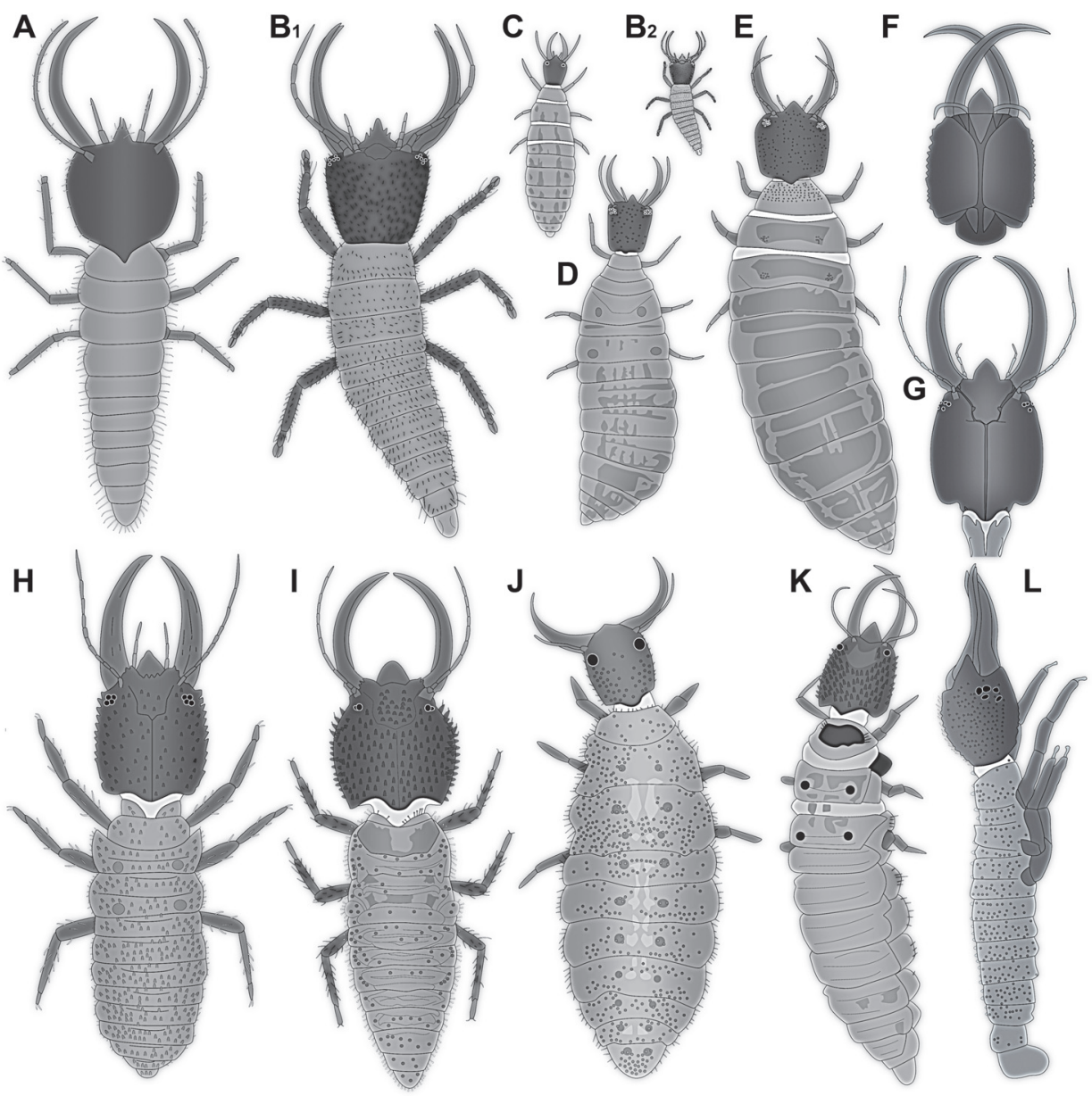

FIGURE 1. All known extant long-nosed antlion larvae, i.e., larvae of silky lacewings (Psychopsidae). Drawings partly simplified. A. Specimen 1, from Froggatt (1907). B-E. All from Tillyard (1918). B1. Specimen 2. B2. Specimen 2 in the same scale as the other specimens from Tillyard (1918). C. Specimen 3. D. Specimen 4. E. Specimen 5. F. Specimen 6, from Withycombe (1925). G. Specimen 7, from Macleod (1964). H. Specimen 8, from New (1989). I. Specimen 9, from New (1991). J. Specimen 10, from Aspöck and Aspöck (1999). K. Specimen 11, from Badano et al. (2017). L. Specimen 12, from Bakkes et al. (2017).

ther stages, an instar 2 (specimen 4; Figure 1D; Tillyard, 1918, his plate LXXIX fig. 4; estimated size about $8 \mathrm{~mm}$ ) and an instar 3 (specimen 5; Figure 1E; Tillyard, 1918, his plate LXXIX fig. 5; estimated size about $11.5 \mathrm{~mm}$ ) were depicted. Additionally, many details have been provided in Tillyard (1918) including: a close-up of an exuvium of an isolated head (his text-fig. 3); a close-up of isolated stylet details (his text-fig. $4 a-c$ ); a close-up of an isolated clypeo-labral complex (his text-fig. $5 a$ ); a close-up of an isolated labium (his text-fig. $5 b$ ); a close-up on specialised setae (dolichasters and others; his text-figs. 7a-c, 8); a close-up on the anal region (his text-fig. 9). The instar 3 specimen (specimen 5) was re-figured with slight modifications by Gepp (1984).

3) Withycombe (1925) provided a drawing of a head of Psychopsis elegans (specimen 6; Figure
$1 F$ ) in ventral view (his plate XXXIX fig. 6). It does not resemble any earlier drawing and is considered as based on an actual specimen. No indication of size was provided.

4) MacLeod (1964) provided the drawing of a head and part of the prothorax of a larva of Psychopsis elegans (specimen 7; Figure 1G). This includes a dorsal view (his fig. 66), a ventral view (his fig. 67), a lateral view (his fig. 68), close-ups of the dissected inner ventral side (his fig. 69), closeup of isolated stylet (mandible and maxilla) (his fig. 70 ), close-up of surface structure of head capsule (his fig. 71), close-up of maxilla (his fig. 72). MacLeod states that he had in total 10 specimens (!) available for study, yet his drawings only refer to a single specimen. According to the provided scale the head capsule would be about $0.2 \mathrm{~mm}$ in length. In comparison to other specimens this would be 
exceptionally small. We suggest that the scale was mislabelled and that the head capsule of the specimen measured about $2 \mathrm{~mm}$. The drawing was refigured with modifications by Aspöck and Aspöck (2007).

5) Gepp (1984) provided a drawing of a stage 3 larva in dorsal view (his fig. 15a). According to his reference list this is a redrawing of specimen 5 of Tillyard (1918). The specimen is not considered for further reaching analysis to avoid data duplication. Gepp also re-figured (his fig. 15b) the close-up of an exuvium of an isolated head from Tillyard (1918).

6) New (1989) provided the drawing of a larva (specimen 8; Figure 1H) in dorsal view (his fig. 145). According to legend it is an original drawing, presumably based on a single actual specimen. No indication of size is provided.

7) New (1991) provided the drawing of a larva (specimen 9; Figure 1I) in dorsal view (his fig. $34.12 \mathrm{~B}$ ). It is distinctly different from the earlier drawing in New (1989). Degree of details indicates that an actual specimen was the basis for this drawing. According to figure legend the drawing is from A. Hastings, which could be read that the figure is re-used from an earlier publication (New appears to cite such cases in the same manner at other places in the same publication). Checking the acknowledgements reveals that Ms. Anne Hastings prepared many of the line drawings; hence the drawing appeared here for the first time. No indication of size is provided. The drawing was re-figured by Tauber et al. (2003).

8) Aspöck and Aspöck (1999) provided a photograph (their Abb. 52) of a larva of Cabralis gloriosus in the field (specimen 10; Figure 1J). The specimen is seen in almost perfect dorsal view. According to figure legend, the photograph was provided by Peter Duelli. No indication of size is provided. The photograph was re-figured by Bakkes et al. (2018).

9) Tauber et al. (2003) re-figured specimen 9 (drawing by New, 1991; their fig. 5A).

10) Aspöck and Aspöck (2007) provided a colour-coded version of specimen 7 (drawing of MacLeod, 1964) as a basis for comparison of mouth parts (their Abb. 100).

11) Badano et al. (2017) provided a photograph of a larva of Psychopsis sp. (specimen 11; Figure $1 \mathrm{~K}$ ). The specimen is seen in slightly lateral, but largely dorsal view (their fig. 1A). According to figure legend, the photograph was provided by Shaun Winterton. No indication of size is provided; the photograph was re-figured by Makarkin (2018); the size is given there as $10-12 \mathrm{~mm}$.

12) Bakkes et al. (2017) figured several micrographs (their figs. 109-111) of an unusually gathered larva (specimen 12; Figure 1L) that apparently developed inside the mother as she was sacrificed short before she was able to lay the egg. The specimen is partly unusual due to its history, and appendages appear somehow displaced and/or deformed. They also re-figured specimen 10 (their fig. 26), i.e., the image by Aspöck and Aspöck (1999), yet attributed it to the species Cabralis pallidus.

13) Bakkes et al. (2018) re-figured specimens 10 and 11 (their figs 1E, G; photographs from Aspöck and Aspöck, 1999 and Badano et al., 2017).

14) Makarkin (2018) re-figured specimen 11 (his fig 5C; photograph from Badano et al., 2017).

\section{Fossil Larval Representatives of Psychopsidae Depicted in the Literature}

Also all occurrences of depicted fossil larvae are listed chronologically. Re-figured cases are included chronologically as well despite the redundancy (see above).

15) MacLeod (1970) provided photographs of two specimens preserved in Baltic amber (specimens 13 and 14). He provided an overview for a specimen from the collection of the Natural History Museum (Museum für Naturkunde) Berlin, MBI 5648 (his fig. 13) as well as a close-up of the head (his fig. 12). The second specimen, from the collection of the MCZ (Museum of Comparative Zoology) Harvard, PALE 18004, is shown as an overview (his fig. 14). Both specimens were interpreted as larvae of Propsychopsis sp. Both specimens are re-figured here (Figure 2), yet no new observations have been made.

16) Larsson (1978) provided a drawing of a head of a very small lacewing larva preserved in Baltic amber. Larsson mentions that in total three such larvae are preserved in a single piece of amber and suggests that these larvae might be representatives of Psychopsidae. This interpretation is tentatively followed by Pérez-de la Fuente et al. (2020). The details of the drawing are not easy to evaluate: 1) There is a certain elevation of the anterior rim of the head capsule that could represent a labrum. 2) The stylets are slightly curved and lack teeth; yet the curvature is not very pronounced. 3) The specimen is extremely small; the head capsule measures less than $0.25 \mathrm{~mm}$. This is 


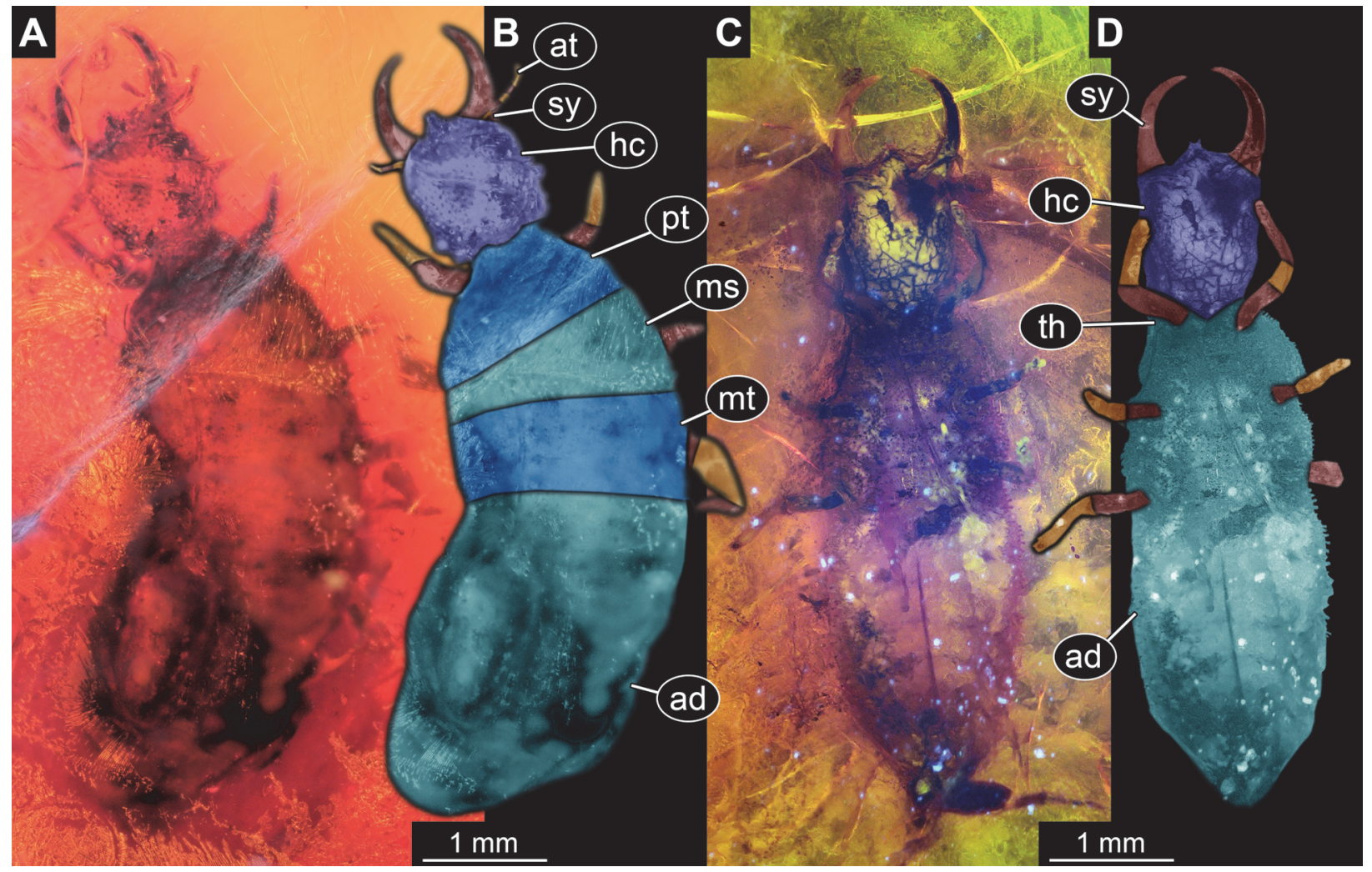

FIGURE 2. Fossils of long-nosed antlion larvae, i.e., larvae of silky lacewings (Psychopsidae). A. Specimen 13, Natural History Museum (Museum für Naturkunde) Berlin, MBI 5648. B. Colour-marked version of A. C. Specimen 14, MCZ (Museum of Comparative Zoology) Harvard, PALE 18004. D. Colour-marked version of C. Abbreviations: ad = abdomen; at = antenna; hc = head capsule; $\mathrm{ms}=$ mesothorax; $\mathrm{mt}=$ metathorax; $\mathrm{pt}=$ prothorax; $\mathrm{sy}=\mathrm{stylet}$; th = thorax.

smaller than any known clear larval representative of Psychopsidae (see also further below for sizes).

Based on the few details, the specimen cannot be easily excluded from being a larval representative of Psychopsidae, yet there are no strong arguments for this interpretation either. We therefore come to the same conclusion as earlier authors, this is a candidate for being a representative of Psychopsidae, but it remains unclear. The specimen is not further considered here but should be re-investigated.

Larsson (1978) makes furthermore interesting statements. He mentions that representatives of Psychopsidae are relatively common (possibly in comparison to other lacewings, but this was not explicitly stated) and that larvae and adults both occur at about the same numbers.

17) Weitschat and Wichard (1998) provided photographs of a specimen preserved in Baltic amber (specimen 15; Figure 3A). This includes an overview in dorsal view as well as a close-up of the head in dorsal view. Remark: this source was not seen by the current authors, the information comes from one of the original authors (Wichard, pers. comm. 2019). The photograph was re-figured by Weitschat and Wichard (2002).

18) Grimaldi (2000) provided a photograph and drawings of a specimen from New Jersey amber. The photograph (his fig. 22c) provides an overview; the drawings provide an overview in ventral view and a close-up of the head in dorsal view (his fig. 3). Grimaldi interpreted the larva as a possible representative of Psychopsidae. Also, Pérezde la Fuente et al. (2020) were unsure about the identification, similarly suggesting Psychopsidae but with a question mark.

Considering the available characters: 1) The mandibles are curved and toothless, hence well compatible with an interpretation as a larva of Psychopsidae. Yet, also interpretations as a larva of other lacewing ingroups such as Chrysopidae would be compatible with this character. 2) The region of the labrum is unfortunately not well preserved, but the specimen may possess a labrum, yet it does not appear to be prominent as typical for larvae of Psychopsidae. 


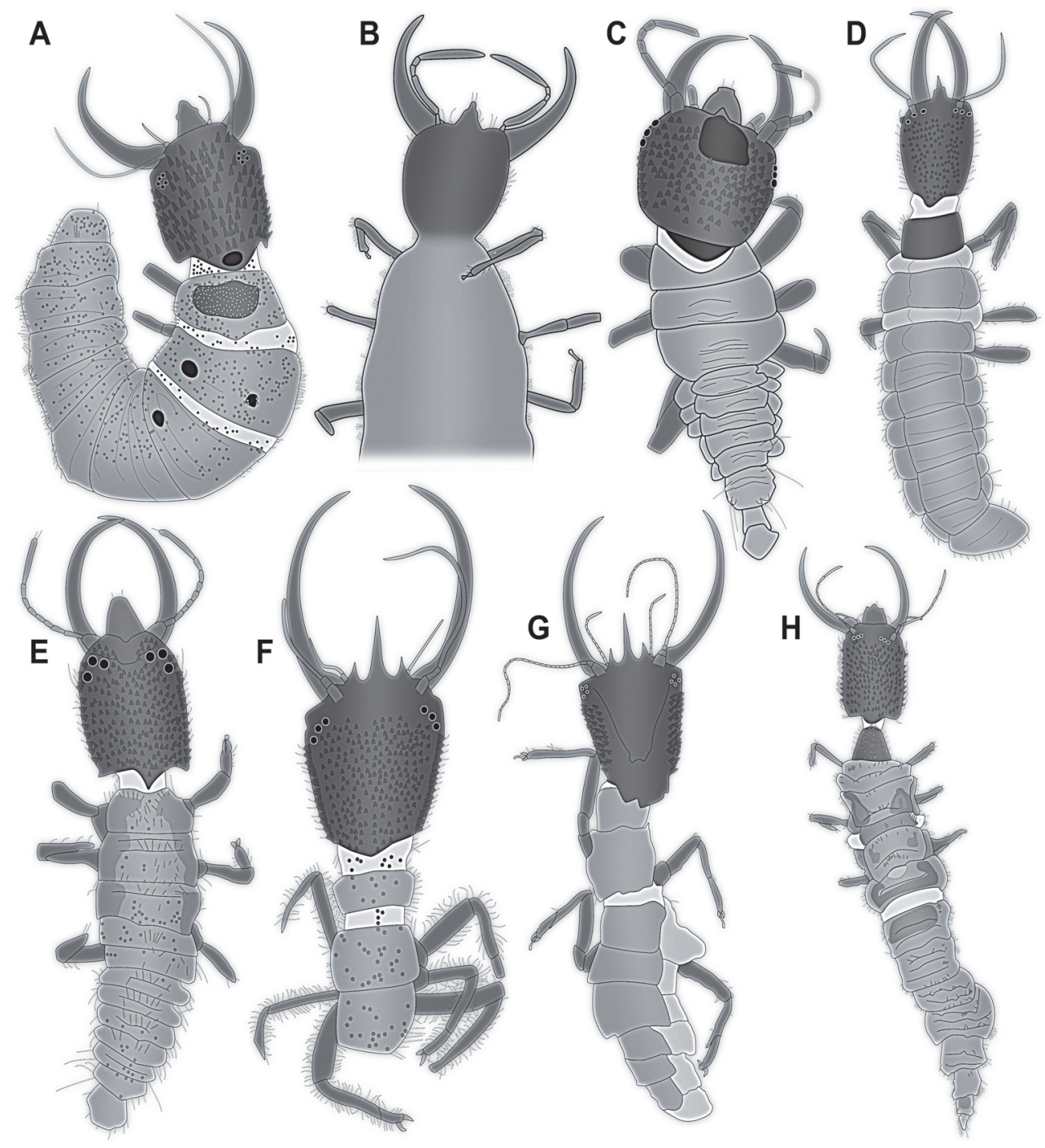

FIGURE 3. Fossils of long-nosed antlion larvae, i.e., larvae of silky lacewings (Psychopsidae), continued. Drawings partly simplified. A. Specimen 15, from Weitschat and Wichard (1998, 2002). B. Specimen 17, from Scheven (2004). C. Specimen 18, from Engel and Grimaldi (2008). D. Specimen 19, from Gröhn (2015). E. Specimen 20, from Zhang (2017). F. Specimen 21, from Badano et al. (2018). G. Specimen 22, from Makarkin (2018). H. Specimen 23, from Makarkin (2018).

Other characters are more problematic. 3) The tip of the antenna appears quite well preserved, yet it does not bear a prominent seta distally. 4) No empodium is directly apparent, yet the area around the distal end of the walking legs appears partly concealed by the typical white coating found around some amber inclusions (hereafter named 'Verlumung' which is the established German expression for this taphonomic effect; the corresponding adjective is 'verlumt'). There seems to be at least an indication of empodia within the Verlumung. Empodia are well compatible with an interpretation as a larva of Psychopsidae but also with other groups including Chrysopidae. 5) Another interesting feature is that the head appears partly surrounded by anterior trunk ("immersed"). This feature is unusual for larvae of Myrmeleontiformia, but known, for example, in larvae of Chrysopidae.

In summary, the specimen is clearly a neuropteran larva, but whether it is a representative of Myrmeleontiformia or of another lineage, for example, more closely related to Chrysopidae, is uncertain. We, therefore, do not further consider this specimen here.

19) Weitschat and Wichard (2002) re-figured the specimen from Weitschat and Wichard (1998; 
specimen 15). An overview image in dorsal view (their plate 55e) as well as a close-up of the head in dorsal view is provided (their plate $55 \mathrm{~g}$ ). A magnification factor is provided, indicating that the specimen measured about $5 \mathrm{~mm}$ in total length.

20) Perrichot (2003) provided a photograph of a specimen from Cretaceous French Charentese amber (his fig. 20b; there labelled as MNHN 205.2, but the specimen's final repository is in fact the Geological Department and Museum of the University of Rennes). The specimen (specimen 16) was interpreted as a larva of Ascalaphidae (Pérez-de la Fuente et al., 2020, also list it as such). The specimen is re-interpreted here; see further below. The photograph was re-figured in Perrichot et al. (2010).

21) Scheven (2004) provided a photograph of a specimen in amber (specimen 17; Figure 3B). The photograph has no label and is presented on page 69 , lower row in the middle. It also does not state whether the specimen is from Baltic or Dominican amber (both types of amber are used in other occasions of the book), yet as there is so far no report of larvae of Psychopsidae from Dominican amber, it is more likely that the specimen is from Baltic amber. The specimen is not fully shown; the posterior end is outside the field of view. The specimen is seen in ventral view and strongly verlumt. The labrum is prominent, resembling that of other larvae from Baltic amber. The antennae are partly out of focus, yet each of them seems to bear a prominent seta distally. The mandibles are curved and lack teeth, the walking legs bear prominent empodia. All characters are clearly compatible with this specimen being a larva of Psychopsidae, despite it being incompletely shown, verlumt and partly out of focus. There is no indication of size. There is also no indication of the collection, most likely the specimen came from the collection of the original author.

22) Engel and Grimaldi (2008) provided a photograph and drawings of a specimen (AMNH Bu-197) preserved in Cretaceous amber from Myanmar (specimen 18; Figure 3C). The photograph provides an overview in dorsal view (their fig. $5)$; drawings provide also overview in dorsal view as well as close-up of mouth parts in ventral view (their fig. 6). Another specimen is depicted (their fig. 7) and labelled as "psychopsid?". The specimen was tentatively re-interpreted as a possible larval representative of Berothidae by Pérez-de la Fuente et al. (2020). We agree with the latter authors that this specimen is unlikely to be a larval representative of Psychopsidae; the specimen is not further considered here. The first specimen was re-figured by Badano et al. (2018).

23) Perrichot et al. (2010) re-figured specimen 16 (their fig. 7E; the specimen from Perrichot 2003) and labelled it as "owlfly larva (Ascalaphidae)."

24) Gröhn (2015) provided a photograph (his fig. 1388 on p. 258) of a specimen preserved in Eocene Baltic amber (specimen 19; Figure 3D) labelled as "Psychopsidae Larve". The specimen is well preserved and accessible in dorsal view.

25) Zhang (2017) provided a photograph of a specimen preserved in Cretaceous amber from Myanmar (specimen 20; Figure 3E). The specimen is depicted in dorsal view and well preserved. It is labelled "Psychopsidae sp.". No figure number is provided, the figure is the lower one on page 392.

26) Badano et al. (2018) re-figured specimen 18 (their fig. 3B; the specimen from Engel and Grimaldi, 2008). Additionally, also another specimen (specimen 21, Figure 3F) is depicted (their suppl. fig. 1f-g). A reconstruction is provided as well (their fig. 4iii). The specimen is formally described as Acanthopsychops triaina. Although incomplete (the posterior trunk is missing) the specimen is well preserved and highly informative. Its labrum appears unusual as one central prominent spine-like protrusion is flanked by a pair of shorter protrusions ("trident").

27) Makarkin (2018) provided photographs of two fossil specimens preserved in Cretaceous amber from Myanmar. The first one (his fig. $5 \mathrm{~A}$ ) is a second specimen of Acanthopsychops triaina (specimen 22; Figure 3G), similar to the holotype with a missing posterior trunk. According to figure legend the photograph was provided by Arnold Staniczek. The second one (his fig. 5B) is a complete larva in dorsal view (specimen 23; Figure $3 \mathrm{H})$.

\section{Additional Fossil Specimens with Clear Long- Nosed Antlion Larva Morphology}

To expand the data set, we figure here additional larval specimens preserved in amber.

28) Specimen 24 (Gröhn 2994) is preserved in Eocene Baltic amber (Figure 4). The specimen is well accessible in dorsal view (Figure 4A, B), but largely concealed in ventral view (Figure $4 \mathrm{C}$ ). The labrum is prominent, simple triangular to pentagonal in dorsal view (Figure 4D). The antenna bears a prominent seta distally (Figure 4E). The surface of the head capsule bears distinct setose tubercles (Figure 4F). The specimen has a length of about $3.9 \mathrm{~mm}$. 


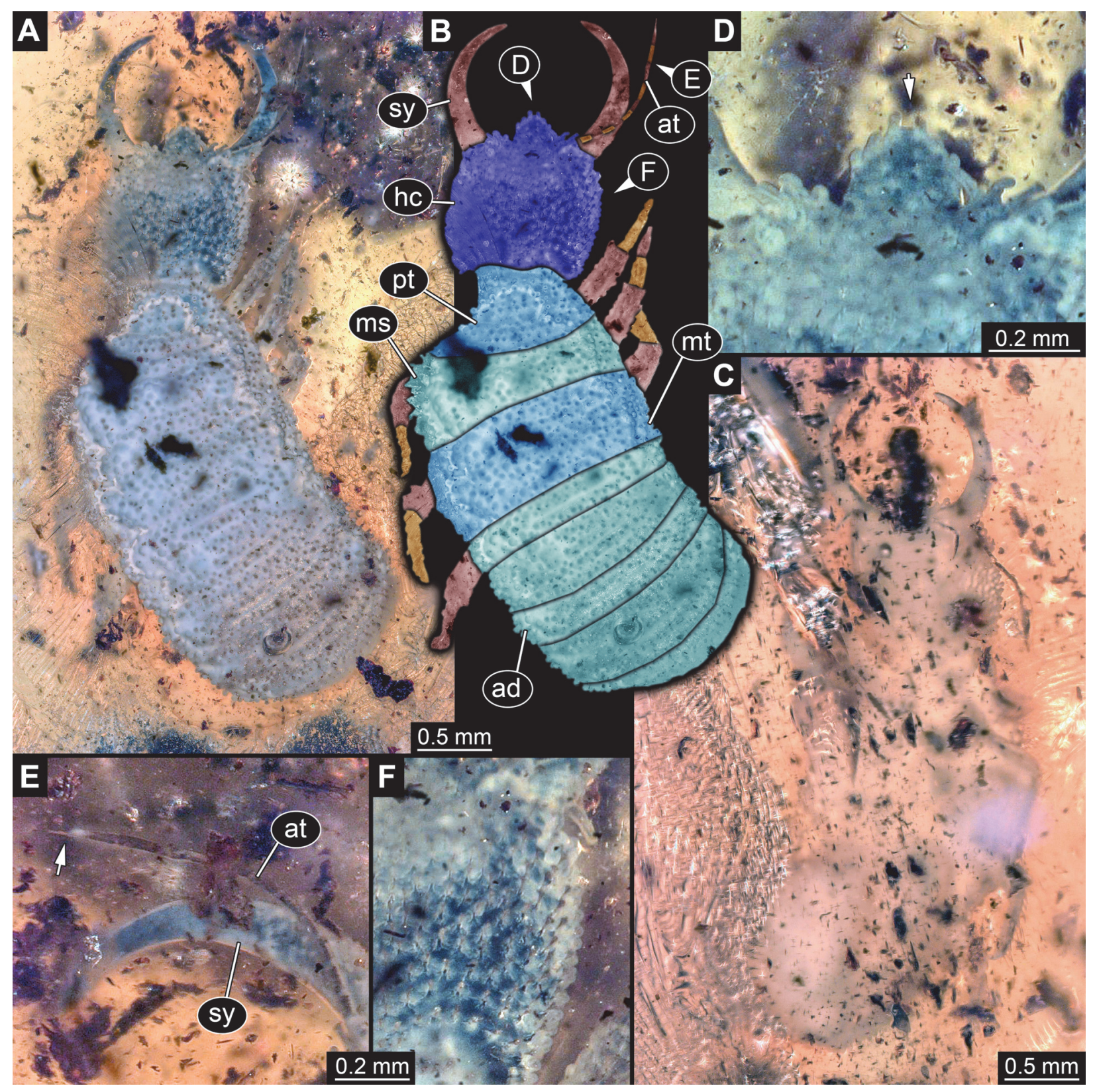

FIGURE 4. Specimen 24 (Gröhn 2994); Baltic amber. A. Dorsal view. B. Dorsal view, colour marked. C. Ventral view. D. Close-up of labrum in dorsal view (arrow). E. Close-up of antenna; arrow points to spine-like seta. F. Close-up of tubercles on head capsule in dorsal view. Abbreviations: ad = abdomen; at = antenna; hc = head capsule; $\mathrm{ms}=$ mesothorax; $\mathrm{mt}=$ metathorax; $\mathrm{pt}=$ prothorax; sy = stylet.

29) Specimen 25 (Gröhn 7639) is preserved in Eocene Baltic amber (Figure 5). The specimen is well accessible in dorsal view (Figure 5A, B), but partly concealed in ventral view (Figure $5 \mathrm{C}$ ). The antenna bears a prominent seta distally (Figure 5D). The labrum is prominent, simple triangular to pentagonal in dorsal view (Figure 5E). Each distal end of the walking appendages bears an empodium (Figure $5 F, G$ ). The specimen has a length of about $7 \mathrm{~mm}$.
30) Specimen 26 (Gröhn 7507) is preserved in Eocene Baltic amber (Figure 6A). The specimen is largely concealed in ventral view. The specimen has a length of about $5.86 \mathrm{~mm}$.

31) Specimen 27 is preserved in Eocene Baltic amber (Figure 6B). The photograph was kindly provided by Jonas Damzen (amberinclusions.eu). The specimen is well accessible in dorsal view. The specimen has a length of about $3.5 \mathrm{~mm}$. 


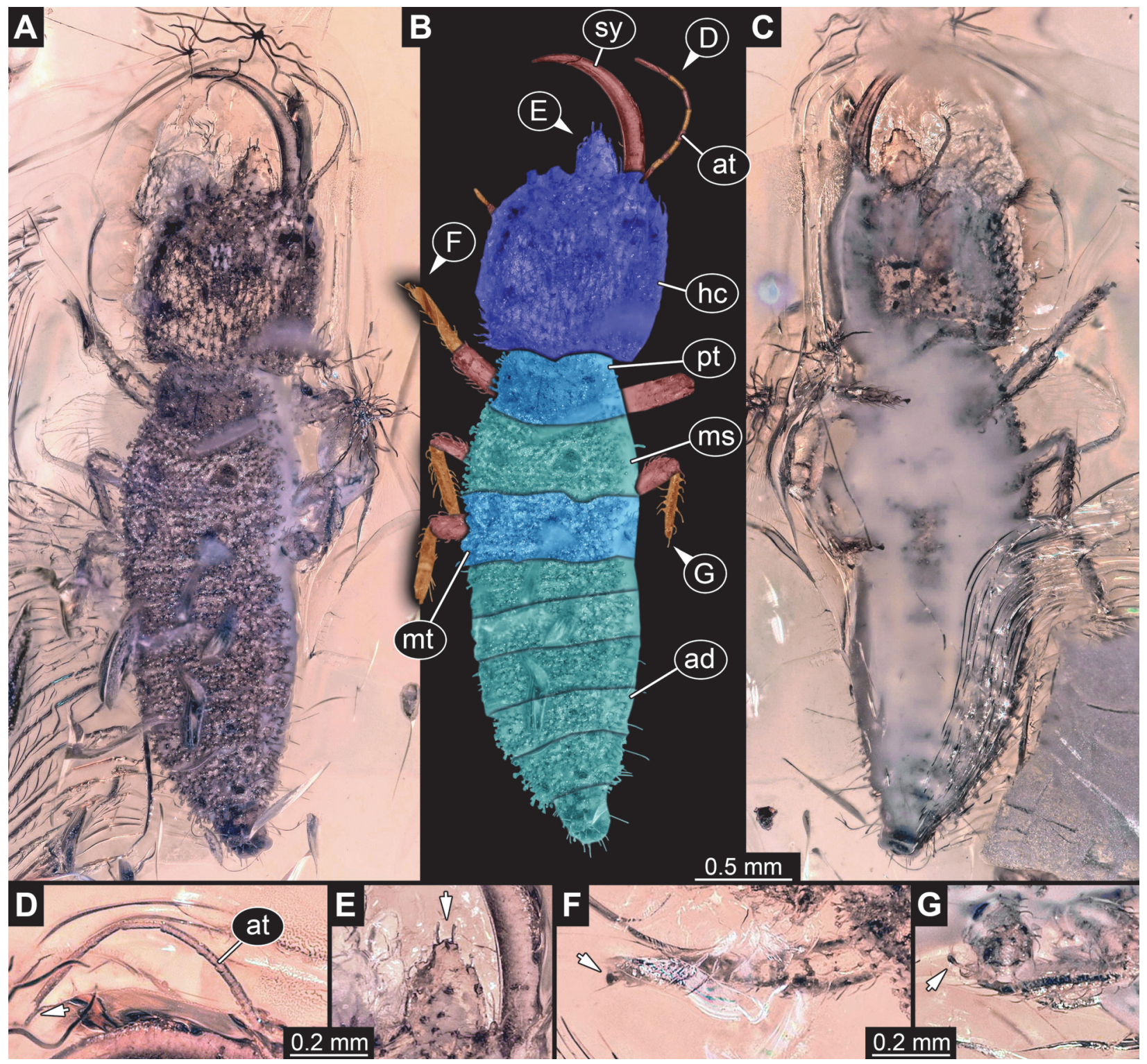

FIGURE 5. Specimen 25 (Gröhn 7639); Baltic amber. A. Dorsal view. B. Dorsal view, colour marked. C. Ventral view. D. Close-up of antenna; arrow points to spine-like seta. E. Close-up of labrum in dorsal view (arrow). F. Close-up of empodium (arrow) of first walking appendage. G. Close-up of empodium (arrow) of second walking appendage. Abbreviations: $\mathrm{ad}=$ abdomen; at = antenna; $\mathrm{hc}=$ head capsule; $\mathrm{ms}=$ mesothorax $\mathrm{mt}=$ metathorax; $\mathrm{pt}=\mathrm{prothorax} ; \mathrm{sy}=\mathrm{sty}$ let.

32) Specimen 28 is preserved in Eocene Baltic amber (Figure 6C). The photograph was kindly provided by Marius Veta (ambertreasure4u.com), number 2455. The specimen is well accessible in dorsal view, but partly concealed by Verlumung. The specimen has a length of about $1.7 \mathrm{~mm}$.

33) Specimen 29 is preserved in Eocene Baltic amber (Figure 6D). The photograph was kindly provided by Marius Veta (ambertreasure4u.com), number 1657 . The specimen is well accessible in dorsal view. The specimen has a length of about 4 $\mathrm{mm}$.

34) Specimen 30 is preserved in Eocene Baltic amber (Figure 6E). The photograph was kindly provided by Marius Veta (ambertreasure4u.com), number 1645 . The specimen is well accessible in dorsal view. The specimen has a length of about $3.2 \mathrm{~mm}$.

35) Specimen 16 (IGR.ARC-205.2) is preserved in Cretaceous French Charentese amber (Figures 7,8 ). The specimen is well accessible in 


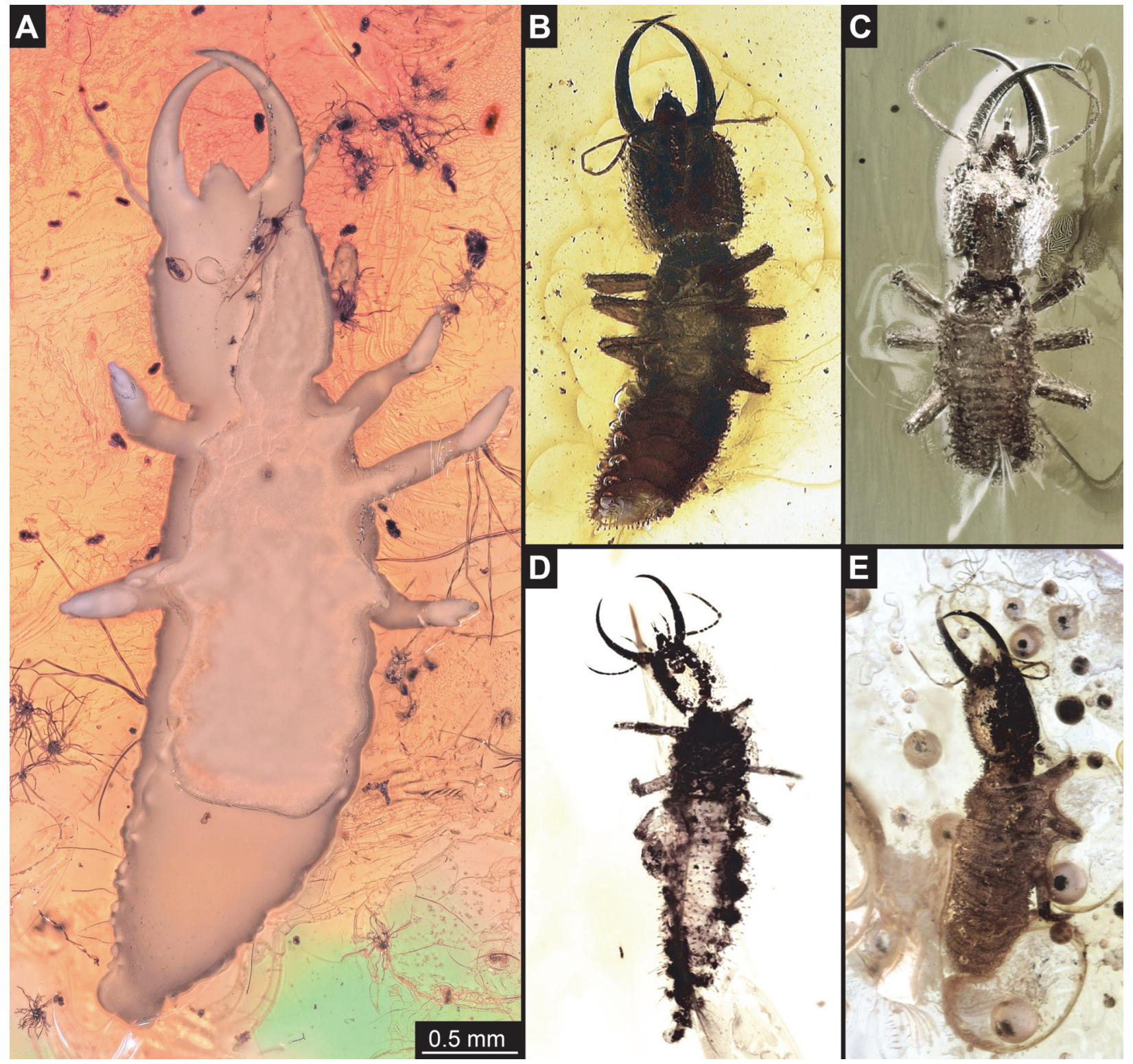

FIGURE 6. Specimens in Baltic amber, continued. A. Specimen 26 (Gröhn 7507), ventral view, strongly verlumt. B. Specimen 27; image from Jonas Damzen. C. Specimen 28. D. Specimen 29. E. Specimen 30. C-E. Images by Marius Veta.

ventral (Figure 7A) and dorsal view (Figure 7B, C), but the amber is rich in small particles partly concealing details. This also leads to fusion artefacts in some of the images. The labrum is prominent, proximally triangular (in ventral view), distally forked with two prominent prongs (Figure 7D). The antenna bears a prominent seta distally (Figure $7 \mathrm{E})$. Each distal end of the walking appendages bears an empodium (Figure 7F). The surface of the head capsule bears distinct setose tubercles (Figure $8 \mathrm{~A}$ ). Also, the surface of the central body bears distinct setose tubercles, mostly apparent under fluorescence illumination (Figure 8B). The body surface also bears numerous setae (Figure $8 \mathrm{C}$ ). The specimen has a length of about $2.7 \mathrm{~mm}$.

36) Specimen 31 (Müller BUB 3356) is preserved in Cretaceous amber from Myanmar (Figure 9). The specimen is well accessible in dorsal (Figure 9A, B) and ventral view (Figure 9D), but partly concealed by Verlumung in ventral view. The labrum is prominent, simple triangular to pentagonal in dorsal view (Figure 9C). The specimen has a length about $3.9 \mathrm{~mm}$. 


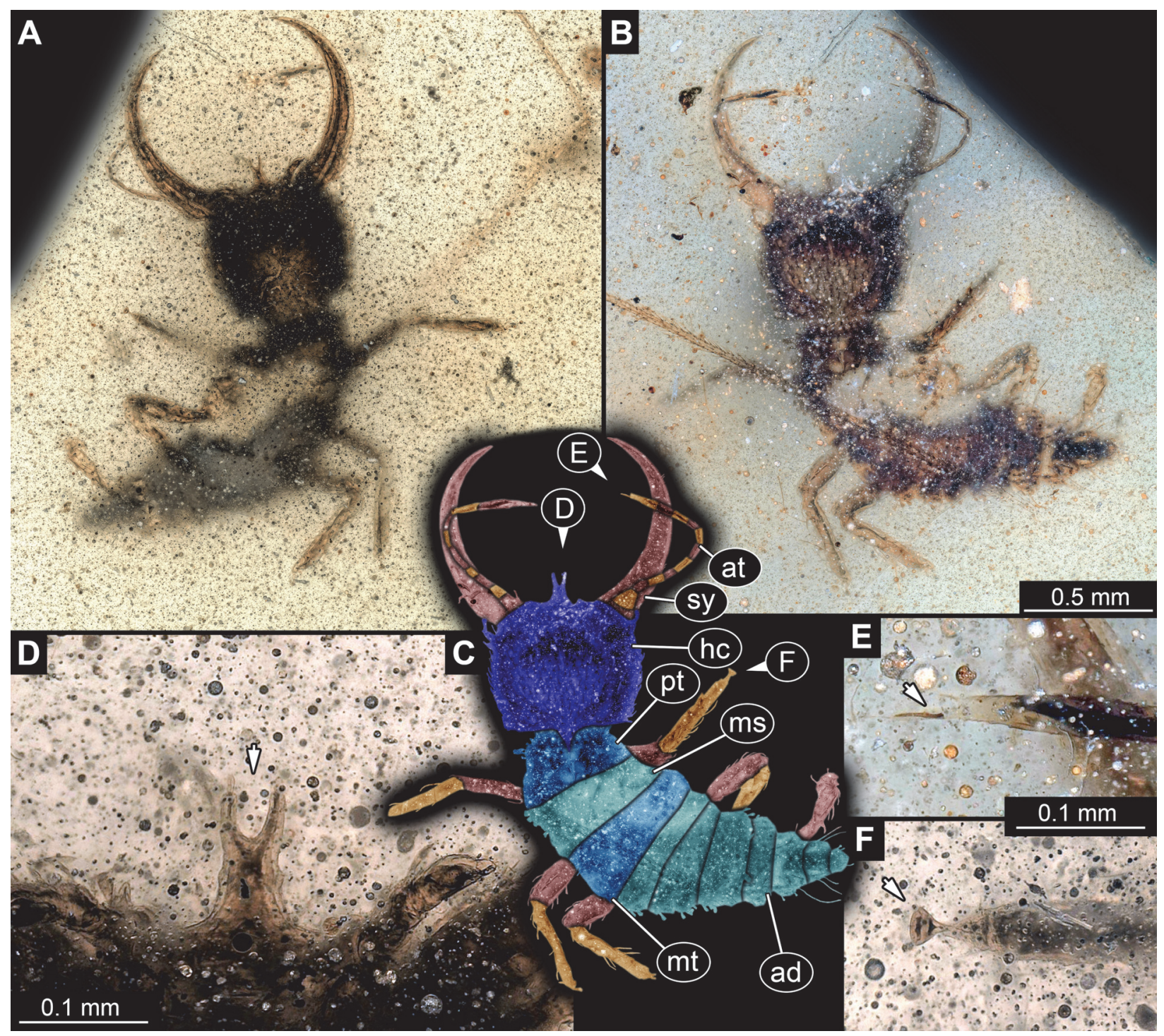

FIGURE 7. Specimen 16 (IGR.ARC-205.2); Charentese amber. A. Ventral view. B. Dorsal view. C. Dorsal view, colour marked. D. Close-up of labrum (arrow) in ventral view. E. Close-up of antenna in dorsal view; arrow points to spine-like

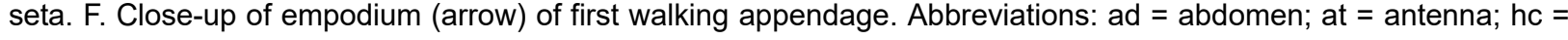
head capsule; $\mathrm{ms}=$ mesothorax $; \mathrm{mt}=$ metathorax; $\mathrm{pt}=$ prothorax; $\mathrm{sy}=$ stylet.

37) Specimen 32 (PED 0055) is preserved in Cretaceous amber from Myanmar (Figure 10). The specimen is well accessible in dorsal (Figure 10A, B) and ventral view (Figure 10C). The labrum is prominent, trapezium-like (in ventral view) with a deep V-shaped cleft distally (Figure 10D). Each distal end of the walking appendages bears an empodium (Figure 10E). The subdivision of the abdomen segments is very apparent, unlike in many other specimens (Figure 10F). The specimen has a length of about $3.5 \mathrm{~mm}$.

38) Specimen 33 (PED 0082) is preserved in Cretaceous amber from Myanmar (Figure 11). The specimen is well accessible in ventral (Figure 11A) and dorsal view (Figure 11B, C). The labrum is prominent, simple triangular to pentagonal in dorsal view (Figure 11F). The antenna bears a prominent seta distally (Figure 11D). Each distal end of the walking appendages bears an empodium (Figure 11E). The specimen has a length of about 3.3 $\mathrm{mm}$.

39) Specimen 34 (PED 0131) is preserved in Cretaceous amber from Myanmar (Figure 12). The specimen is well accessible in dorsal view (Figure $12 \mathrm{~A}, \mathrm{~B})$. The antenna bears a prominent seta distally (Figure 12C). Each distal end of the walking 


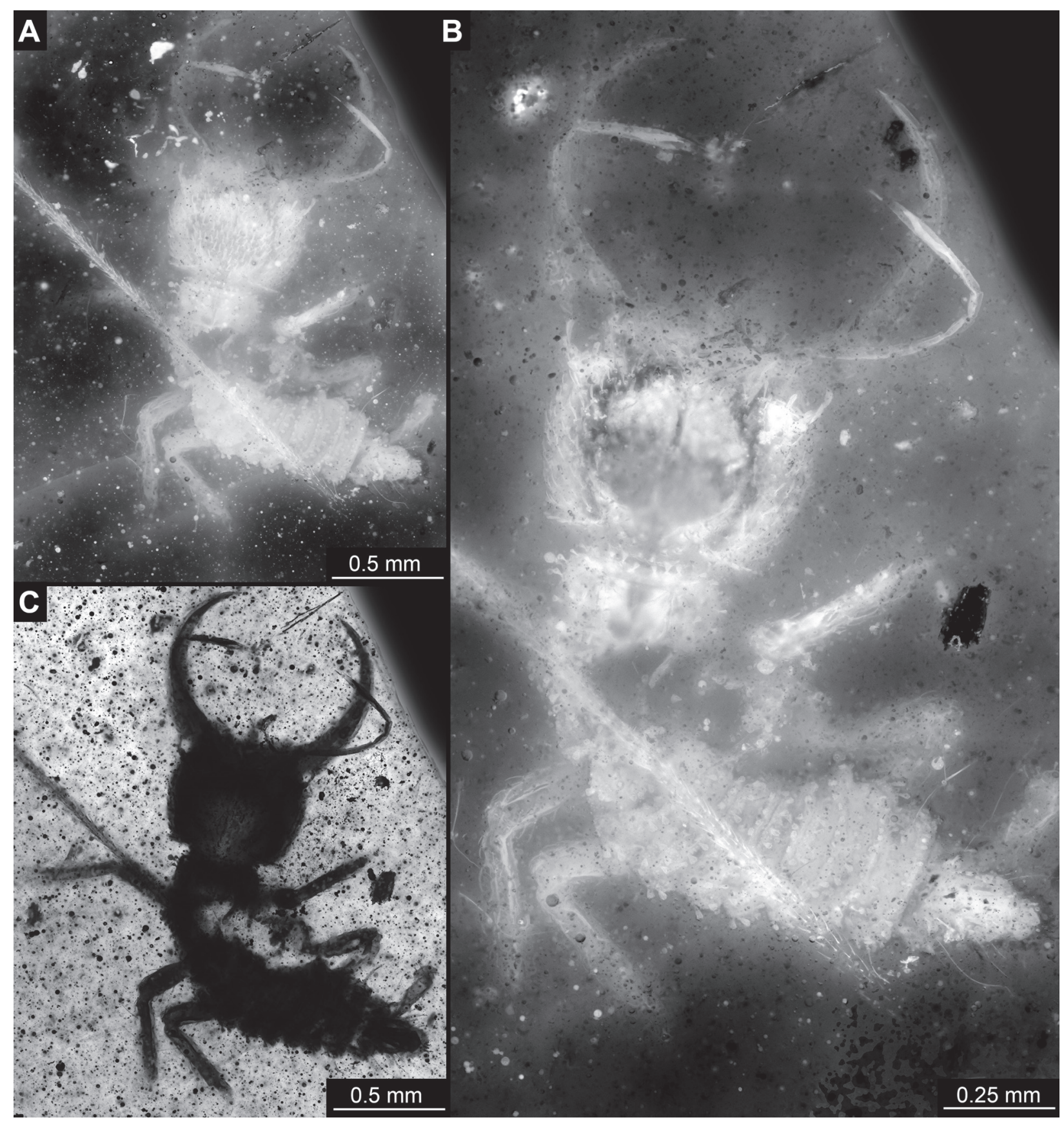

FIGURE 8. Specimen 16 (IGR.ARC-205.2), continued. A-B. Composite fluorescence images in dorsal view, note the surface details. A. Blue light (GFP). B. Green light (TRITC). C. Composite bright-field image.

appendages bears an empodium (Figure 12D, E). The specimen has a length of about $7.14 \mathrm{~mm}$.

40) Specimen 35 (PED 0080) is preserved in Cretaceous amber from Myanmar (Figure 13). The specimen is well accessible in dorsal view (Figure $13 \mathrm{~A}, \mathrm{~B}, \mathrm{C})$. The labrum is prominent, simple triangular to pentagonal in dorsal view, quite broad in comparison to those of other specimens (Figure 13D). Each distal end of the walking appendages bears an empodium (Figure 13E). The posterior trunk is partly damaged. The specimen has a length of about $17.8 \mathrm{~mm}$.

41) Specimen 36 (PED 0137) is preserved in Cretaceous amber from Myanmar (Figure 14). The specimen is well accessible in dorsal (Figure 14A, B) and ventral view (Figure $14 \mathrm{C}$ ). The labrum is prominent, is quite broad and short, with a cleft anteriorly (Figure 14D). Each distal end of the 


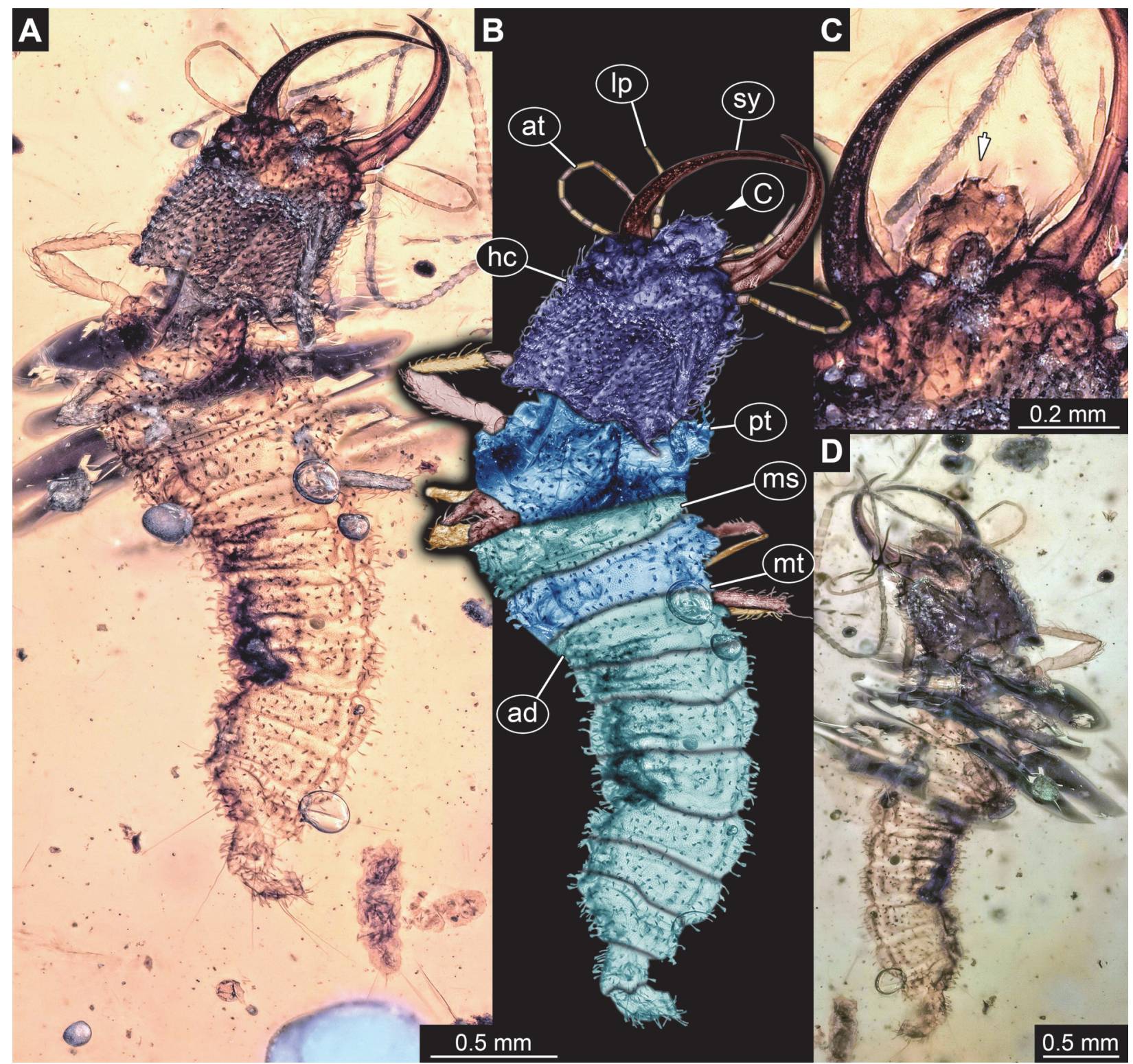

FIGURE 9. Specimen 31 (BUB 3356); Burmese amber. A. Dorsal view. B. Dorsal view, colour marked. C. Close-up of labrum (arrow) in ventral view. D. Ventral view. Abbreviations: ad = abdomen; at = antenna; hc = head capsule; Ip = labial palp; $\mathrm{ms}=$ mesothorax; $\mathrm{mt}=$ metathorax; $\mathrm{pt}=$ prothorax; $\mathrm{sy}=$ stylet.

walking appendages bears an empodium (Figure $14 \mathrm{E})$. The specimen has a length of about $3 \mathrm{~mm}$.

42) Specimen 37 (PED 0205) is preserved in Cretaceous amber from Myanmar (Figure 15). The specimen is well accessible in ventral (Figure 15A) and dorsal view (Figure 15B, C). The labrum is prominent, pentagonal in dorsal view, rather broad; each corner bearing a small spine (Figure 15E). The antenna bears a prominent seta distally (Figure 15D). Each distal end of the walking appendages bears an empodium (Figure 15F). The specimen has a length of about $5.5 \mathrm{~mm}$.
43) Specimen 38 (Müller BUB 3389) is preserved in Cretaceous amber from Myanmar (Figure 16). The specimen is well accessible in ventral (Figure 16A) and dorsal view (Figure 16B, C), but partly concealed in dorsal and ventral view. The labrum is prominent, trapezium-like (in ventral view) with a shallow cleft distally (Figure 16E). The antenna bears a prominent seta distally (Figure 16D). The surface of the head capsule bears distinct setose tubercles (Figure 16F). The specimen has a length of about $7.75 \mathrm{~mm}$. 


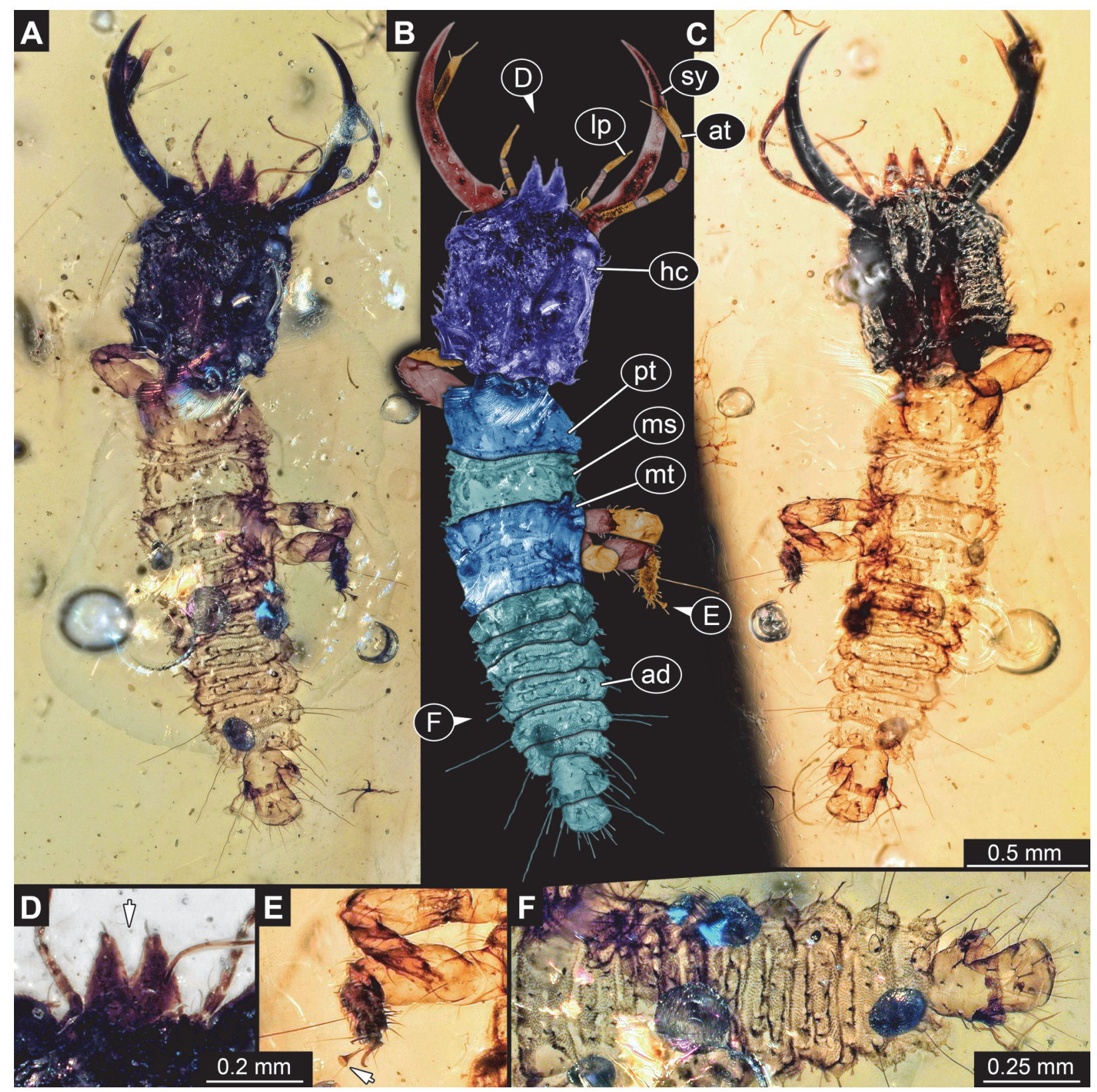

FIGURE 10. Specimen 32 (PED 0055); Burmese amber. A. Dorsal view. B. Dorsal view, colour marked. C. Ventral view. D. Close-up of labrum (arrow) in dorsal view. E. Close-up of empodium (arrow) of third walking appendage. F. Close-up of abdomen. Abbreviations: ad = abdomen; at = antenna; hc = head capsule; lp = labial palp; ms = mesothorax; $\mathrm{mt}=$ metathorax; $\mathrm{pt}=$ prothorax; $\mathrm{sy}=$ stylet.

44) Specimen 39 (PED 0060) is preserved in Cretaceous amber from Myanmar (Figure 17). The specimen is well accessible in dorsal (Figure 17A, B) and ventral view (Figure 17C), but partly concealed in dorsal and ventral view by dirt particles and Verlumung. The antenna bears a prominent seta distally (Figure 17D). The labrum is prominent trident-like with a fork-like protrusion in the middle (Figure 17E) and two flanking spine-like protrusions. Posterior trunk is missing. The amber bears another insect larva (Figure 17F) close to the specimen of interest. The specimen has a length of about $5.55 \mathrm{~mm}$.

45) Specimen 40 (PED 0051) is preserved in Cretaceous amber from Myanmar (Figure 18). The specimen is well accessible in ventral (Figure 18A) and dorsal view (Figure 18B, C), but is slightly verlumt. The labrum is prominent, triangular symmetric to trapezium-like in dorsal view, but relatively elongate in comparison to those of other speci- 


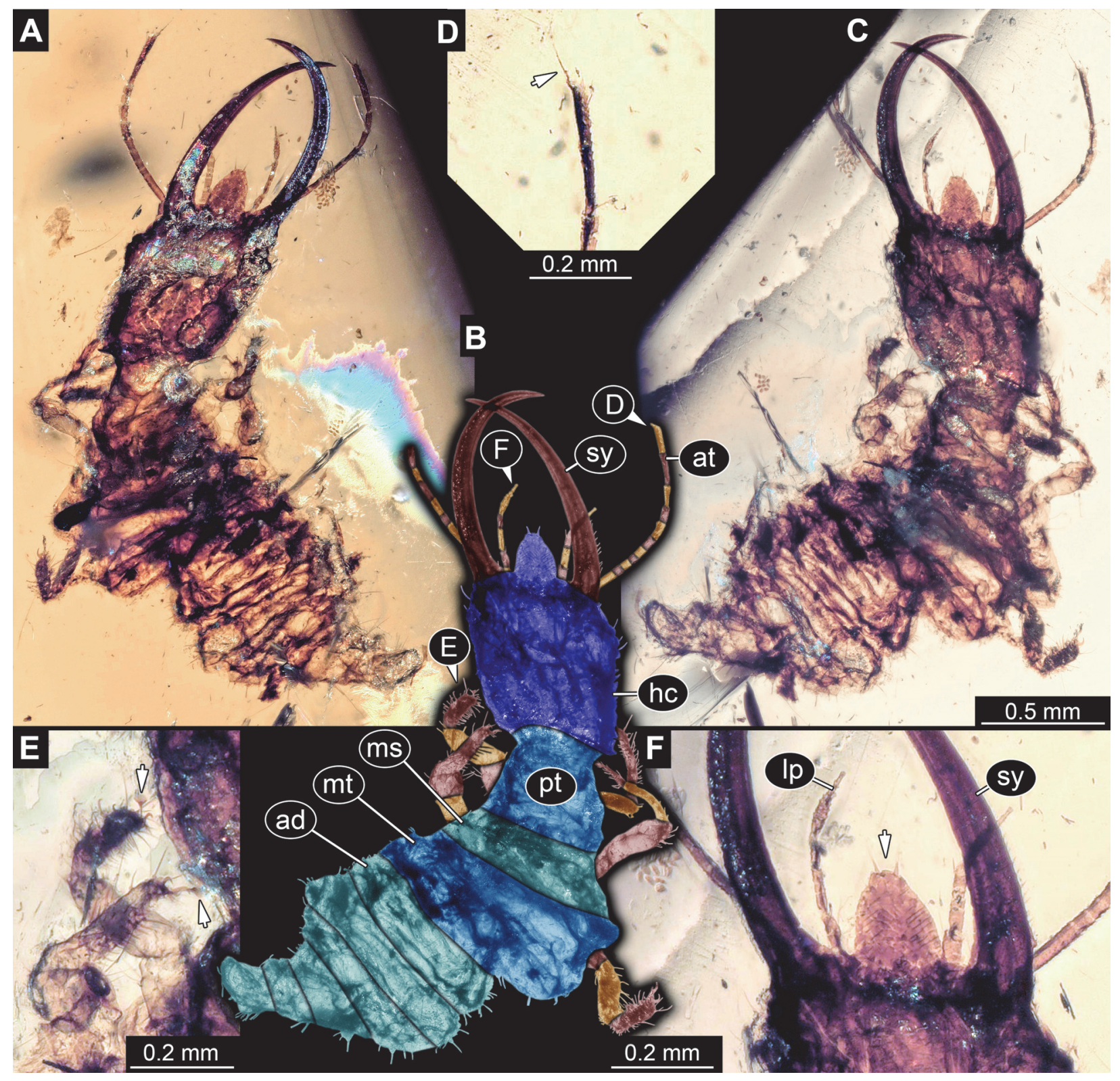

FIGURE 11. Specimen 33 (PED 0082); Burmese amber. A. Ventral view. B. Dorsal view. C. Dorsal view, colour marked. D. Close-up of antenna; arrow points to spine-like seta. E. Close-up of empodia (arrows) of first and second walking appendage. F. Close-up of labrum (arrow) in dorsal view. Abbreviations: $a d=$ abdomen; at $=$ antenna; hc $=$ head capsule; $\mathrm{ms}=$ mesothorax; $\mathrm{mt}=$ metathorax; $\mathrm{pt}=$ prothorax; $\mathrm{sy}=$ stylet.

mens (Figure 18D). Each distal end of the walking appendages bears an empodium (Figure 18E, F). The specimen has a length of about $3.4 \mathrm{~mm}$.

46) Specimen 41 (PED 0127) is preserved in Cretaceous amber from Myanmar (Figure 19A-C). The specimen is well accessible in dorsal view (Figure 19A, B). The labrum is prominent, tridentlike with a larger spine-like protrusion in the middle and two flanking smaller spine-like protrusions in dorsal view (Figure 19C). The posterior trunk is missing. The specimen has a length of about 5.77 $\mathrm{mm}$.

47) Specimen 42 (PED 0063) is preserved in Cretaceous amber from Myanmar (Figure 19D, E). The trunk is missing completely, only the head is preserved. The head is well accessible in dorsal view. The specimen has a length of about $1.2 \mathrm{~mm}$.

48) Specimen 43 (PED 0153) is preserved in Cretaceous amber from Myanmar (Figure 20A-D). The specimen is well accessible in dorsal view (Figure 20A, B). The labrum is prominent, pentago- 


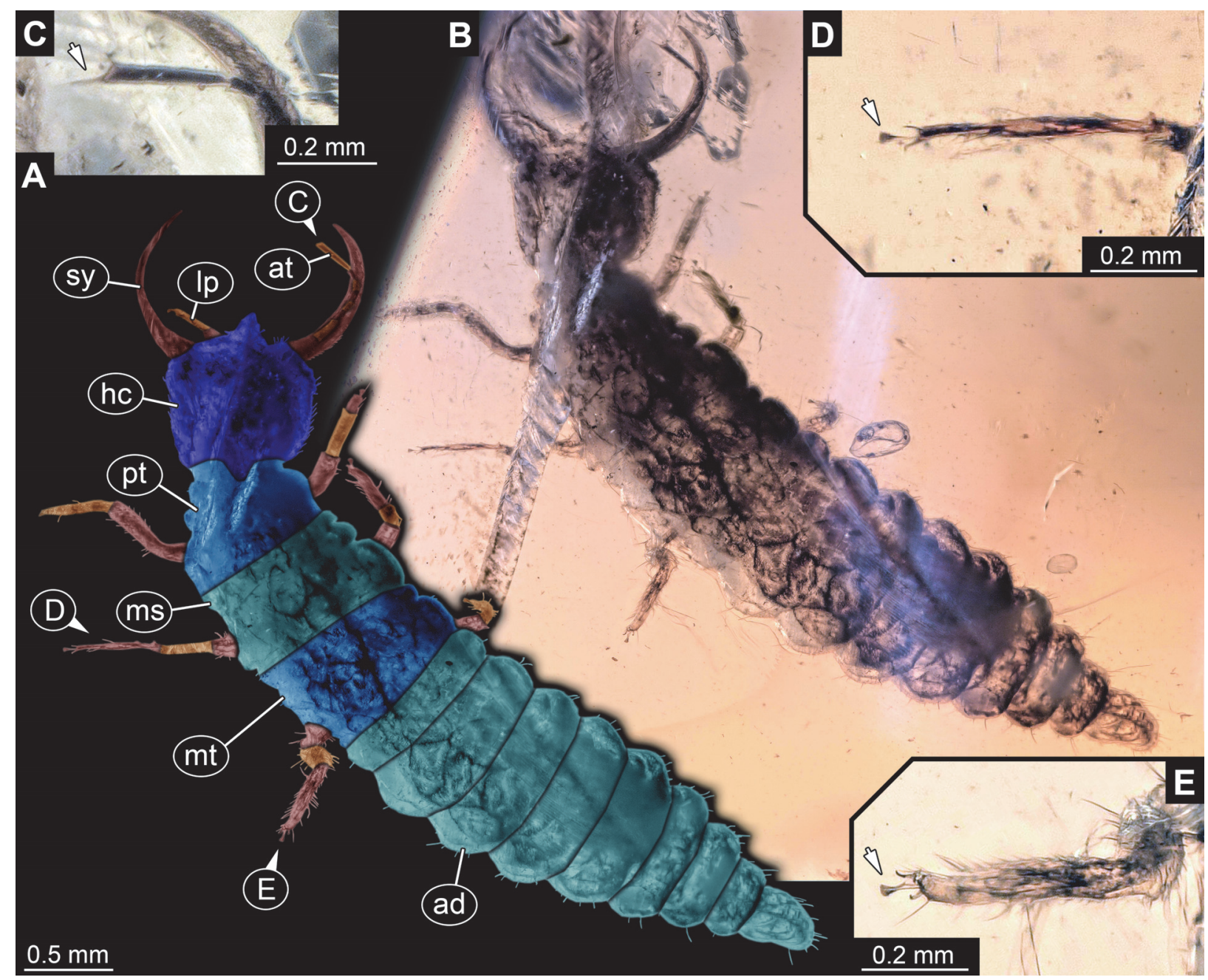

FIGURE 12. Specimen 34 (PED 0131); Burmese amber. A. Dorsal view. B. Dorsal view, colour marked. C. Close-up of antenna; arrow points to spine-like seta. D. Close-up of empodium (arrow) of second walking appendage. E. Closeup of empodium (arrow) of third walking appendage. Abbreviations: ad = abdomen; at = antenna; hc = head capsule; $\mathrm{l} p$ = labial palp; $\mathrm{ms}=$ mesothorax; $\mathrm{mt}=$ metathorax; $\mathrm{pt}=$ prothorax; $\mathrm{sy}=$ stylet.

nal in dorsal view, rather broad (Figure 20C). Each distal end of the walking appendages bears an empodium (Figure 20D). The specimen has a length of about $6.1 \mathrm{~mm}$.

49) Specimen 44 (Müller BUB 3179) is preserved in Cretaceous amber from Myanmar (Figure $20 \mathrm{E}, \mathrm{F}$ ). The trunk is missing completely and only the head is preserved. The head is well accessible in dorsal view (Figure 20E, F). The specimen has a length of about $1.3 \mathrm{~mm}$.

50) Specimen 45 (PED 0045) is preserved in Cretaceous amber from Myanmar (Figure 21). The head is well accessible in dorsal (Figure 21A, B) and ventral view (Figure 21C), but partly concealed by dirt particles and Verlumung. The labrum is prominent, pentagonal in dorsal view, rather broad; each corner bearing a small spine (Figure 21D). The labial palp is visible, tube-shaped (Figure
21E). The posterior trunk is missing. The specimen has a length of about $2.7 \mathrm{~mm}$.

51) Specimen 46 (PED 0133) is preserved in Cretaceous amber from Myanmar (Figure 22A-C). The specimen is well accessible in ventral (Figure 22A) and dorsal view (Figure 22B, C), but partly concealed by Verlumung and dirt particles. The posterior trunk is missing. The specimen has a length of about $2 \mathrm{~mm}$.

52) Specimen 47 (PED 0128) is preserved in Cretaceous amber from Myanmar (Figure 22D-F). The specimen is well accessible in ventral (Figure 22D) and dorsal view (Figure 22E, F), but partly concealed by Verlumung and dirt particles in dorsal and ventral view. The posterior trunk is partly damaged. The specimen has a length of about 2.86 $\mathrm{mm}$. 


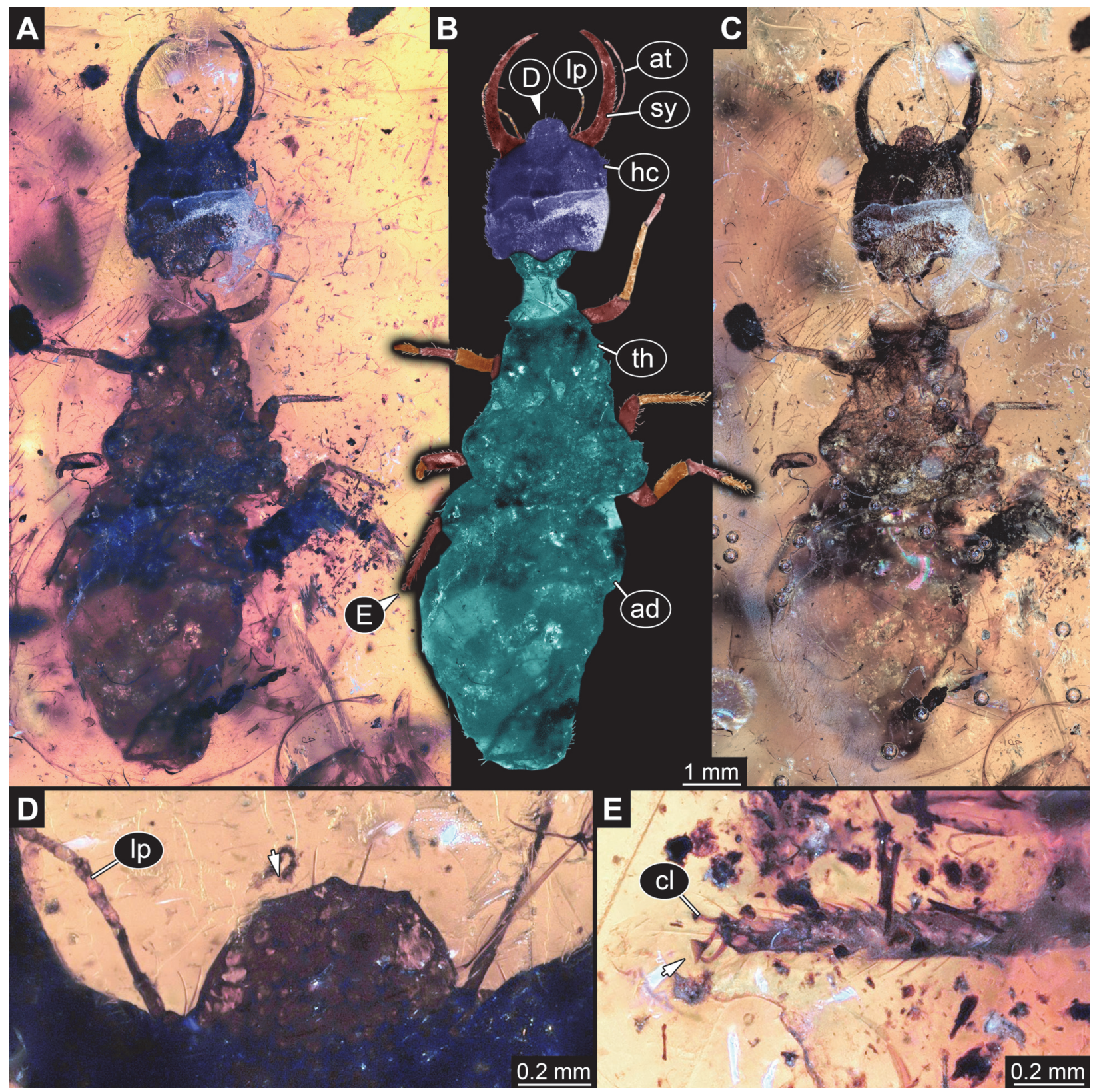

FIGURE 13. Specimen 35 (PED 0080); Burmese amber. A-C. Dorsal view. A. Cross-polarised light. B. Colour marked. C. Ring light. D. Close-up of labrum (arrow) in dorsal view. E. Close-up of empodium (arrow) of third walking appendage. Abbreviations: $\mathrm{ad}=$ abdomen; $\mathrm{at}=$ antenna; $\mathrm{cl}=\mathrm{claw}$; $\mathrm{hc}=$ head capsule; $\mathrm{Ip}=$ labial palp; sy = stylet; th = thorax.

53) Specimen 48 (Müller BUB 3386) is preserved in Cretaceous amber from Myanmar (Figure $22 \mathrm{G}, \mathrm{H})$. The specimen is partly concealed by Verlumung and dirt particles in dorsal view (Figure $22 \mathrm{G}$ ). The labrum is roundish triangular in dorsal view (Figure $22 \mathrm{H}$ ). The posterior trunk is missing. The specimen has a length of about $1.55 \mathrm{~mm}$.

54) Specimen 49 (PED 0125) is preserved in Cretaceous amber from Myanmar (Figure 23). Head and anterior trunk are well accessible in dor- sal view (Figure 23B) and lateral view (Figure 23A, C), but partly concealed. The labrum is prominent, triangular symmetric to trapezium-like in dorsal view, but relatively elongate in comparison to those of other specimens (Figure 23D). The eyes are visible in lateral view (Figure 23E). Each distal end of the walking appendages bears an empodium (Figure 23F). The posterior trunk is missing. The specimen has a length of about $2.64 \mathrm{~mm}$. 


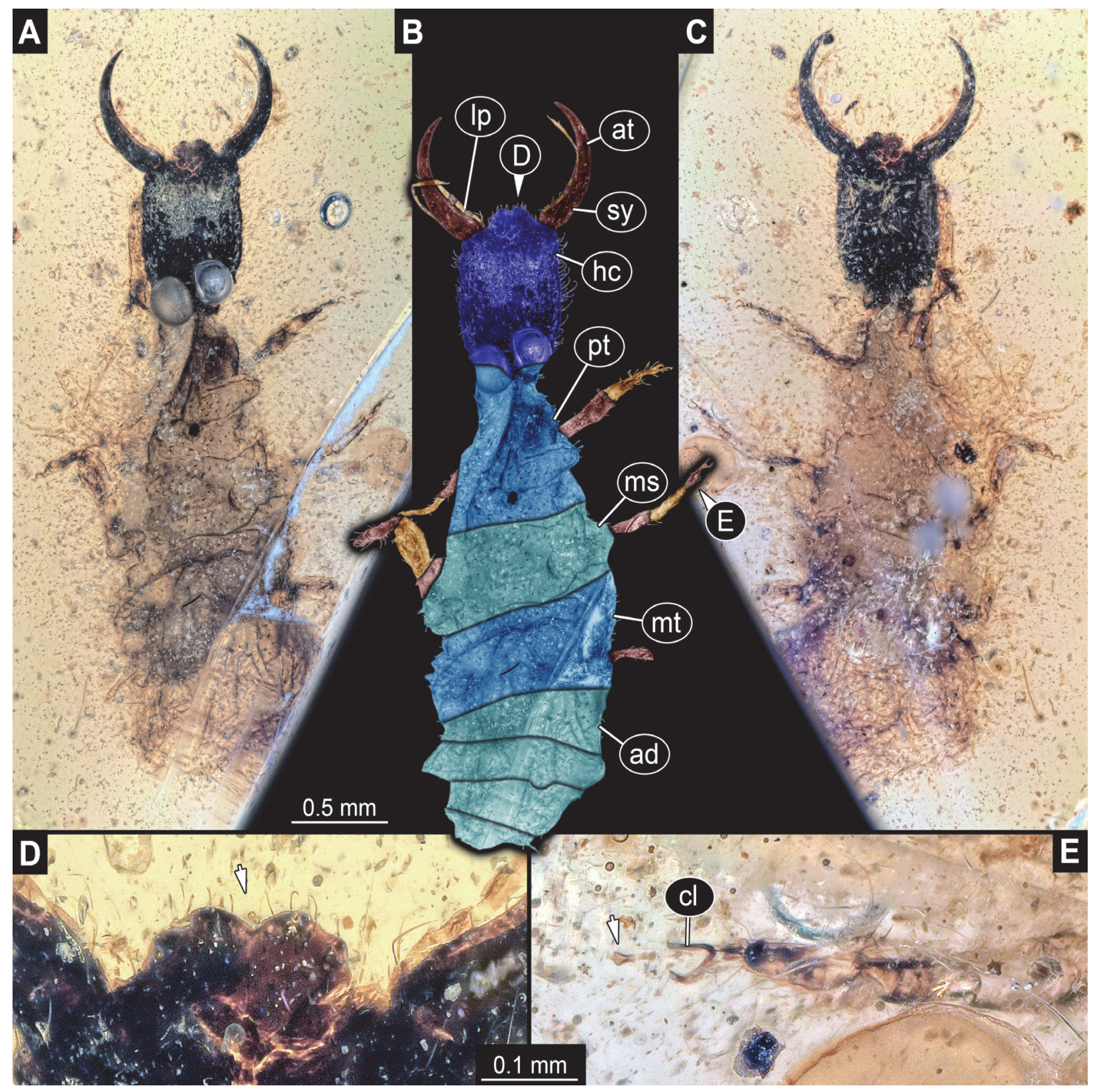

FIGURE 14. Specimen 36 (PED 0137); Burmese amber. A. Dorsal view. B. Dorsal view, colour marked. C. Ventral view. D. Close-up of labrum (arrow) in dorsal view. E. Close-up of empodium (arrow) of second walking appendage. Abbreviations: $\mathrm{ad}=$ abdomen; at = antenna; $\mathrm{cl}=$ claw; $\mathrm{hc}=$ head capsule; $\mathrm{lp}=$ labial palp; $\mathrm{ms}=$ mesothorax; $\mathrm{mt}=$ metathorax; $p t=$ prothorax; sy $=$ stylet.

55) Specimen 50 (PED 0039) is preserved in Cretaceous amber from Myanmar (Figure 24A-C). The head is well accessible in dorsal view, but partly concealed in dorsal view by dirt particles. The posterior trunk is missing. The specimen has a length of about $2.1 \mathrm{~mm}$.

56) Specimen 51 (PED 0109) is preserved in Cretaceous amber from Myanmar (Figure 24D). The specimen is largely concealed in dorsal or ventral view by dirt particles, only the rough outline is apparent. The specimen has a length of about $10 \mathrm{~mm}$.

57) Specimen 52 (PED 0100) is preserved in Cretaceous amber from Myanmar (Figure 25). The trunk is missing completely, only the head is preserved. The head is largely concealed in dorsal or ventral view by Verlumung and dirt particles (Figure $25 \mathrm{~A}, \mathrm{~B}$ ). The labrum is small triangular in dorsal view but appears incomplete (Figure 25C). The specimen has apparently been damaged during 


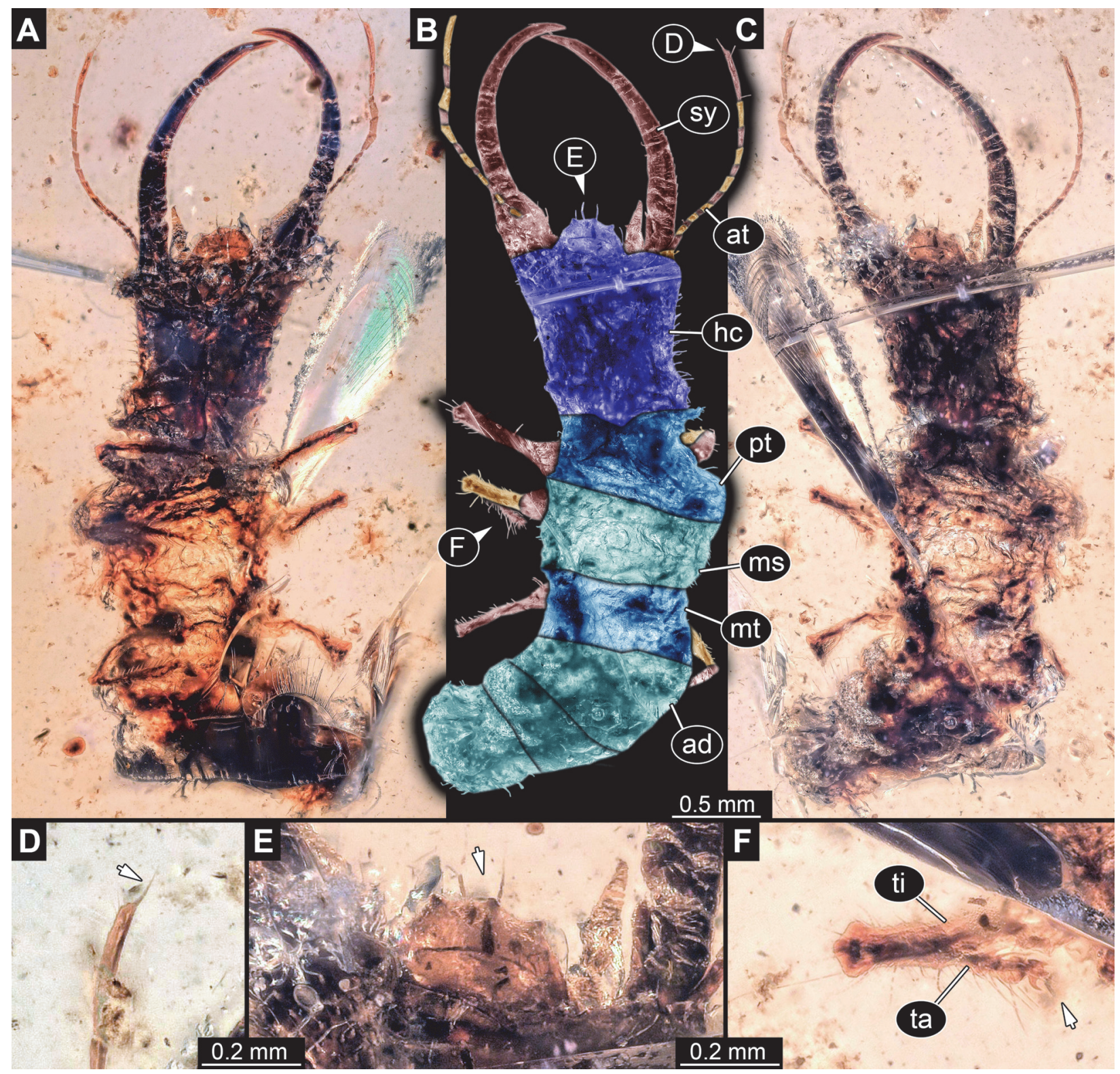

FIGURE 15. Specimen 37 (PED 0205); Burmese amber. A. Ventral view. B. Dorsal view, colour marked. C. Dorsal view. D. Close-up of antenna; arrow points to spine-like seta. E. Close-up of labrum (arrow) in dorsal view. F. Close-up of empodium (arrow) of second walking appendage. Abbreviations: ad = abdomen; at = antenna; hc = head capsule; $\mathrm{ms}=$ mesothorax; $\mathrm{mt}=$ metathorax; $\mathrm{pt}=$ prothorax; $\mathrm{sy}=\mathrm{stylet} ; \mathrm{ta}=$ tarsus; $\mathrm{ti}=\mathrm{tibia}$.

grinding. Note the size of the specimen. The specimen has a length of about $9.4 \mathrm{~mm}$.

\section{Shape Analysis}

Not all specimens could be included in the shape analysis for different reasons. In specimen 6 , the posterior border of the head capsule was not apparent in the original drawing. In specimen 12, many structures appear partly deformed, even some that should be heavily sclerotised such as the stylets. This might have accounted for the head capsule. In specimens 17 and 26, the strong Verlumung does not allow access to the posterior border of the head capsule. Specimen 48 is oblique and partly verlumt, hence not accessible in direct dorsal or ventral view. In specimen 51 , only a vague outline of the head is accessible, the posterior border is concealed. In specimen 52 , the original shape of the labrum is not available as it has been partly ground away. Hence, in total 45 specimens could be used for shape analysis. 


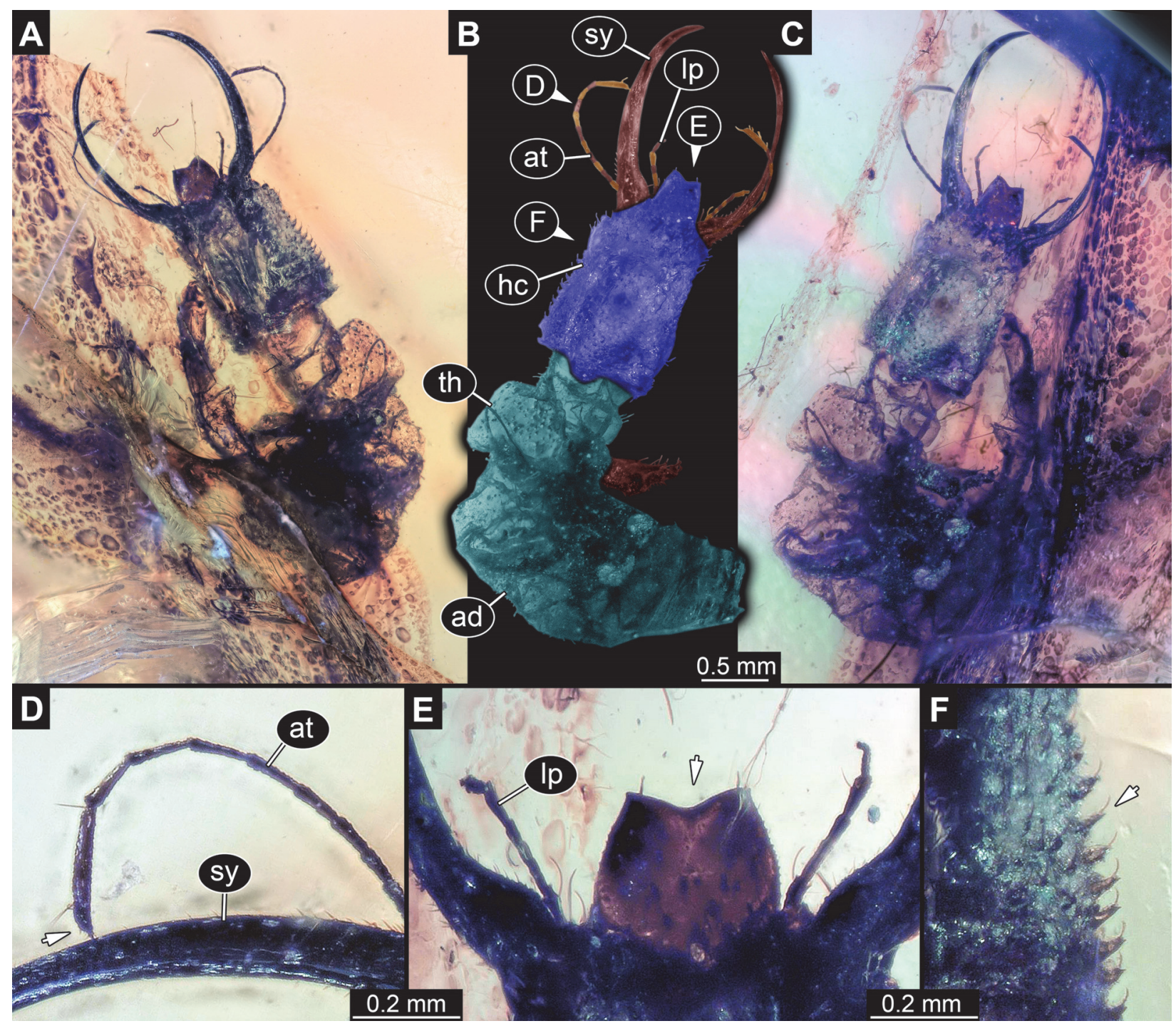

FIGURE 16. Specimen 38 (BUB 3389); Burmese amber. A. Ventral view. B. Dorsal view, colour marked. C. Dorsal view. D. Close-up of antenna in dorsal view; arrow points to spine-like seta. E. Close-up of labrum (arrow) in dorsal

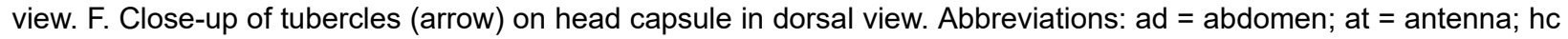
$=$ head capsule; Ip = labial palp; sy = stylet; th = thorax.

The shape analysis resulted in six effective Principal Components summarizing a total of $95.6 \%$ of variation apparent in the data set. The first two Principal Components summarize $82.5 \%$ of variation in the data set. The first Principal Component (PC1) explains $55.7 \%$ of overall variation, and the second Principal Component (PC2) explains $26.9 \%$ (differences in sum due to rounding) of overall variation.

PC1 appears to be dominated by width, i.e., describes very slender to very broad shapes; yet also the labrum seems to have an influence, especially its length. PC2 is dominated by the differentiation of the anterior and posterior rims, and hence especially the labrum shape. PC3 explains only
$5.7 \%$ of the overall variation. It appears to be dominated by "triangularity", reaching from forward directed triangle shape (tapering anteriorly and broad posteriorly) over a more rectangular shape to a more backward directed triangle (broad anteriorly and tapering posteriorly). PC4 explains 3.6\% of the overall variation and appears to be dominated by a more rectangular versus a more rounded shape. PC5 explains $2.3 \%$ of the overall shape variation. It appears to be dominated by the relative width of the anterior or the posterior rim. PC6 explains $1.4 \%$ of the overall shape variation. It appears to be dominated by how much the labrum and anterior corners of the head are narrowed to form distinct tips. As stated above, further analysis 


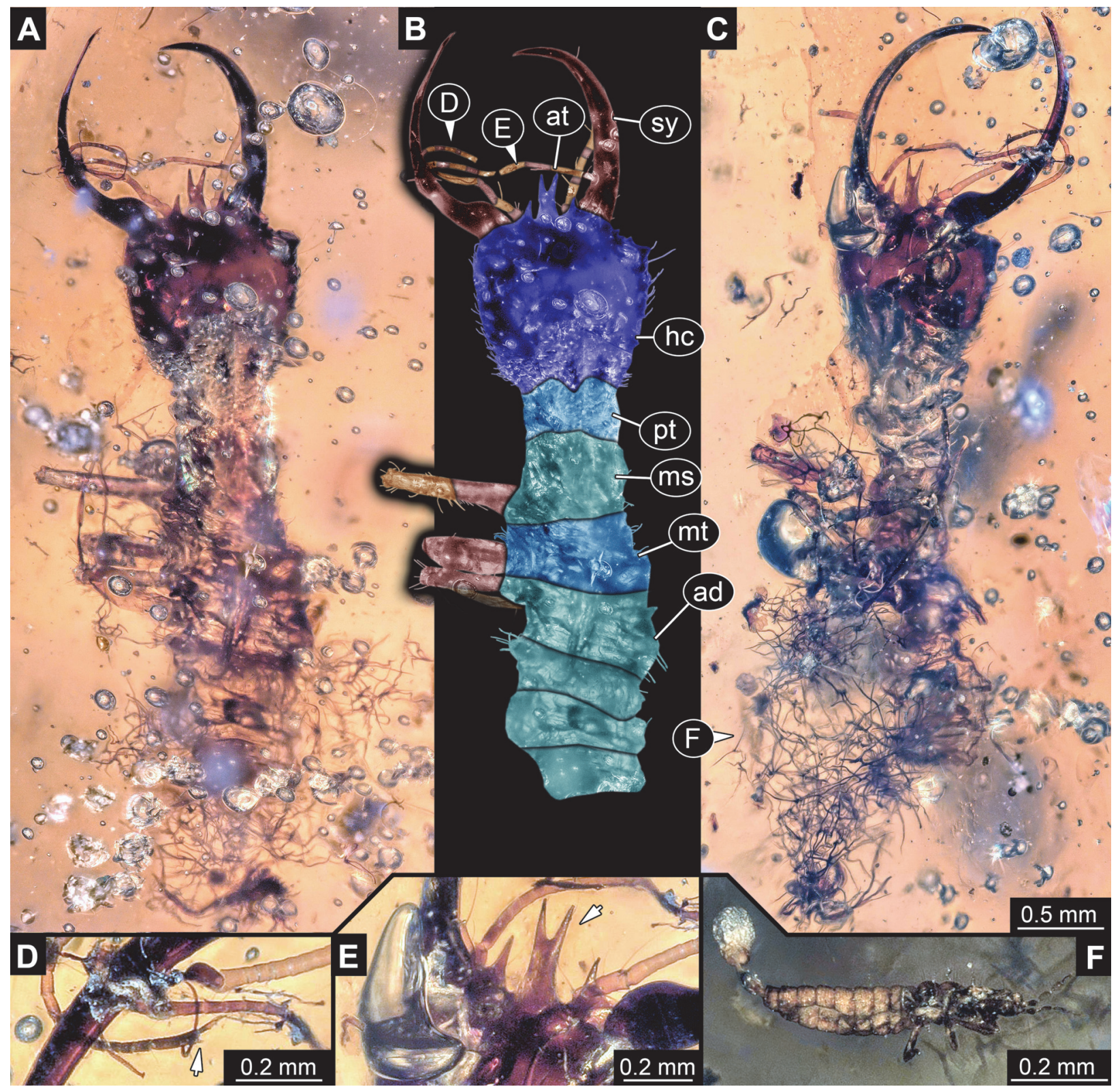

FIGURE 17. Specimen 39 (PED 0060); Burmese amber. A. Dorsal view. B. Dorsal view, colour marked. C. Ventral view. D. Close-up of antenna; arrow points to spine-like seta. E. Close-up of labrum (arrow) in dorsal view. F. Close-up of syn-inclusion, insect larva in lateral view. Abbreviations: $\mathrm{ad}=$ abdomen; at $=$ antenna; $\mathrm{hc}=$ head capsule; $\mathrm{ms}=$ mesothorax; $\mathrm{mt}=$ metathorax; $\mathrm{pt}=$ prothorax; sy = stylet.

will be conducted solely on PC1 and PC2. Factor loadings for all six significant PCs are provided in Supplementary Figure 1. The general outcome of the analysis is given in Supplementary Text 1. Length measurements and PC1 and PC2 are provided in Supplementary Table 1.

In the plot, positive PC1 values represent broad heads, negative values represent slim heads. On the PC2 axis, positive values depict differentiated posterior rims; negative values depict differentiated anterior rims (Figure 26, Supplemen- tary Figure 1). The Cretaceous specimens are distributed in all four quadrants of the plot with the highest spread among PC values, indicating the highest diversity among all three time slice groups. Interestingly, they show comparably dense clustering for positive PC2 values and are rather separated for negative PC2 values. The Eocene specimens are not as widely spread as the Cretaceous specimens and are almost exclusively located on the upper part of the plot, showing positive PC2 values. They are distributed along the 


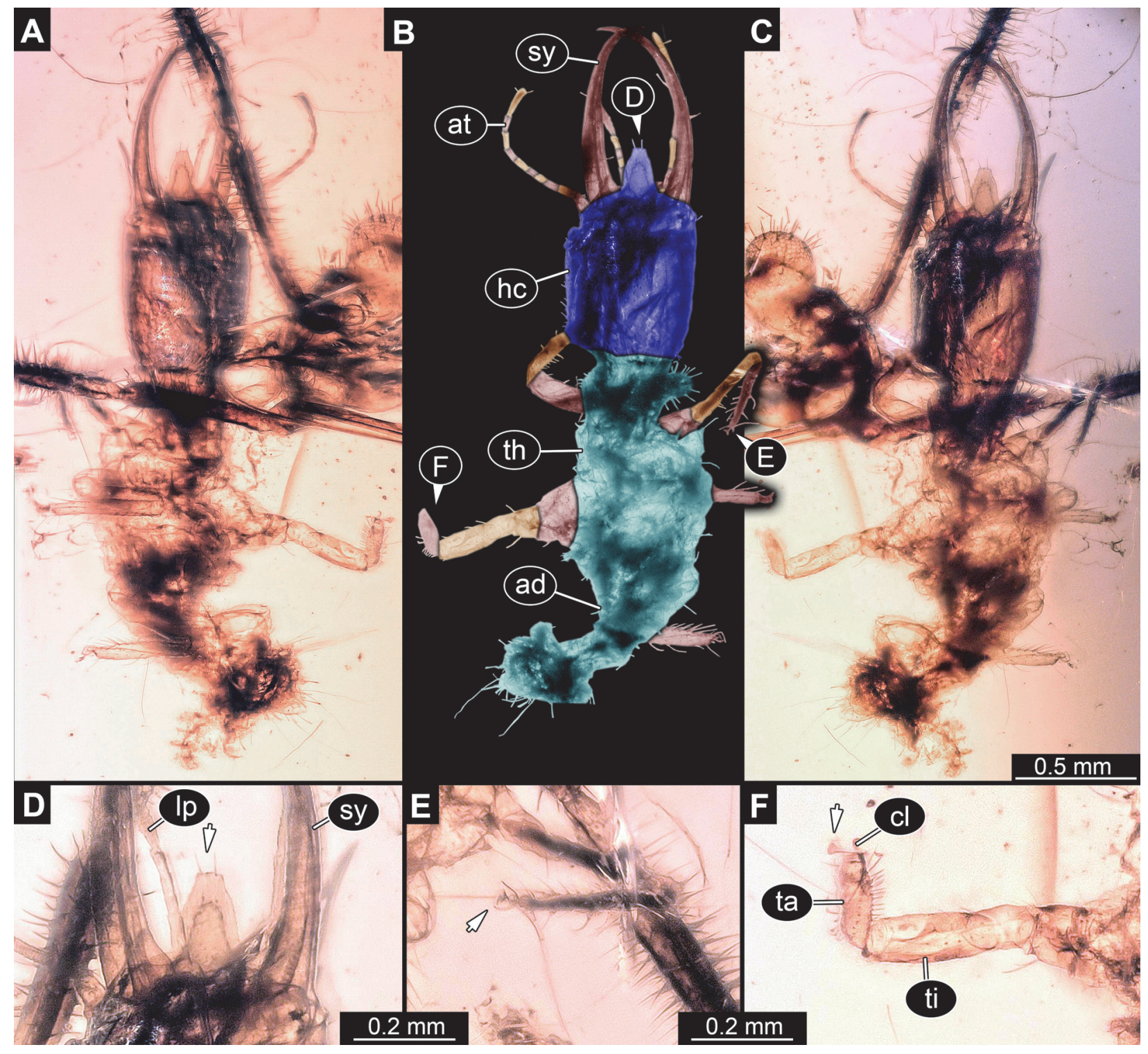

FIGURE 18. Specimen 40 (PED 0051); Burmese amber. A. Ventral view. B. Dorsal view, colour marked. C. Dorsal view. D. Close-up of labrum (arrow) in dorsal view. E. Close-up of empodium (arrow) of first walking appendage. F. Close-up of empodium (arrow) of second walking appendage. Abbreviations: $a d=$ abdomen; at = antenna; cl = claw; hc = head capsule; $\mathrm{lp}=$ labial palp; sy = stylet; ta = tarsus; th = thorax; $\mathrm{ti}$ = tibia.

PC1 axis and are almost as far spread out as the Cretaceous specimens. The modern specimens show an ellipsoid distribution around the centre of the plot with the least spread compared to the other time slice groups, and generally show more positive values for the PC1 axis.

\section{Occupation of Dimensions}

For PC1, Cretaceous specimens occupy the largest range (Figure 27A). However, in the sample-size-corrected PC1, the Cretaceous range is similar to the range occupied by the Eocene speci- mens. Sample-size-corrected ranges of both the Cretaceous and Eocene specimens, however, are about 1.6 times larger than the range occupied by the modern specimens. The modern specimens are also separated from the Cretaceous and Eocene specimens by occupying more positive than negatives values, while the ranges of the Cretaceous and Eocene specimens are more centred.

For PC2, the Cretaceous specimens again occupy the largest range of all three time slice groups, even after sample size correction (Figure 27A). Their sample-size-corrected range is about 


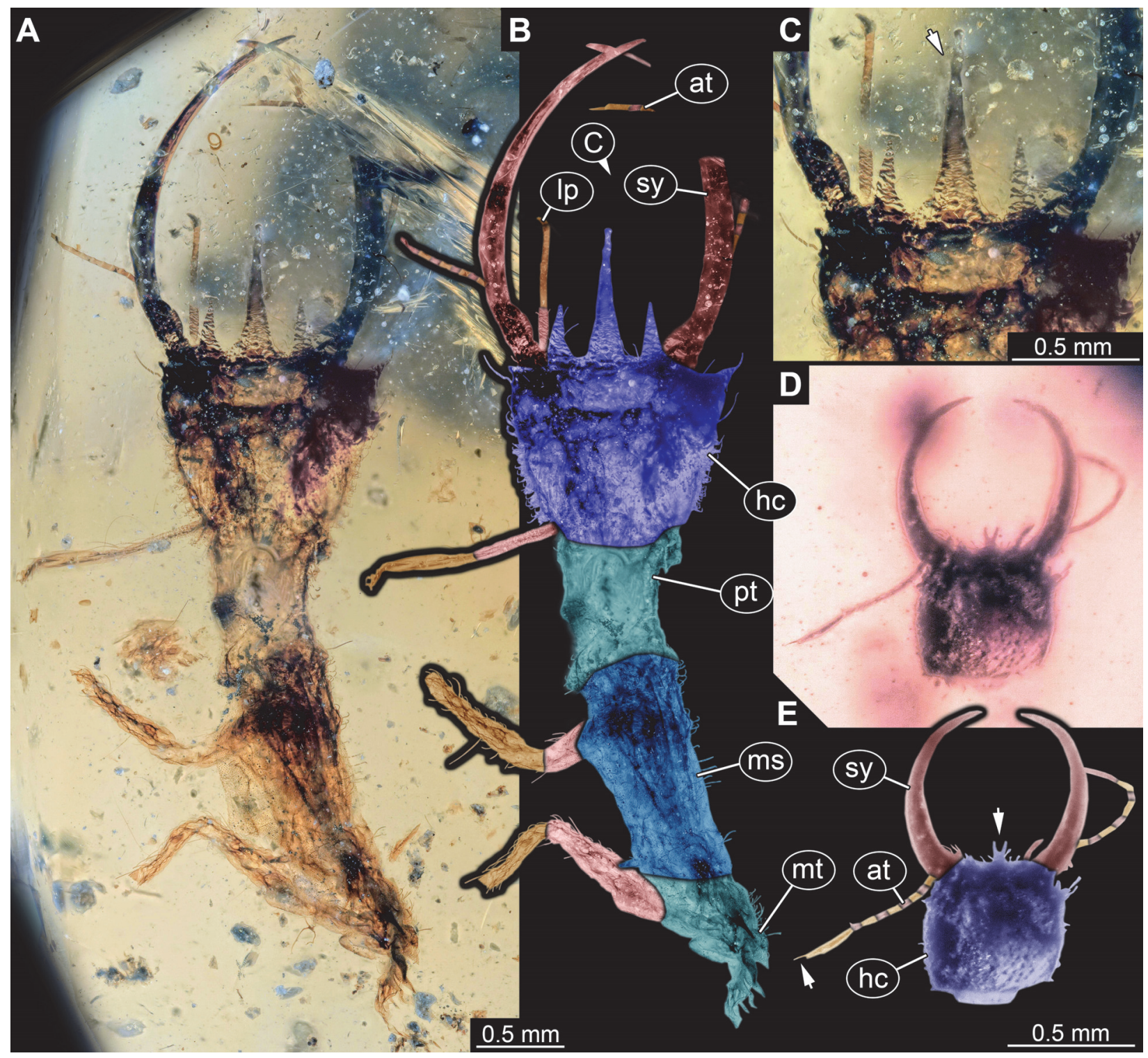

FIGURE 19. Specimens in Burmese amber, continued. A-C. Specimen 41 (PED 0127). A. Dorsal view. B. Dorsal view, colour marked. C. Close-up of labrum (arrow) in dorsal view. D-E. Specimen 42 (PED 0063). D. Dorsal view. E. Dorsal view, colour marked; arrows point to spine-like seta and labrum. Abbreviations: at $=$ antenna; $h c=$ head capsule; $\mathrm{I}$ = labial palp; $\mathrm{ms}=$ mesothorax; $\mathrm{mt}=$ metathorax; $\mathrm{pt}=$ prothorax; $\mathrm{sy}=$ stylet.

1.7 times larger than that of the modern specimens. The range of the Eocene specimens, in contrast to their $\mathrm{PC} 1$ range, is much smaller, about 0.5 times the range of the modern specimens. The Cretaceous specimens predominantly have negative values for PC2, while the Eocene specimens, on the other hand, have almost exclusively positive values, and modern specimens occupy a more centred, but still skewed position similar to their PC1 range.

\section{Size}

The studied specimens show large variation in size when plotting individual head length against head width. However, there are no distinct clusters of size classes that would cause distortion and artefacts in other analyses (Figure 27B). Moreover, plotting PC1 and PC2 against head length reveals no strong correlation of shape and size (PC1: $\mathrm{R}^{2}=0.039$; PC2: $\mathrm{R}^{2}=0.027$; Figure $27 \mathrm{C}$ ). 


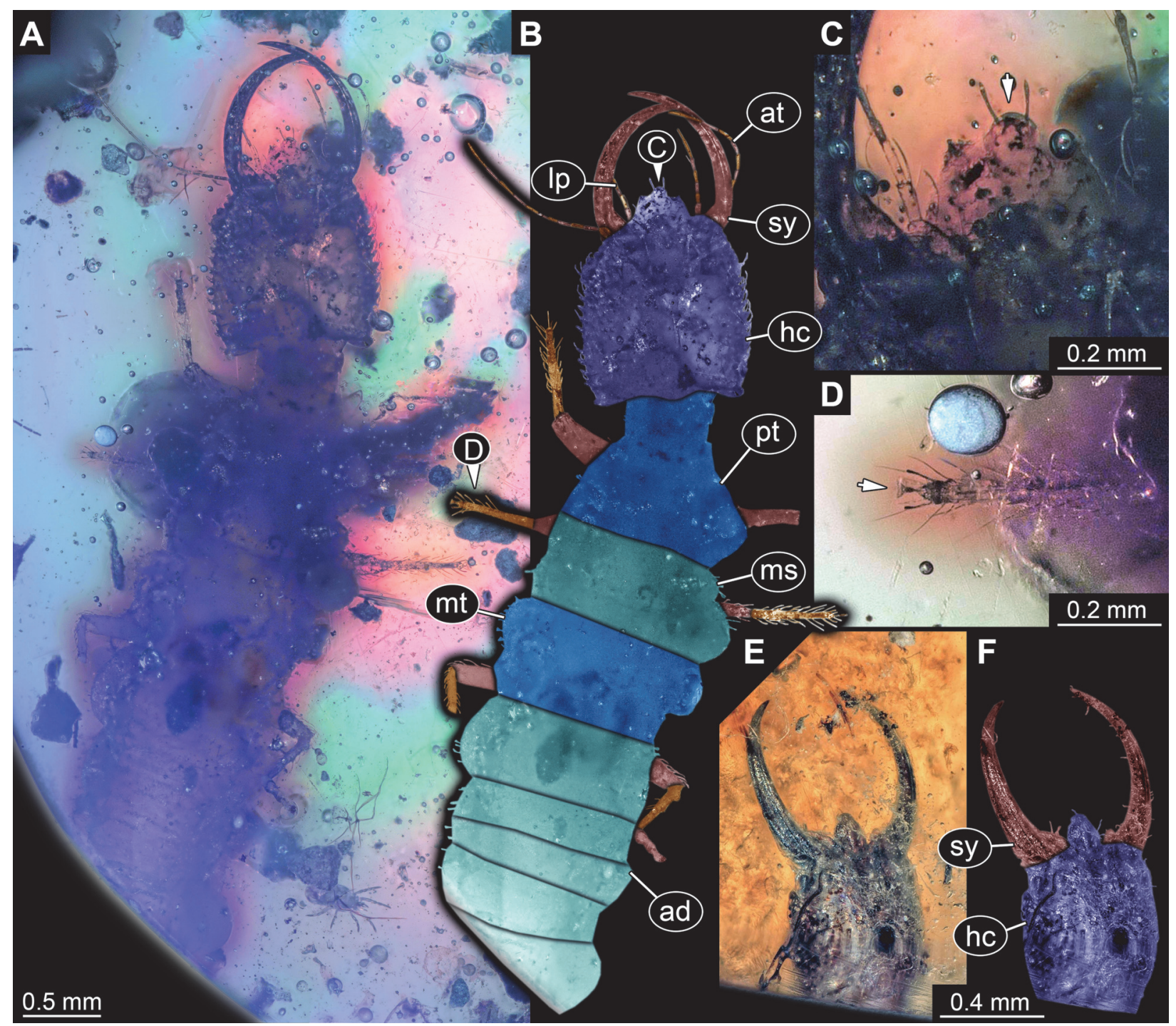

FIGURE 20. Specimens in Burmese amber, continued. A-D. Specimen 43 (PED 0153). A. Dorsal view. B. Dorsal view, colour marked. C. Close-up of labrum (arrow) in dorsal view. D. Close-up of empodium (arrow) of second walking appendage. E-F. Specimen 44 (BUB 3179). E. Dorsal view. F. Dorsal view, colour marked. Abbreviations: ad = abdomen; at = antenna; hc = head capsule; $\mathrm{l} p=$ labial palp; $\mathrm{ms}=$ mesothorax; $\mathrm{mt}=$ metathorax; $\mathrm{pt}=\mathrm{prothorax}$; sy = stylet.

\section{DISCUSSION}

\section{Rarity of the Specimens}

There are less than 30 known species of Psychopsidae in the extant fauna, and the number of known larval specimens is very low. Larger data sets estimate that we know the larvae of about $10 \%$ of lacewing species (Gepp, 1984). Hence, we expect that proper documentation exists for larvae of at least three species of Psychopsidae. This includes the work of Tillyard (1918) and also the work of MacLeod (1964) to a certain degree as the documentation is restricted to the head region in the latter. That results in about 1.5 species of which we know the larvae, leaving a gap of documentation for additional 1.5 species. It is astonishing that in the current biodiversity crisis and insect decline, classical relic groups such as Psychopsidae are not more intensely studied. It will be an important future task to further expand the data set of extant fauna.

According to Makarkin (2018), there are in total 144 described fossil species of Psychopsoidea (= Psychopsidae and closer relatives). Larsson (1978) pointed out that representatives of Psychopsidae are not rare in Baltic amber, and larvae seem to be as common as adults. Therefore, the fact that to acquire a sample size from Baltic 


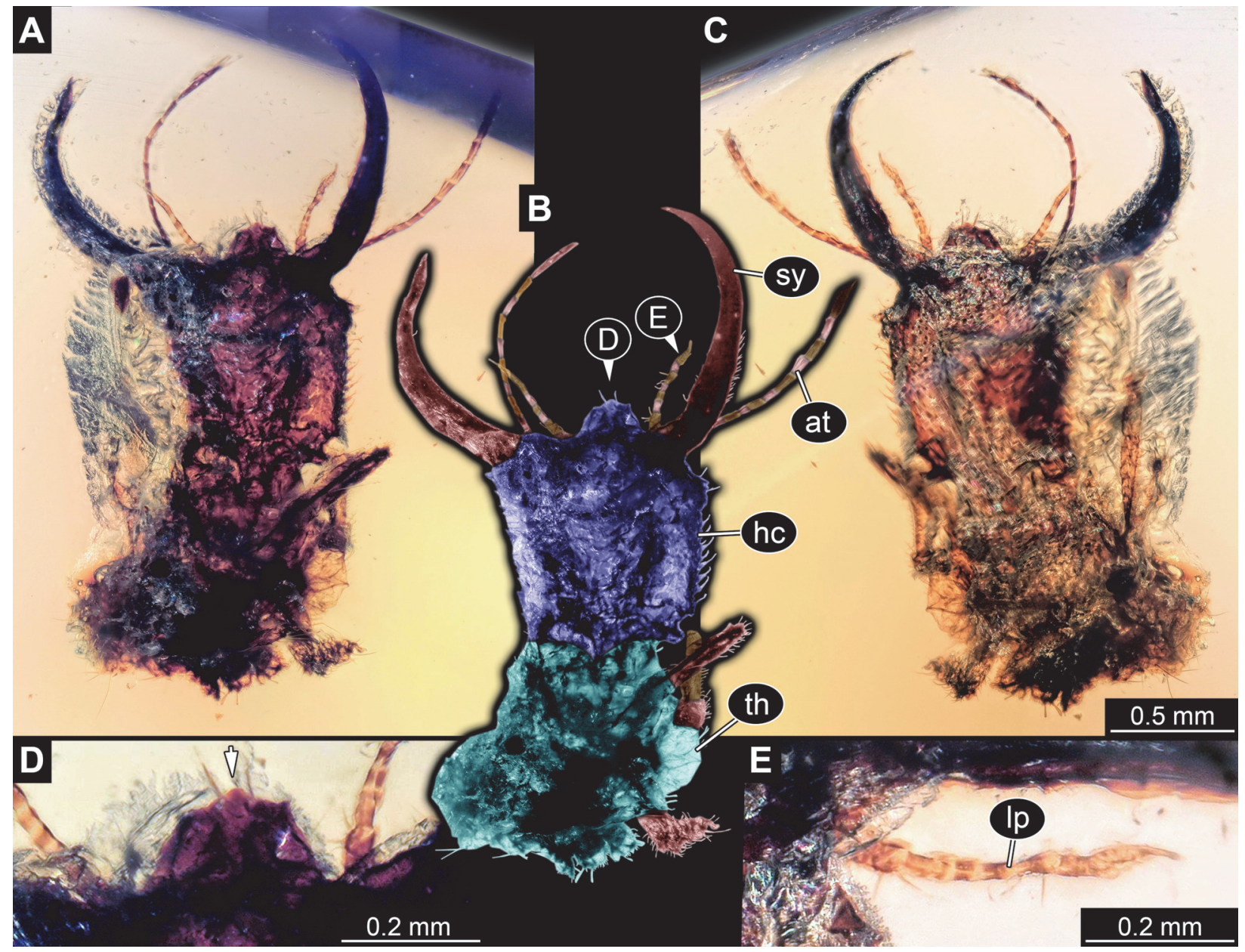

FIGURE 21. Specimen 45 (PED 0045); Burmese amber. A. Dorsal view. B. Dorsal view, colour marked. C. Ventral view. D. Close-up of labrum (arrow) in dorsal view. E. Close-up of labial palp. Abbreviations: at $=$ antenna; hc $=$ head capsule; Ip = labial palp; sy = stylet; th = thorax.

amber comparable to that of extant fauna was difficult is partly astonishing. Yet, the general pattern that the focus of research is placed on adult forms because they are viewed as more distinctive persists. This leads to the fact that larvae are seldomly deposited in museum collections.

Specimens from Myanmar amber are quite common, and Makarkin (2018) mentions that he had seen nine further specimens, or at least images of them in non-institutional collections, in addition to five specimens known to him from the literature. Here we present more than 20 previously unreported specimens. For the present analysis, heavily damaged and incomplete specimens (Figures 3F, 18, 19A, B, 21, 22A-F, 23, 24A-C) and even isolated heads could be included (Figures 19D, E, 20E, F). The number of lacewing larvae currently known from amber was recently summarised to be slightly above 100 specimens (Pérez-de la Fuente et al., 2020) and has been sig- nificantly expanded by the present study. It is expected that this number will increase in the near future, at least for Cretaceous ambers.

\section{Structure of the Dataset}

The dataset used for the present analyses is heterogeneous in terms of sample size for different time slices: modern, Eocene, and Cretaceous fauna. Additionally, there are differences in data quality and availability.

All extant specimens are exclusively based on literature data. These include highly detailed drawings such as the one of MacLeod (1964), but also simplified overview-type drawings such as the one from Froggatt (1907). Of the three known photographs, two are images from the field, and one of these is not in perfect dorsal view. There is so far only one habitus image based on ethanol-fixed material recorded under laboratory conditions (Bakkes et al., 2017), and this is from a partly 


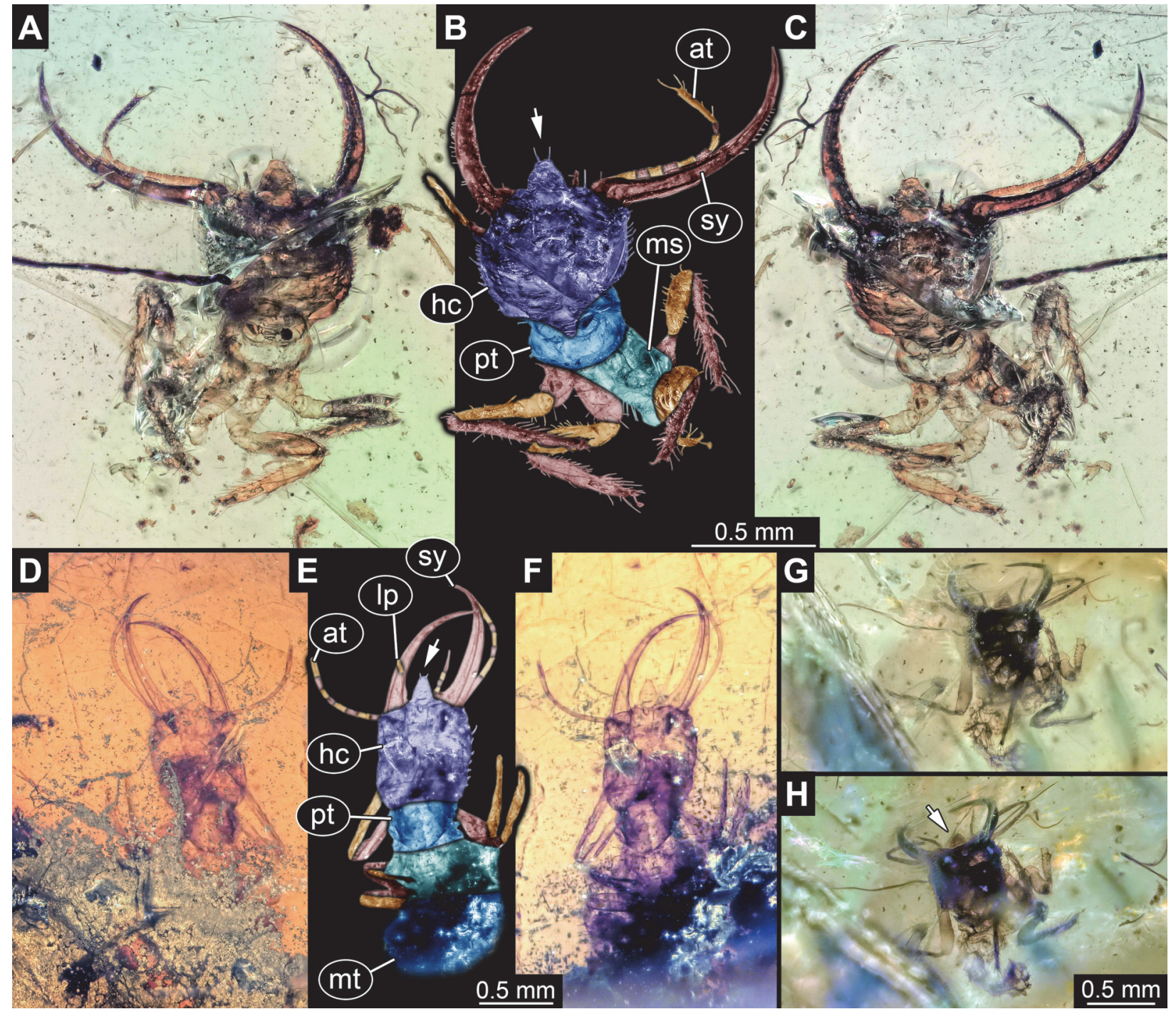

FIGURE 22. Specimens in Burmese amber, continued. A-C Specimen 46 (PED 0133). A. Ventral view. B. Dorsal view, colour marked; arrow points to labrum. C. Dorsal view. D-F. Specimen 47 (PED 0128). D. Ventral view. E. Dorsal view, colour marked; arrow points to labrum. F. Dorsal view. G-H. Specimen 48 (BUB 3386). G. Dorsal view. H. Dorsal view, slightly different angle; arrow points to labrum. Abbreviations: at = antenna; hc = head capsule; Ip = labial palp; $m s$ = mesothorax; $m t=$ metathorax; $p t=$ prothorax; sy = stylet.

deformed specimen and also not in dorsal view. Moreover, most collected extant specimens have not been deposited in a collection, with the exceptions of the specimens from MacLeod (1964) and Bakkes et al. (2017).

For the Eocene fauna, data from literature plays an important role, and as is the case for the extant specimens, not all Eocene specimens seem to have been deposited in museum collections. We included three specimens from non-museum collections, which were documented by the authors, but also four specimens for which only photographs were available. These came from two amber collectors (and traders) that are considered trustworthy by the community (e.g., Fowler, 2018). Both have already contributed images to other projects (e.g., Gröhn, 2015; Gröhn et al., 2015). Hence these data are considered reliable. The photos are provided here, and analysis is based solely on outlines of the head shape drawn from these photos, making the analysis repeatable. By providing the images here, the information is available for further study, and is comparable with many other fossil specimens, which have been published in books and peer-reviewed papers, but are not available from institutional collections (e.g., Weitschat and Wichard, 1998; Scheven, 2004; Gröhn, 2015; Zhang, 2017; Makarkin, 2018), yet 


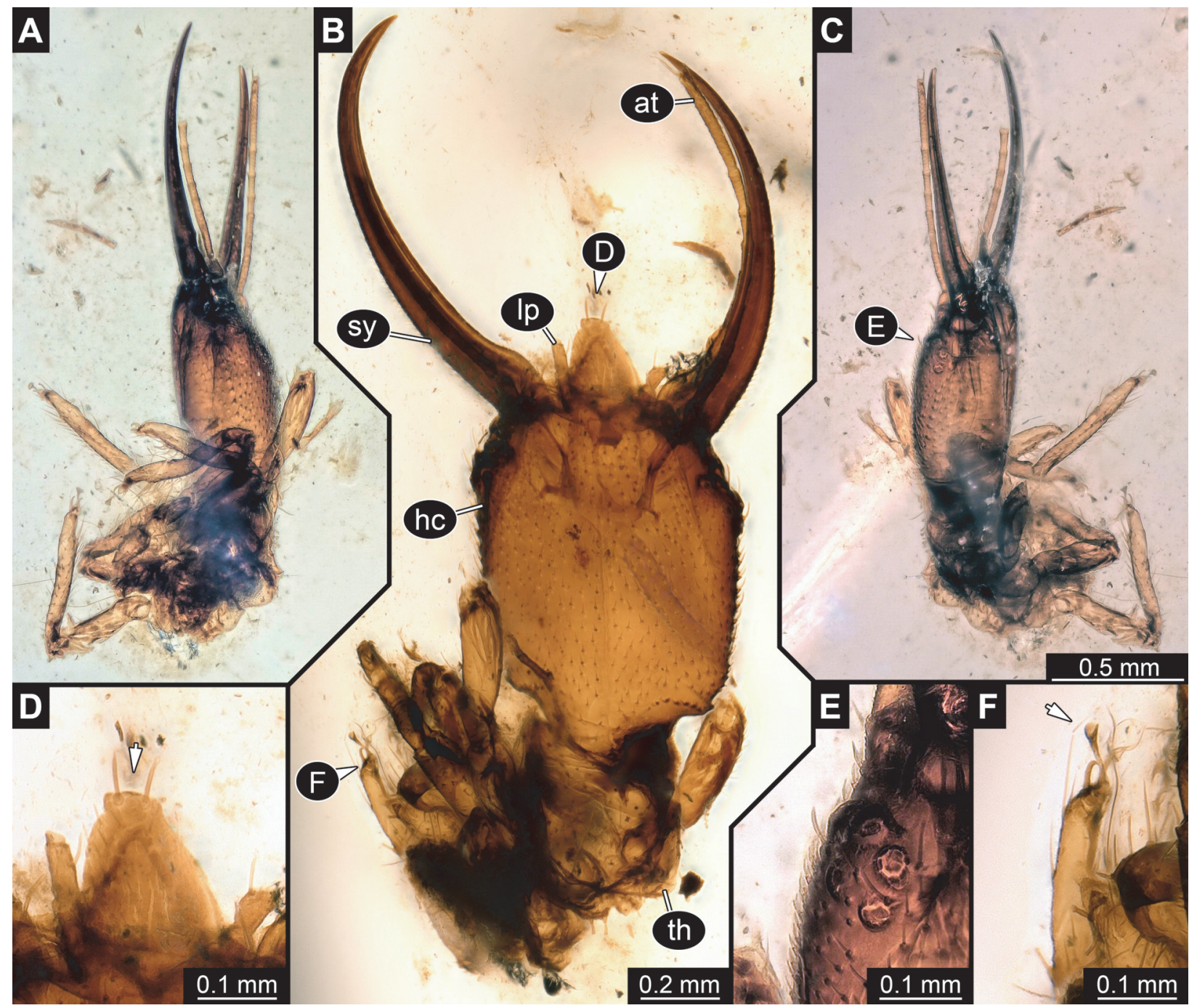

FIGURE 23. Specimen 49 (PED 0125); Burmese amber. A. Lateral view. B. Dorsal view. C. Lateral view, other side. D. Close-up of labrum (arrow) in dorsal view. E. Close-up of eyes in lateral view. F. Close-up of empodium (arrow) of a walking appendage. Abbreviations: at = antenna; hc = head capsule; $I p=$ labial palp; $s y=$ stylet; th = thorax.

are still generally considered as "available data". Furthermore, compared to most extant specimens the availability of these fossil specimens is better, concerning reliability. These fossil specimens are presented as high-resolution photo-micrographs that capture all specimen details clearly, while most of the extant specimens have been provided as drawings, which potentially include a degree of interpretation and bias toward certain features. It is often considered critical to use photographs of non-available specimens, yet in the present case the use of photograph data is well founded for the purposes of repeatability and further study.

For the Cretaceous fauna, most specimens have been deposited into institutional collections. Other specimens, deposited into private collections, are available for researchers and have been documented with high-end photo-micrographs, meeting the standards for virtual specimens.

Pérez-de la Fuente et al. (2020) have pointed out that non-institutional collections play a major role in research on fossil insect larvae and will continue to do so in the future. The use of specimens from these collections is generally accepted for non-taxonomic purposes (Makarkin et al., 2012; Wedmann et al., 2013; Haug et al., 2018). Furthermore, the acceptance of the use of such specimens for valuable research can be increased by extensive high-quality documentation that generates virtual specimens and can be used in analyses such as those presented here.

A critical point to make is that extant specimens must be made available. It remains uncommon practice to deposit extant larvae in museum 


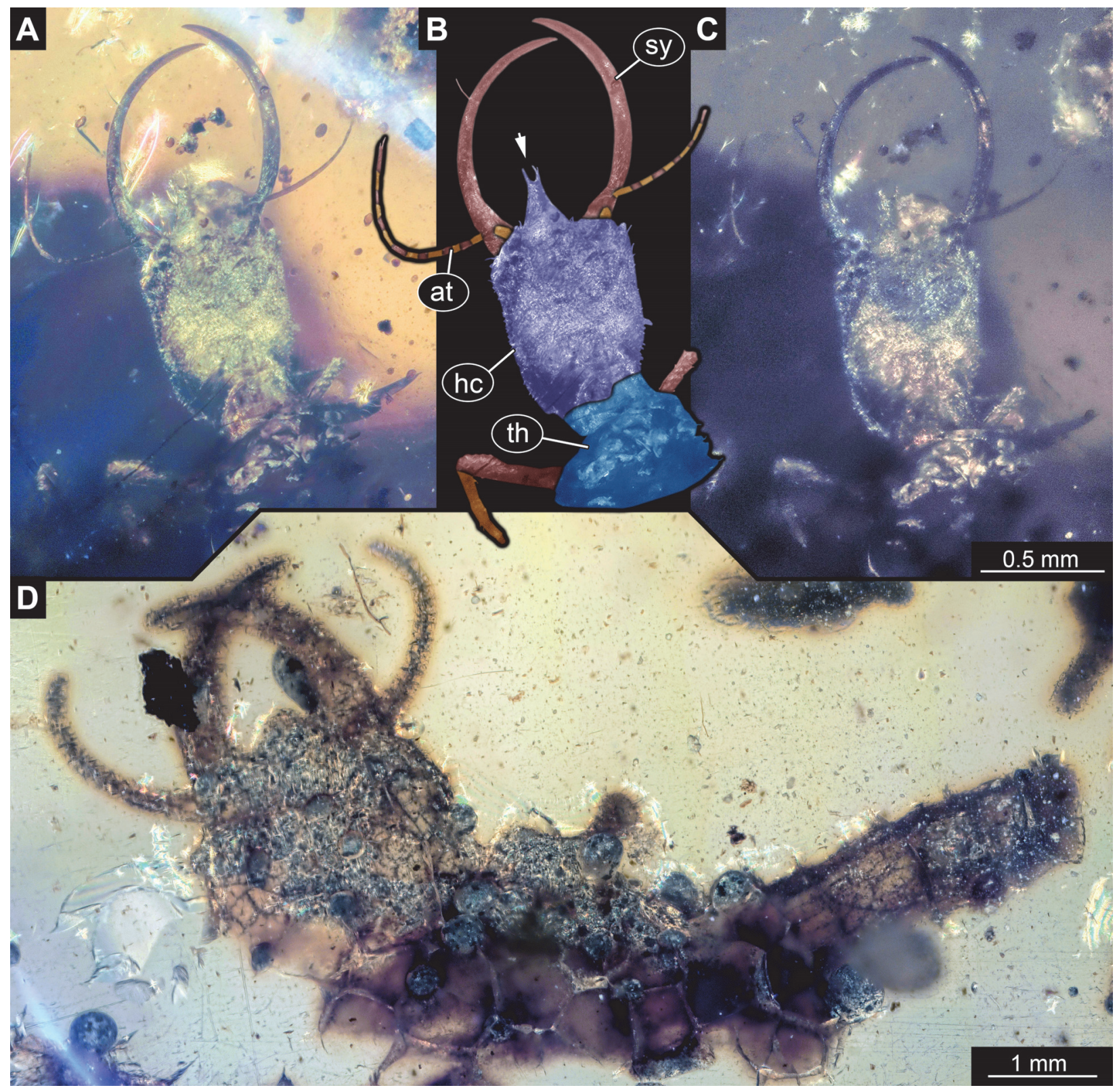

FIGURE 24. Specimens in Burmese amber, continued. A-C. Specimen 50 (PED 0039). A-C. Dorsal view. A. Ring light. B. Colour marked. C. Cross-polarised light. D. Specimen 51 (PED 0109). Abbreviations: at = antenna; hc = head capsule; sy = stylet; th = thorax.

collections. This is a critical aspect that needs improvement in the future.

\section{Morphological Diversity and Identity}

It is important to determine whether all of the fossil larvae studied are indeed representatives of Psychopsidae. All specimens possess a prominent anterior-projecting labrum, as well as stylets that are gently curved, lacking teeth. Additionally, most specimens possess well-preserved empodia (Figures 5F, G, 7F, 10E, 11E, 12D, E, 13E, 14E, 15F, $18 \mathrm{E}, \mathrm{F}, 20 \mathrm{D}, 22 \mathrm{~B}, 23 \mathrm{~F})$. These three characters are 'necessary' identifying characters, i.e., they are known to be present in all larval representatives of Psychopsidae (Figure 28A). Yet, each of these characters is not a 'sufficient' one, as they are known to be also present in larvae of other ingroups of Neuroptera. Examples include Nevrorthidae (Figure 28B; Beutel et al., 2010, their fig. 2), Berothidae (Figure 28F; MacLeod, 1964, his fig. 36), Coniopterygidae (Figure 28D; MacLeod, 1964, his fig. 62), Dilaridae (Figure 28E; MacLeod, 1964, his fig. 33), or Chrysopidae (MacLeod, 1964, his fig. 17). Even some larval representatives of Myr- 


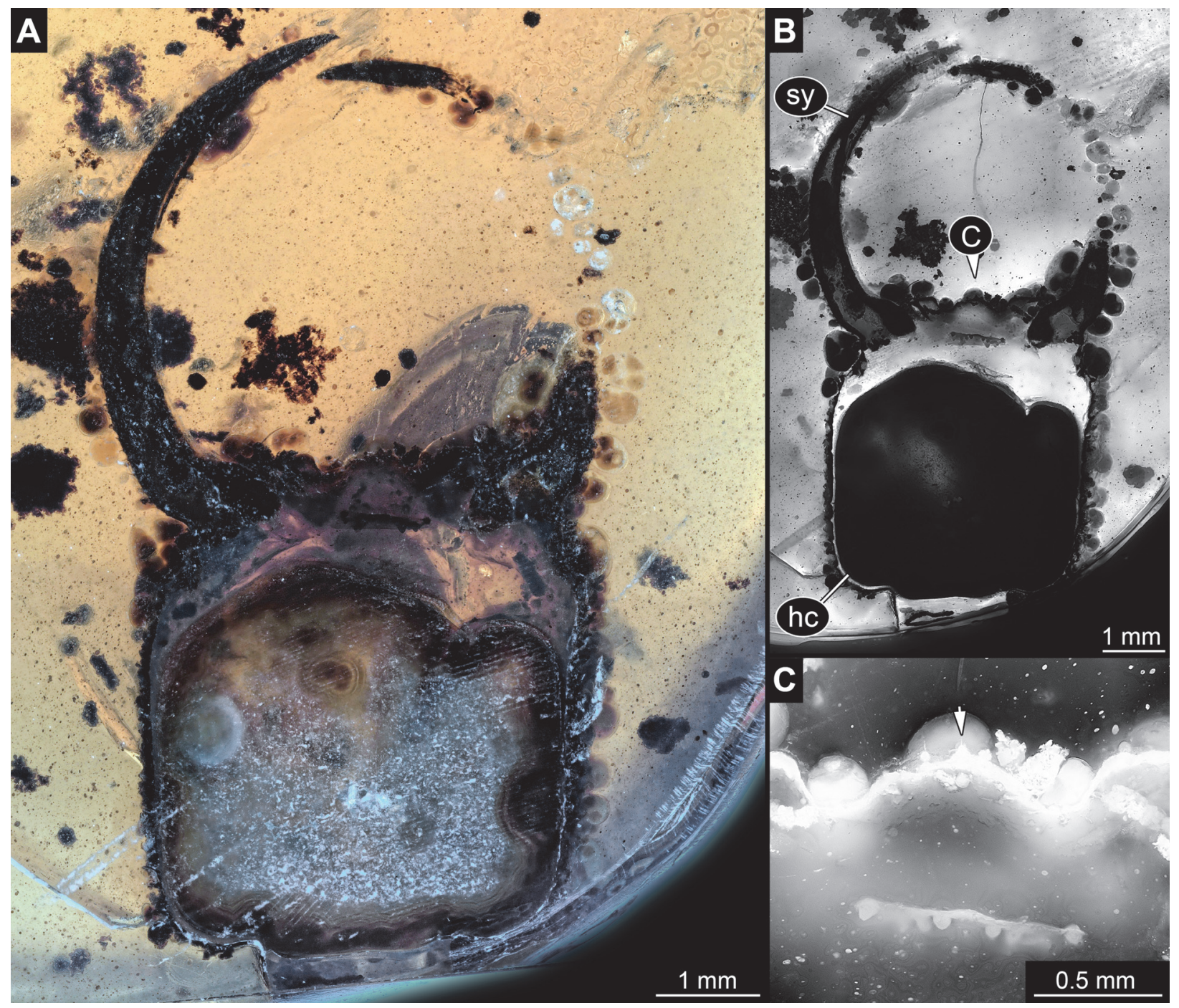

FIGURE 25. Specimen 52 (PED 0100); Burmese amber. A. White light composite image. B-C. Fluorescence images under blue light (GFP). B. Overview. C. Close-up of labrum; tip marked by arrow. Abbreviations: hc = head capsule; sy $=$ stylet.

meleontidae have occasional indications of a labrum present (Figure 28C; Acanthaclisis occitanica; Badano, 2012, image on p. 90; re-figured in Badano et al., 2017, their fig. 7C).

The combination of all three characters is also not sufficient to unequivocally identify larval representatives of Psychopsidae. The presence of an empodium is a plesiomorphy (Beutel et al., 2010), hence cannot be a reliable identifier. All early representatives of the group Myrmeleontiformia presumably possess empodia, as in larvae of the fossil species Macleodiella electrina, which was interpreted as a representative of Myrmeleontiformia, but not of Psychopsidae (Badano et al., 2018). The curved stylets are (most likely) another plesiomorphy, and the absence of teeth may be one as well (but see Haug et al., 2019a). The presence of a projecting labrum is also widespread among neuropteran larvae, but it remains unclear whether this could be plesiomorphic as well. Hence these three characters may all have been present in early representatives of Myrmeleontiformia that are not representatives of Psychopsidae.

Fortunately, among other available characters, the strong tuberculate surface of the head and presence of a spine-like seta distally on the antenna might serve as possible unequivocal identifiers for larvae of Psychopsidae. The spine-like seta distally on the antenna is more detailed and easier to evaluate, and is apparent in many of the fossils studied (Figures 4E, 5D, 6C-E, 7E, 9A, 10A, 11D, 12C, 13A, 14A, 15D, 16D, 17D, 18C, 

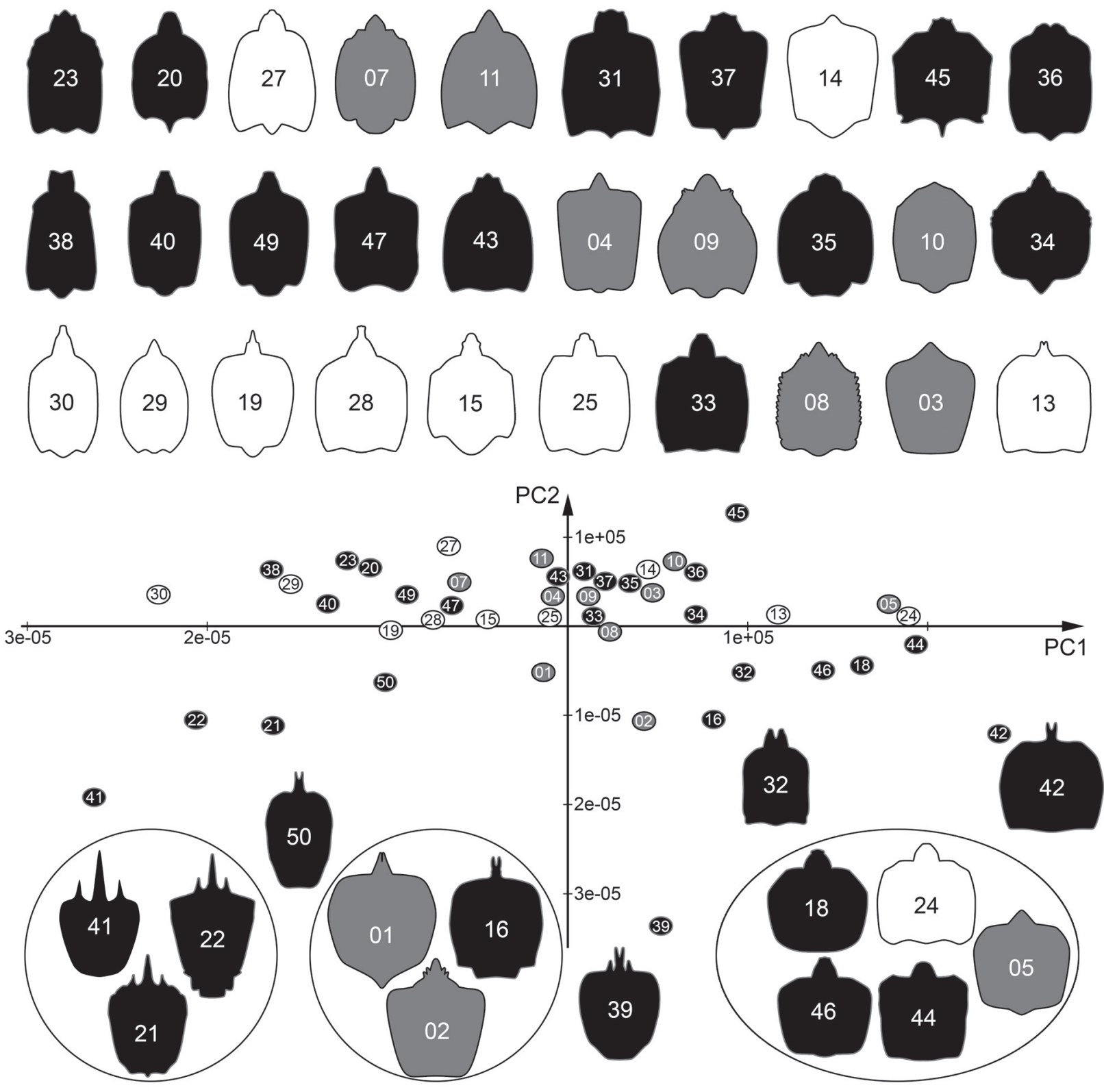

FIGURE 26. Scatterplot of PC1 and PC2 surrounded by all analysed heads. Numbers in the ellipses correspond to the numbers of the heads. Extant specimens as grey ellipses, Eocene specimens as white ellipses, Cretaceous specimens as black ellipses. The heads grouped together in circles cluster relatively closely together and possibly form relatively discrete types.

19A, E, 20A, 21A, 22A, C, 23B, 24A). This presents a strong argument that all these fossils are representatives of Psychopsidae. Still, it should be further investigated whether the presence of this specialised seta is indeed an apomorphy for Psychopsidae. In the few specimens in which this character is not available, no characters are present that could be used to identify them as closer related to any other lineage within Myrmeleontiformia. We consider all fossils presented here as representatives of Psychopsidae.

\section{Size}

Most lacewing larvae develop through three discrete larval stages. We expect a discrete threecluster distribution when plotting sizes. The larvae studied here represent a number of species that would differ in final size. However, shape variables along PC axes 1 and 2 were uncorrelated with size (Figure 27C), indicating that size did not affect the shape analysis. However, the potential for mixing developmental stages remains a possibility that 


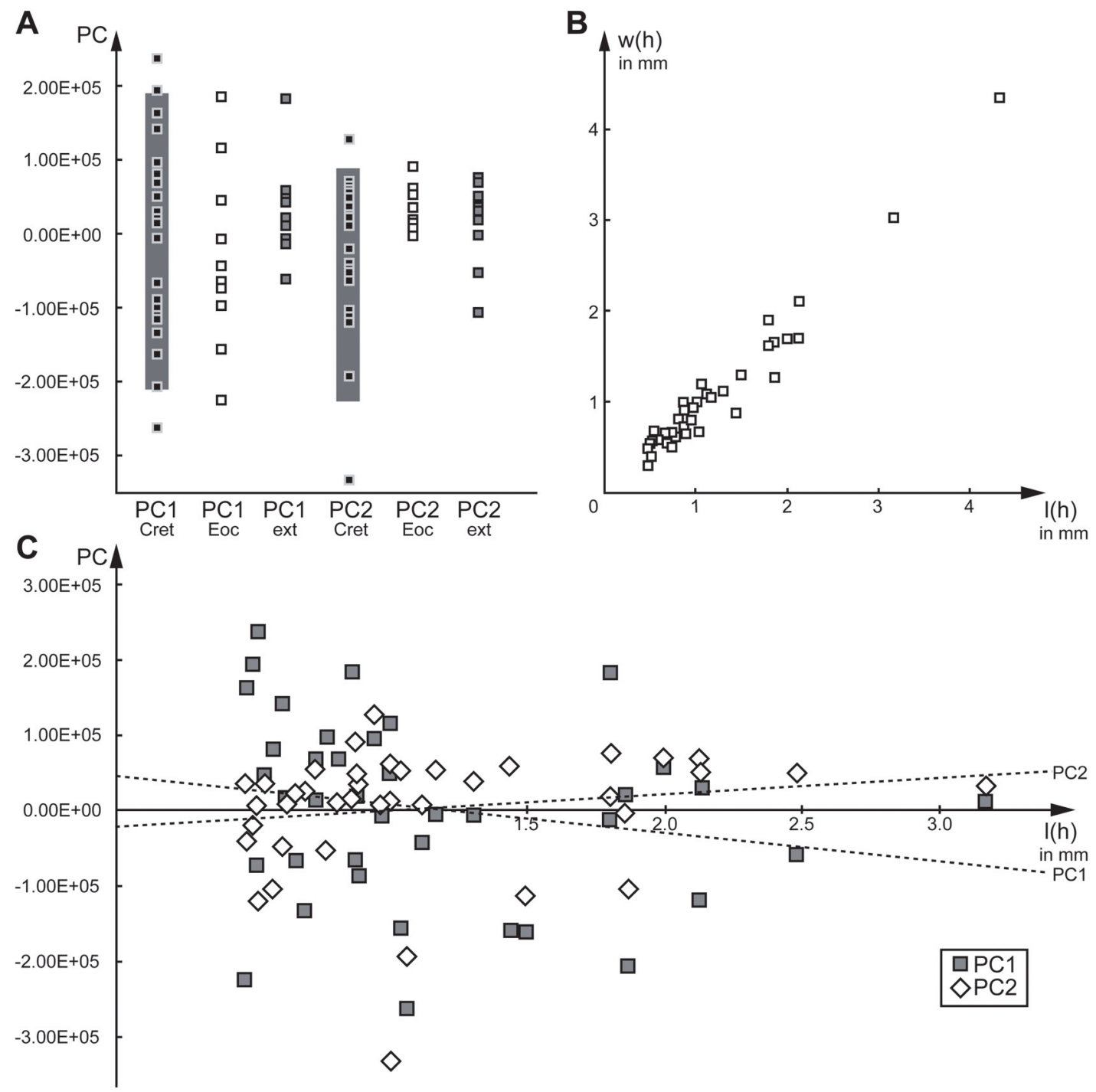

FIGURE 27. Different plots of the data of the analysed long-nosed antlion larvae. A. Range of PC1 and PC2 for specimens from different time slices. For Cretaceous specimens, the grey bars provide the sample-size-corrected ranges. B. Scatter plot of head capsule width $w(h)$ vs. capsule length I(h) (without labrum). C. PC1 and PC2 plotted against head capsule length (without labrum). Note the low degree of correlation as well as low coefficient of determination: $P C 1: R^{2}=0.039, P C 2: R^{2}=0.027$.

would be resolved by adding significantly more specimens.

Specimen 52 is by far the largest; it is not even fully within the amber, with part of it ground off (Figure 25A). The labrum is thus incomplete, however, the available characters identify this specimen as a larva of Psychospidae. As a rough estimation, this specimen must have been about $30 \mathrm{~mm}$ in overall body size. This is much larger than any of the modern known long-nosed antlion larvae.
The specimens reported in Tillyard (1918) are identified to stage, and it would be ideal to similarly recognise developmental stages in the specimens studied here. Yet, other extant forms cannot be clearly identified in the same manner due to lack of research. Naturally this is more challenging for fossils, and we can only guess for some of the smaller, better preserved specimens that they are first stage larvae (e.g., specimens 16 and 39; Figures 8 and 17). This is partly frustrating but a common problem when dealing with a rather small sample size of fossils. 


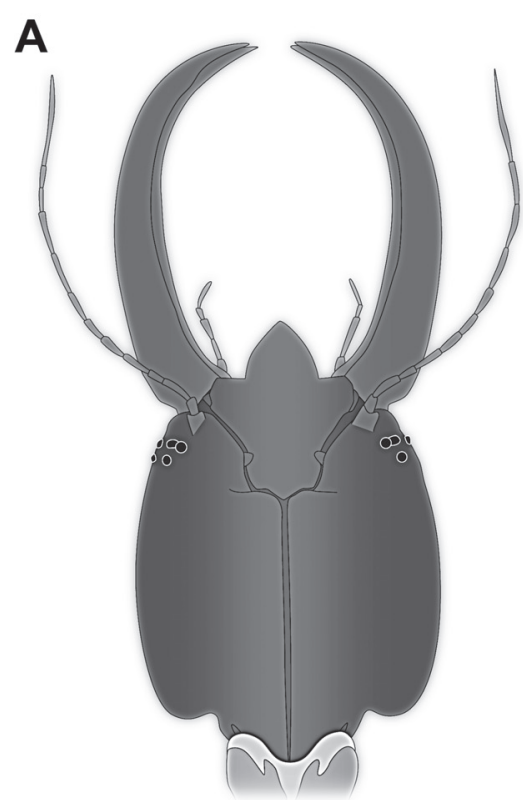

D

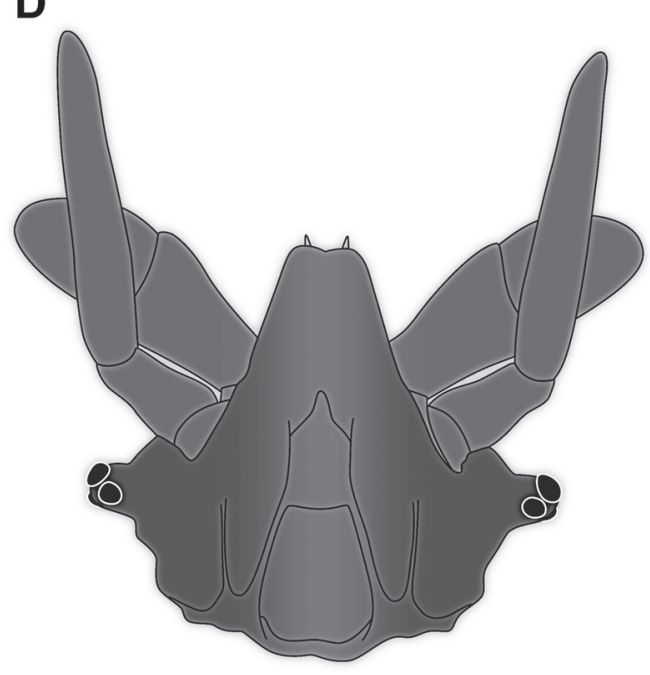

B

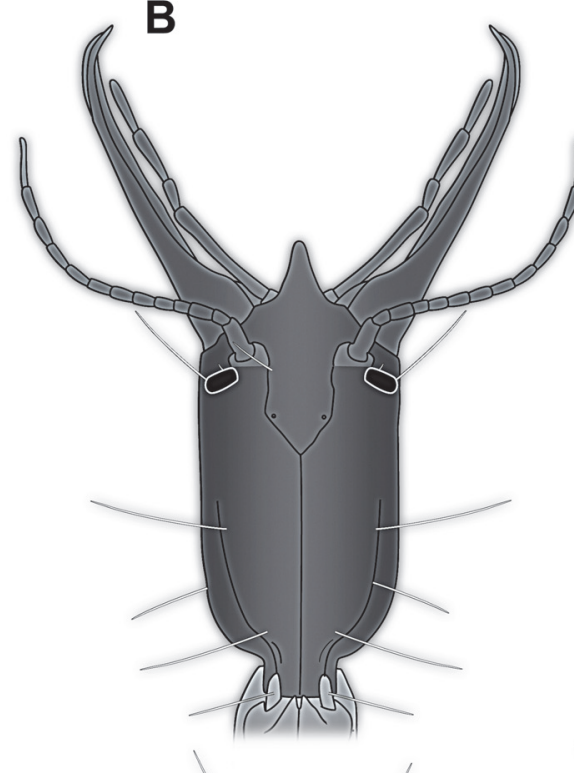

E

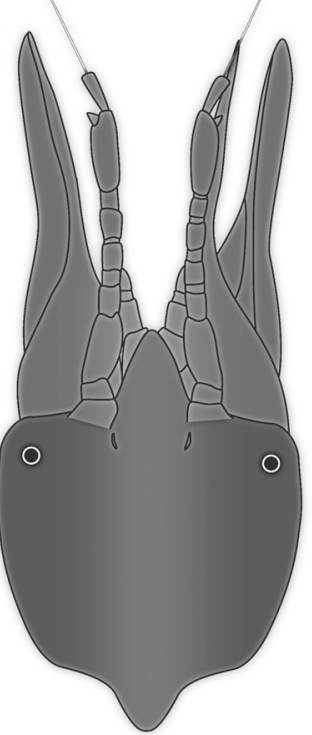

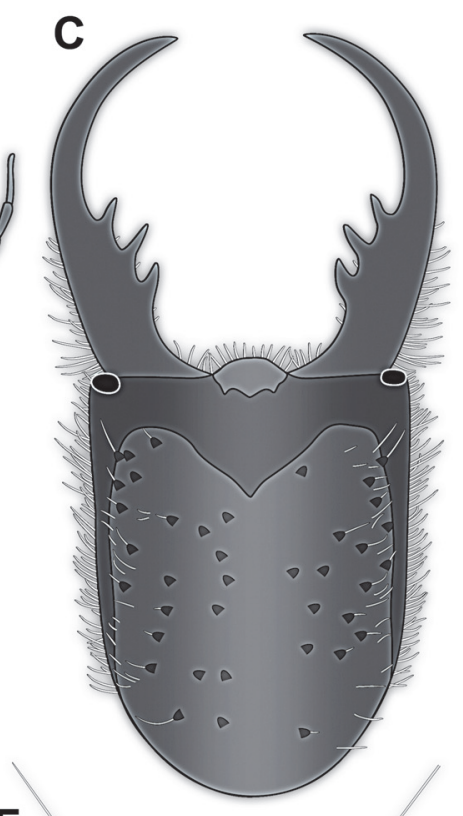

$\mathbf{F}$

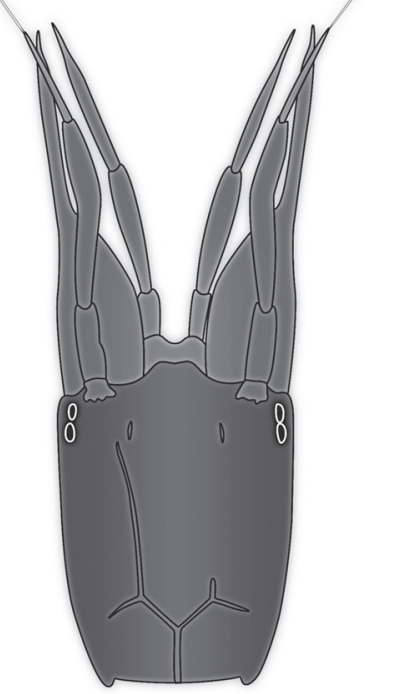

FIGURE 28. Comparison of different heads of lacewing larvae with labrum. A. Psychopsidae (MacLeod 1964, his fig. 66). B. Nevrorthidae (Beutel et al. 2010, their fig. 2). C. Myrmeleontidae (Acanthaclisis occitanica; Badano 2012, image on p. 90; re-figured in Badano et al. 2017, their fig. 7C). D. Coniopterygidae (MacLeod 1964, his fig. 62). E. Dilaridae (MacLeod 1964, his fig. 33). F. Berothidae (MacLeod 1964, his fig. 36).

\section{Diversity in the Cretaceous: Recognising Different Types}

Makarkin (2018) differentiated three types of labrum shapes in fossil larvae of Psychopsidae: type A, B and C. Type A is a trident-type labrum, as in the species Acanthopsychops trianus. We have three Cretaceous specimens of this type that cluster together (specimens 21, 22, 41; Figure 26, lower left).

Type $B$ is represented by a single specimen (specimen 23) with a three-lobed anterior margin described by Makarkin (2018) and is similar to modern forms in his view. Indeed, this larva clusters loosely with modern and Eocene specimens (Figure 26), despite its Cretaceous origin and unique tri-lobed labrum that would otherwise set it apart from nearby clustered specimens. This indicates similarity in other aspects of shape that link these specimens, such as more elongate and slender heads, as well as smoothly rounded corners. There is large variance in this cluster, with gradual transitions between labrum and head shapes along 
the PC1 axis, and no distinct sub-clusters. Also, not all labra of specimens in this cluster are trilobed. Some labra are simple triangular (e.g., specimen 34), and some more pentagonal (e.g., specimen 37 ), with almost every variation in between. Other specimens differ much more significantly. For example, specimen 36 has a cleft in the labrum, which is short and broad; it could well be considered as a separate type. This also accounts for specimen 38 that has a large prominent labrum with a broad $V$-shaped cleft.

Type $C$ is similar to type B according to Makarkin (2018), but slightly different by being one-lobed, represented by specimen 18 . In the shape analysis it clusters with specimens from all three time slices (specimens 05, 24, 44, 46; Figure 26). This type is not distinguished by the labrum shape, but rather by the very broad head.

Another distinct type is represented by specimens 01,02 and 16 (Figure 26). All three have spiny labra, broad heads and are small. However, given the lack of life stage determination among the studied samples, this morphology may be due to an early developmental stage rather than phylogeny or function.

Finally, four specimens are plotted in isolated positions (Figure 26) and are all unique. Specimens 50 and 42 both have a distinct bifid labrum, yet specimen 50 has a slender head, while specimen 42 has a broad head. Specimen 42 is plotted in an isolated position, while specimen 50 is less isolated. Specimen 32 is also less isolated and has a unique labrum morphology, with a cleft that is extremely deep, resembling a bifid labrum, but is much broader. Specimen 39 is also isolated, having a distinct bifid central part of the labrum, but additionally has a pair of adjacent spines similar to type A.

Overall, there is a large variety of different labral types and head shapes, especially among the Cretaceous forms. No distinct correlations between shape principal components and size were recovered, however, some shapes may be correlated to specific ontogenetic stages. Bifid labral tips may be more common among first stage larvae. For example, specimen 39 could represent a stage 1 larva of Acanthopsychops trianus. However, more specimens are required to study this further.

Many Eocene larvae have more triangular labra, while most modern forms have shorter labra. This hints to a correlation between shape and extinction, and possibly even shape and function that shifted to leave fewer remaining labrum types and head shapes over time as the diversity of silky lacewings declined. Such a shift in labrum morphology is due to extinction of lineages with non-triangular labra. The causes of this are speculative but may include specialization in prey species among larvae of surviving silky lacewing species. However, this requires deeper knowledge on functional morphology of the mouth parts of the larvae of Psychopsidae.

These quantitative characters, especially those related to the labrum, could be used as distinct characters for taxonomic differentiation of these larval forms. However, a larger dataset would be desirable to recognise distinct patterns.

\section{Morphological Diversity}

The Cretaceous larvae show significantly larger morphological diversity than their modern counterparts, i.e., the range of values for individual dimensions ( $P C$ axes) is larger than in the modern fauna (Figures 26, 27).

In the plot without sample size correction (Figure 26), there are more recognisable types of labra and higher shape variability among Cretaceous larvae than among those from other time slices. Even after sample size correction, the Cretaceous larvae retain the highest occupation of most principal components (Figure 27A). In both corrected and uncorrected analyses, modern larvae are the least diverse overall. However, the Eocene larvae are the least diverse in principal component 2 , which is linked to differentiation of anterior and posterior rims of the head capsules. This may be due to a lack of early developmental stage specimens (indicated by size) from this time that would partly explain the absence of certain developmentallydependent morphologies. However, this remains unclear because the correlation between size and shape is weak (Figure 27C).

Taxonomic diversity and geographic distribution of silky lacewings was higher in the past (e.g., Aspöck and Aspöck, 2007), as indicated by their present-day relic distribution and low abundance of species (Oswald, 1993: Bakkes et al., 2017). We show that morphological diversity of larvae was also higher in the past, especially in the Cretaceous. This suggests a decline between the Cretaceous and the Eocene, possibly related to the Cretaceous-Palaeogene extinction event. Indeed, some of the more special types of labrum shapes, such as the trident labrum, are absent after the Cretaceous. Yet, the overall decline in diversity of shapes is after the Eocene, especially in PC1. The loss of long-nosed antlion larval diversity must 
therefore have begun during the later Mesozoic to early Cenozoic. Younger amber deposits could be informative in this aspect, unfortunately productive candidate ambers, such as Miocene Mexican or Dominican ambers are in the wrong geographical region to recover silky lacewings. However, a recently discovered, highly fossiliferous amber of middle Miocene (Langhian) age from Fujian Province of southern China is promising (Shi et al., 2014; Wang, 2016). This Chinese amber, as well as Australian Cape York amber (exact Cenozoic age unclear; Hand et al., 2010) and New Zealand amber (Oligocene/Miocene; Schmidt et al., 2018) should be screened with a focus on long-nosed antlion larvae.

The head of larvae provides a good proxy for the diversity of feeding strategies, because mouthpart morphology, including the labrum, is presumably highly correlated to function. The larger diversity of head shapes in the past therefore also indicates that diversity of ecological roles of these larvae or of their prey species was higher in the past and have gone extinct after the Cretaceous. Unfortunately, there are no well-documented descriptions of functional or comparative morphology in the feeding process of silky lacewing larvae or their closer relatives that do not have a forward projecting labrum. Moreover, due to the incomplete knowledge of the modern forms, it is currently not possible to guess how different labra were used during the feeding process. Potentially, these different morphologies could also relate to differences in habitat or microhabitat preferences, yet this remains speculative.

Cretaceous larvae of other lacewings and closer relatives, such as those of snake flies, appear to have morphologies no longer represented in the modern fauna (Liu et al., 2016, 2018; Pérez-de la Fuente et al., 2012, 2016, 2018, 2019; Haug et al., 2019b, c, 2020). The pattern of declining morphological diversity through time of lacewings and the closer relatives is supported by our observations of silky-lacewings.

The neutral outline shape analysis applied in this study is a useful tool that facilitates recognition and comparison of diversity through time, even for samples that cannot be studied using traditional taxonomic methods. Moreover, it enables recogni- tion of multivariate aspects of shape that cannot be gathered by using univariate length measurements (Haug et al., 2019b, c, 2020).

\section{CONCLUSIONS}

- Outline analysis is a useful tool for recognising changes in diversity through time. It can be used for larvae without being able to narrow down their taxonomic/systematic identity.

- The morphological diversity of silky lacewing larvae was higher in the past, especially in the Cretaceous.

- Reconstructing the biology of fossil larvae is often hampered by incomplete knowledge of their extant counterparts. We know significantly more larval specimens of silky lacewings from the Cretaceous than from modern fauna.

\section{ACKNOWLEDGEMENTS}

This study heavily benefited from the help of various people and institutions; we thank them for their support. J. Matthias Starck, Munich, is thanked for long time support. JTH is kindly supported by the Volkswagen Foundation with a Lichtenberg Professorship. PGP is currently funded via Capes/Doctoral Program (CAPES/DAAD/CNPQ, Notice $n^{\circ}$. 15-2017/ Process $n^{\circ}$ 88887.161379/ 2017-00). CH was funded via the LMUexcellent Junior Researcher Fund and an award for equal opportunities for women in research of the LMU Munich. Collection of French Charentese amber in the early 2000s was supported by CNRS project ECLIPSE 'Interactions climat/écosystèmes de l'Aptien au Paléocène'. C. Farnum and P. Perkins, both Museum of Comparative Zoology Harvard, and C. Neumann, Natural History Museum (Museum für Naturkunde) Berlin, are thanked for access to material and help in the collections. J. Damzen (amberinclusions.eu) and M. Veta (ambertreasure4u.com), both Vilnius, kindly provided images. J. Belojević, Munich, kindly translated the abstract into Montenegrin. M. Engel, Lawrence, is thanked for discussion and help with literature. We are grateful to all people providing free software. This is LEON publication \#13. 


\section{REFERENCES}

Aspöck, U. and Aspöck, H. 1999. Kamelhälse, Schlammfliegen, Ameisenlöwen. Wer sind sie? (Insecta: Neuropterida: Raphidioptera, Megaloptera, Neuroptera). Stapfia, 60(138):1-34.

Aspöck, U. and Aspöck, H. 2007. Verbliebene Vielfalt vergangener Blüte. Zur Evolution, Phylogenie und Biodiversität der Neuropterida (Insecta: Endopterygota). Denisia, 20, Kataloge der Oberöstereichischen Landesmuseen Neue Serie, 66:451-516.

Aspöck, U., Haring, E., and Aspöck, H. 2012. The phylogeny of the Neuropterida: long lasting and current controversies and challenges (Insecta: Endopterygota). Arthropod Systematics and Phylogeny, 70:119-129.

Badano, D. 2012. The larvae of European Myrmeleontidae and Ascalaphidae (Neuroptera). Unpublished PhD Thesis, Università degli Studi di Sassari, Sassari, Italy.

Badano, D., Aspöck, U., Aspöck, H., and Cerretti, P. 2017. Phylogeny of Myrmeleontiformia based on larval morphology (Neuropterida: Neuroptera). Systematic Entomology, 42:94-117. https://doi.org/10.1111/syen.12200

Badano, D., Engel, M.S., Basso, A., Wang, B., and Cerretti, P. 2018. Diverse Cretaceous larvae reveal the evolutionary and behavioural history of antlions and lacewings. Nature Communications, 9:3257. https://doi.org/10.1038/s41467-018-05484-y

Bakkes, D.K., Sole, C.L., and Mansell, M.W. 2017. Revision of Afrotropical silky lacewings (Neuroptera: Psychopsidae). Zootaxa, 4362(2):151-212. https://doi.org/10.11646/ zootaxa.4362.2.1

Bakkes, D.K., Mansell, M.W., and Sole, C.L. 2018. Phylogeny and historical biogeography of silky lacewings (Neuroptera: Psychopsidae). Systematic Entomology, 43:43-55. https:// doi.org/10.1111/syen.12247

Beutel, R.G., Friedrich, F., and Aspöck, U. 2010. The larval head of Nevrorthidae and the phylogeny of Neuroptera (Insecta). Zoological Journal of the Linnean Society, 158:533-562. https://doi.org/10.1111/j.1096-3642.2009.00560.x

Braig, F., Haug, J.T., Schädel, M., and Haug, C. 2019. A new thylacocephalan crustacean from the Upper Jurassic lithographic limestones of southern Germany and the diversity of Thylacocephala. Palaeodiversity, 12:69-87. https://doi.org/10.18476/pale.v12.a6

Cover, M.R. and Bogan, M.T. 2015. Chapter 41 - Minor insect orders, p. 1059-1072. In Thorp, J.H. and Rogers, D.C. (eds.), Thorp and Covich's Freshwater Invertebrates. Ecology and General Biology. Academic Press, Cambridge.

Dunn, R.R. 2005. Modern insect extinctions, the neglected majority. Conservation Biology, 19:1030-1036. https://doi.org/10.1111/j.1523-1739.2005.00078.x

Engel, M.S. and Grimaldi, D.A. 2008. Diverse Neuropterida in Cretaceous amber, with particular reference to the paleofauna of Myanmar (Insecta). Nova Supplementa Entomologica, 20:186.

Engel, M.S., Winterton, S.L., and Breitkreuz, L.C. 2018. Phylogeny and evolution of Neuropterida: where have wings of lace taken us? Annual Review of Entomology, 63:531551. https://doi.org/10.1146/annurev-ento-020117-043127

Fowler, M.J.F. 2018. Eocene world: fossil insects from Baltic amber. Bulletin of the Amateur Entomologists' Society, 77:178-188.

Froggatt, W.W. 1907. Australian Insects. William Brooks and Company, Ltd., Sydney.

Gepp, J. 1984. Erforschungsstand der Neuropteren. Larven der Erde (mit einem Schlüssel zur Larvaldiagnose der Familien, einer Übersicht von 340 beschriebenen Larven und 600 Literaturzitaten). Progress in Worlds Neuropterology. Proceedings of the First International Symposium on Neuropterology, Graz, 183-239.

Grimaldi, D.A. 2000. A diverse fauna of Neuropterodea in amber from the Cretaceous of New Jersey, p. 259-303. In Grimaldi, D.A. (ed.), Studies on Fossils in Amber, with Particular Reference to the Cretaceous of New Jersey. Backhuys Publishers, Leiden.

Gröhn, C. 2015. Einschlüsse im baltischen Bernstein. Verlag Wachholtz, Kiel.

Gröhn, C., Hornemann, M., Joger, U., Koch, A., Kosma, R., Krüger, F.J., Vahldiek, B.-W., Wilde, V., and Zellmer, H. 2015. Zeitkapsel Bernstein. Verlag Dr. Friedrich Pfeil, München. 
Hallmann, C.A., Sorg, M., Jongejans, E., Siepel, H., Hofland, N., Schwan, H., Stenmans, W., Müller, A., Sumser, H., Hörren, T., Goulson, D., and de Kroon, H. 2017. More than 75 percent decline over 27 years in total flying insect biomass in protected areas. PloS ONE, 12(10):e0185809. https://doi.org/10.1371/journal.pone.0185809

Hand, S., Archer, M., Bickel, D., Creaser, P., Dettmann, M., Godthelp, H., Jones, A., Norris, B., and Wicks, D. 2010. Australian Cape York amber, p. 69-79. In Penney, D. (ed.), Biodiversity of Fossils in Amber from the Major World Deposits. Siri Scientific Press, Manchester.

Haug, J.T., Haug, C., and Ehrlich, M. 2008. First fossil stomatopod larva (Arthropoda: Crustacea) and a new way of documenting Solnhofen fossils (Upper Jurassic, Southern Germany). Palaeodiversity, 1:103-109.

Haug, J.T., Haug, C., Kutschera, V., Mayer, G., Maas, A., Liebau, S., Castellani, C., Wolfram, U., Clarkson, E.N.K., and Waloszek, D. 2011. Autofluorescence imaging, an excellent tool for comparative morphology. Journal of Microscopy, 244:259-272. https://doi.org/10.1111/j.13652818.2011.03534.x

Haug, J.T., Müller, C.H.G., and Sombke, A. 2013a. A centipede nymph in Baltic amber and a new approach to document amber fossils. Organisms Diversity and Evolution, 13:425-432. https:/ /doi.org/10.1007/s13127-013-0129-3

Haug, C., Shannon, K.R., Nyborg, T., and Vega, F.J. 2013b. Isolated mantis shrimp dactyli from the Pliocene of North Carolina and their bearing on the history of Stomatopoda. Boletín de la Sociedad Geológica Mexicana, 65:273-284. https://doi.org/10.18268/bsgm2013v65n2a9

Haug, J.T., Müller, P., and Haug, C. 2018. The ride of the parasite: a 100-million-year old mantis lacewing larva captured while mounting its spider host. Zoological Letters, 4:31. https:// doi.org/10.1186/s40851-018-0116-9

Haug, C., Herrera-Flórez, A.F., Müller, P., and Haug, J.T. 2019a. Cretaceous chimera-an unusual 100-million-year old neuropteran larva from the "experimental phase" of insect evolution. Palaeodiversity, 12:1-11. https://doi.org/10.18476/pale.v12.a1

Haug, J.T., Müller, P., and Haug, C. 2019b. A 100-million-year old predator: a fossil neuropteran larva with unusually elongated mouthparts. Zoological Letters, 5:29. https://doi.org/10.1186/ s40851-019-0144-0

Haug, J.T., Müller, P., and Haug, C. 2019c. A 100-million-year old slim insectan predator with massive venom-injecting stylets - a new type of neuropteran larva from Burmese amber. Bulletin of Geosciences, 94:431-440. https://doi.org/10.3140/bull.geosci.1753

Haug, J.T., Müller, P., and Haug, C. 2020. A 100 million-year-old snake-fly larva with an unusually large antenna. Bulletin of Geosciences, 95:167-177. https://doi.org/10.3140/ bull.geosci.1757

Iwata, H. and Ukai, Y. 2002. SHAPE: A computer program package for quantitative evaluation of biological shapes based on elliptic Fourier descriptors. Journal of Heredity, 93:384-385. https://doi.org/10.1093/jhered/93.5.384

Larsson, S.G. 1978. Baltic amber: a palaeobiological study. Scandinavian Science Press, Klampenborg, Denmark.

Liu, X., Zhang, W., Winterton, S.L., Breitkreuz, L.C., and Engel, M.S. 2016. Early morphological specialization for insect-spider associations in Mesozoic lacewings. Current Biology, 26:1590-1594. https://doi.org/10.1016/j.cub.2016.04.039

Liu, X., Shi, G., Xia, F., Lu, X., Wang, B., and Engel, M.S. 2018. Liverwort mimesis in a Cretaceous lacewing larva. Current Biology, 28:1475-1481. https://doi.org/10.1016/ j.cub.2018.03.060

MacLeod, E.G. 1964. A comparative morphological study of the head capsule and cervix of larval Neuroptera (Insecta). Unpublished PhD Thesis, Harvard University, Cambridge, Massachusetts, USA.

MacLeod, E.G. 1970. The Neuroptera of the Baltic Amber. I. Ascalaphidae, Nymphidae, and Psychopsidae. Psyche: A Journal of Entomology, 77(2):147-180. https://doi.org/10.1155/ 1970/45459

Makarkin, V.N. 2018. Re-description of Grammapsychops lebedevi Martynova, 1954 (Neuroptera: Psychopsidae) with notes on the Late Cretaceous psychopsoids. Zootaxa, 4524:581-594. https://doi.org/10.11646/zootaxa.4524.5.5

Makarkin, V.N., Wedmann, S., and Weiterschan, T. 2012. First record of a fossil larva of Hemerobiidae (Neuroptera) from Baltic amber. Zootaxa, 3417:53-63. https://doi.org/ 10.11646/zootaxa.3417.1.3 
New, T.R. 1989. Planipennia, Lacewings. Handbuch der Zoologie, Vol. 4. Arthropoda: Insecta, part 30. Walter de Gruyter, Berlin.

New, T.R. 1991. Neuroptera, p. 525-542. In Naumann, I.D. (ed.), The Insects of Australia, $2^{\text {nd }}$ ed. Melbourne University Press, Carlton, Victoria.

Oswald, J.D. 1993. Phylogeny, taxonomy, and biogeography of extant silky lacewings (Insecta: Neuroptera: Psychopsidae). Memoirs of the American Entomological Society (USA), 40:165.

Pérez-de la Fuente, R., Delclòs, X., Peñalver, E., Speranza, M., Wierzchos, J., Ascaso, C., and Engel, M.S. 2012. Early evolution and ecology of camouflage in insects. Proceedings of the National Academy of Sciences, 109:21414-21419. https://doi.org/10.1073/pnas.1213775110

Pérez-de la Fuente, R., Delclos, X., Peñalver, E., and Engel, M.S. 2016. A defensive behavior and plant-insect interaction in Early Cretaceous amber-the case of the immature lacewing Hallucinochrysa diogenesi. Arthropod Structure and Development, 45:133-139. https:// doi.org/10.1016/j.asd.2015.08.002

Pérez-de la Fuente, R., Peñalver, E., Azar, D., and Engel, M.S. 2018. A soil-carrying lacewing larva in Early Cretaceous Lebanese amber. Scientific Reports, 8:16663. https://doi.org/ 10.1038/s41598-018-34870-1

Pérez-de la Fuente, R., Engel, M.S., Azar, D., and Peñalver, E. 2019. The hatching mechanism of 130-million-year-old insects: an association of neonates, egg shells and egg bursters in Lebanese amber. Palaeontology, 62:547-559. https://doi.org/10.1111/pala.12414

Pérez-de la Fuente, R., Engel, M.S., Delclòs, X., and Peñalver, E. 2020. Straight-jawed lacewing larvae (Neuroptera) from Lower Cretaceous Spanish amber, with an account on the known amber diversity of neuropterid immatures. Cretaceous Research, 106:104200. https:// doi.org/10.1016/j.cretres.2019.104200

Perrichot, V. 2003. Environnements Paraliques à Ambre et à Végétaux du Crétacé Nord-aquitain (Charentes, Sud-Ouest de la France). Unpublished PhD Thesis, Université Rennes 1, Rennes, France. https://tel.archives-ouvertes.fr/tel-00011639/file/Memoire_GS_Web.pdf

Perrichot, V., Néraudeau, D., and Tafforeau, P. 2010. Charentese Amber, p. 192-207. In Penney, D. (ed.), Biodiversity of Fossils in Amber from the Major World Deposits. Siri Scientific Press, Manchester.

R Core Team 2018. R: A language and environment for statistical computing. R Foundation for Statistical Computing, Vienna, Austria. https://www.R-project.org/.

Sadowski, E.M., Schmidt, A.R., Seyfullah, L.J., and Kunzmann, L. 2017. Conifers of the 'Baltic amber forest' and their palaeoecological significance. Stapfia, 106:1-73.

Scheven, J. 2004. Bernstein-Einschlüsse: Eine untergegangene Welt bezeugt die Schöpfung. Erinnerungen an die Welt vor der Sintflut. Kuratorium Lebendige Vorwelt e.V., Hofheim a.T.

Schmidt, A., Kaulfuss, U., Bannister, J.M., Baranov, V., Beimforde, C., Bleile, N., Borkent, A., Busch, A., Conran, J.G., Engel, M.S., Harvey, M., Kennedy, E.M., Kerr, P., Kettunen, E., Philie Kiecksee, A., Lengeling, F., Lindqvist, J.K., Maraun, M., Mildenhall, D.C., Perrichot, V., Rikkinen, J., Sadowski, E.-M., Seyfullah, L.J., Stebner, F., Szwedo, J., Ulbrich, P., and Lee, D.E. 2018. Amber inclusions from New Zealand. Gondwana Research, 56:135-146. https:// doi.org/10.1016/j.gr.2017.12.003

Shi, G., Dutta, S., Paul, S., Wang, B., and Jacques F.M.B. 2014. Terpenoid compositions and botanical origins of Late Cretaceous and Miocene amber from China. PLoS One, 9:e111303. https://doi.org/10.1371/journal.pone.0111303

Tauber, C.A., Tauber, M.J., and Albuquerque, G.S. 2003. Neuroptera (lacewings, antlions), p. 695-707. In Resh, V.H. and Cardé, R.T. (eds.), Encyclopedia of Insects. Academic Press, San Diego, London, Burlington.

Tillyard, R.J. 1918. Studies in Australian Neuroptera. No. 7. The life-history of Psychopsis elegans (Guérin). Proceedings of the Linnean Society of New South Wales, 43:787-818.

Wang, B. 2016. Chinese amber: Progress and prospects, p. 55. In Penney, D. and Ross, A.J. (eds.), 7th International Conference on Fossil Insects, Arthropods and Amber (Edinburgh, UK) - Abstracts. Siri Scientific Press, Manchester.

Wedmann, S., Makarkin, V.N., Weiterschan, T., and Hörnschemeyer, T. 2013. First fossil larvae of Berothidae (Neuroptera) from Baltic amber, with notes on the biology and termitophily of the family. Zootaxa, 3716:236-258. https://doi.org/10.11646/zootaxa.3716.2.6

Weitschat, W. and Wichard, W. 1998. Atlas der Tiere und Pflanzen im Baltischen Bernstein. Dr. Friedrich Pfeil, München. 
Weitschat, W. and Wichard, W. 2002. Atlas of Plants and Animals in Baltic Amber. Dr. Friedrich Pfeil, München.

Winterton, S.L., Hardy, N.B., and Wiegmann, B.M. 2010. On wings of lace: phylogeny and Bayesian divergence time estimates of Neuropterida (Insecta) based on morphological and molecular data. Systematic Entomology, 35:349-378. https://doi.org/10.1111/j.13653113.2010.00521.x

Winterton, S.L., Lemmon, A.R., Gillung, J.P., Garzon, I.J., Badano, D., Bakkes, D.K., Breitkreuz, L.C.V., Engel, M., Moriarty, E.M., Liu, X., Machado, R.J.P., Skevington, J.H., and Oswald, J.D. 2018. Evolution of lacewings and allied orders using anchored phylogenomics (Neuroptera, Megaloptera, Raphidioptera). Systematic Entomology, 43:330-354. https:// doi.org/10.1111/syen.12278

Withycombe, C.L. 1925. XV. Some aspects of the biology and morphology of the Neuroptera. With special reference to the immature stages and their possible phylogenetic significance. Transactions of the Royal Entomological Society of London, 72:303-411. https://doi.org/10.1111/j.1365-2311.1925.tb03362.x

Zhang, W.W. 2017. Frozen Dimensions. The Fossil Insects and Other Invertebrates in Amber. Chongqing University Press, Chongqing. 


\section{SUPPLEMENTARY FIGURE 1.}

Factor loadings of the shape analysis.

PC1

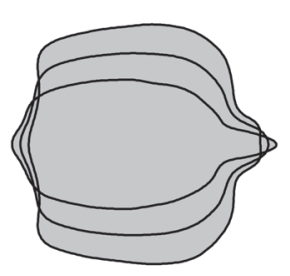

$-2 S . D$.
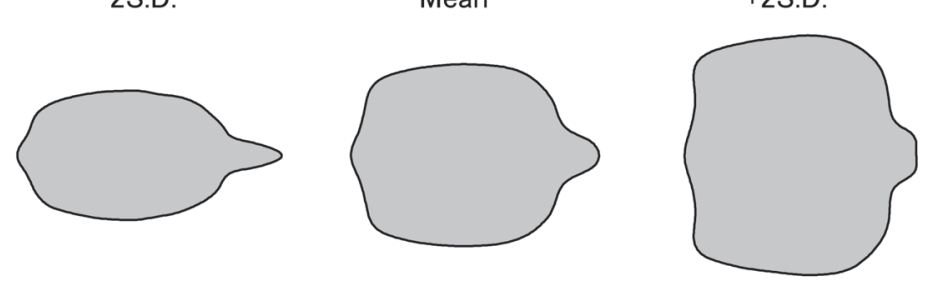

PC2
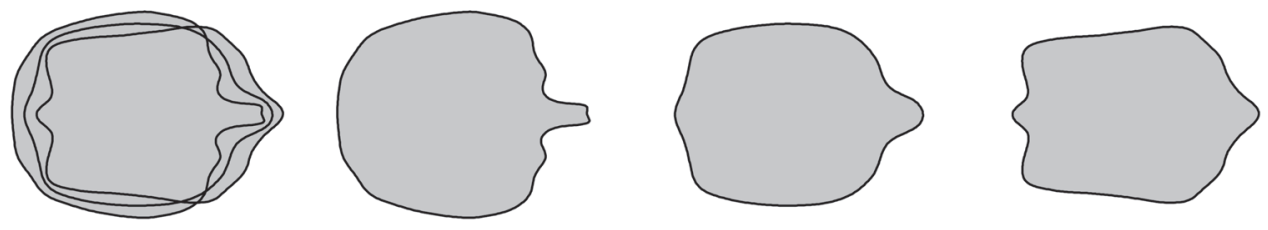

PC3
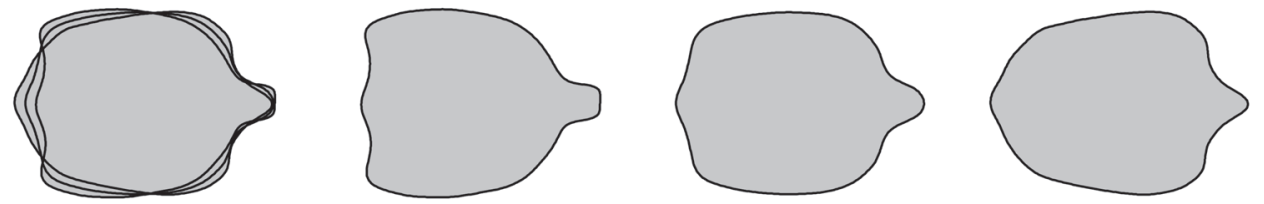

PC4
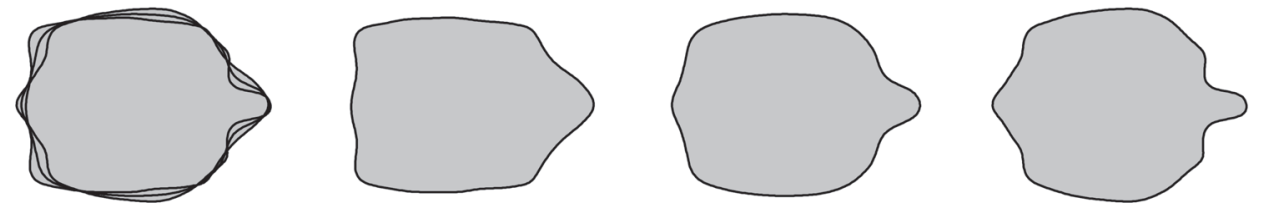

PC5
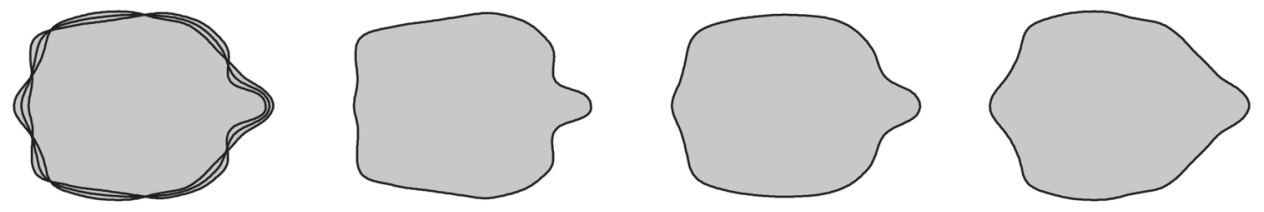

PC6
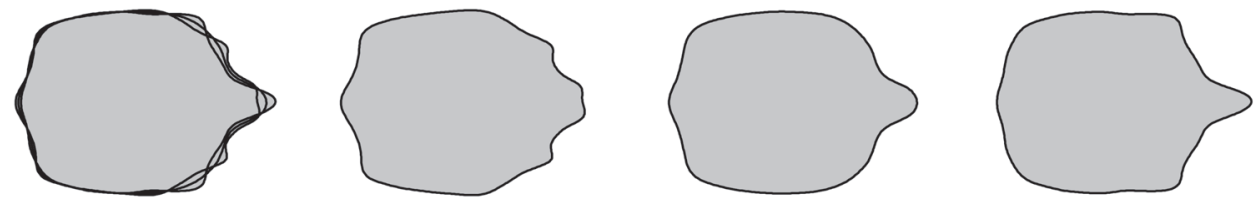


\section{SUPPLEMENTARY TABLE 1.}

Measured values of the specimens and values for PC1 and PC2. (Available online as zipped download at https://palaeo-electronica.org/content/2020/3113-long-nosed-antlion-diversity.)

\begin{tabular}{|c|c|c|c|c|c|c|c|}
\hline Age & Specimen & $\begin{array}{l}\text { Specimen source } \\
\text { reference }\end{array}$ & PC1 & PC2 & $\begin{array}{c}\text { Length } \\
\text { head } \\
\text { capsule wo } \\
\text { labrum in } \\
\text { mm }\end{array}$ & $\begin{array}{l}\text { Length head } \\
\text { capsule } \mathrm{w} \\
\text { labrum in } \mathrm{mm}\end{array}$ & $\begin{array}{c}\text { Width head } \\
\text { capsule in } \\
\mathrm{mm}\end{array}$ \\
\hline Cretaceous & 21 & Badano_etal_2018 & $-1.62 \mathrm{E}+05$ & $-1.13 E+05$ & 1.49 & 2.08 & 1.30 \\
\hline Cretaceous & 31 & BUB_3356 & $1.42 \mathrm{E}+04$ & $5.50 \mathrm{E}+04$ & 0.73 & 0.93 & 0.65 \\
\hline Cretaceous & 48 & BUB_3386 & $1.94 \mathrm{E}+05$ & $-2.01 \mathrm{E}+04$ & 0.50 & 0.60 & 0.54 \\
\hline Cretaceous & 38 & BUB_3389 & $-1.61 \mathrm{E}+05$ & $5.87 \mathrm{E}+04$ & 1.44 & 1.68 & 0.88 \\
\hline Cretaceous & 18 & Engel_\&Grimaldi_2008 & $1.62 \mathrm{E}+05$ & $-4.05 E+04$ & 0.48 & 0.57 & 0.49 \\
\hline Cretaceous & 16 & Perichot_2003 & $8.17 \mathrm{E}+04$ & $-1.04 \mathrm{E}+05$ & 0.57 & 0.70 & 0.58 \\
\hline Cretaceous & 22 & Makarkin_2018_1 & $-1.19 \mathrm{E}+05$ & $6.94 \mathrm{E}+04$ & 2.12 & 2.86 & 1.70 \\
\hline Cretaceous & 23 & Makarkin_2018_2 & $-2.06 \mathrm{E}+05$ & $-1.05 E+05$ & 1.86 & 2.25 & 1.27 \\
\hline Cretaceous & 50 & PED_0039 & $-1.01 \mathrm{E}+05$ & $-6.35 E+04$ & 0.75 & 0.93 & 0.56 \\
\hline Cretaceous & 45 & PED_0045 & $9.52 \mathrm{E}+04$ & $1.28 \mathrm{E}+05$ & 0.94 & 1.06 & 0.80 \\
\hline Cretaceous & 40 & PED_0051 & $-1.33 E+05$ & $2.52 \mathrm{E}+04$ & 0.69 & 0.86 & 0.54 \\
\hline Cretaceous & 32 & PED_0055 & $9.71 \mathrm{E}+04$ & $-5.27 E+04$ & 0.77 & 0.82 & 0.61 \\
\hline Cretaceous & 39 & PED_0060 & $5.06 \mathrm{E}+04$ & $-3.33 E+05$ & 1.00 & 1.17 & 1.00 \\
\hline Cretaceous & 42 & PED_0063 & $2.37 \mathrm{E}+05$ & $-1.21 \mathrm{E}+05$ & 0.52 & 0.56 & 0.56 \\
\hline Cretaceous & 35 & PED_0080 & $3.03 E+04$ & $5.04 \mathrm{E}+04$ & 2.13 & 2.47 & 2.10 \\
\hline Cretaceous & 33 & PED_0082 & $1.47 \mathrm{E}+04$ & $1.02 \mathrm{E}+04$ & 0.62 & 0.80 & 0.58 \\
\hline Cretaceous & 52 & PED_0100 & - & - & 4.33 & 4.72 & 4.35 \\
\hline Cretaceous & 49 & PED_0125 & $-8.83 E+04$ & $3.58 \mathrm{E}+04$ & 0.89 & 1.06 & 0.65 \\
\hline Cretaceous & 41 & PED_0127 & $-2.63 E+05$ & $-1.93 E+05$ & 1.06 & 1.82 & 1.21 \\
\hline Cretaceous & 47 & PED_0128 & $-6.59 E+04$ & $2.28 \mathrm{E}+04$ & 0.65 & 0.85 & 0.64 \\
\hline Cretaceous & 34 & PED_0131 & $7.02 \mathrm{E}+04$ & $9.30 \mathrm{E}+03$ & 0.81 & 0.85 & 0.81 \\
\hline Cretaceous & 46 & PED_0133 & $1.42 \mathrm{E}+05$ & $-4.85 E+04$ & 0.61 & 0.72 & 0.60 \\
\hline Cretaceous & 36 & PED_0137 & $6.91 \mathrm{E}+04$ & $6.39 \mathrm{E}+04$ & 0.73 & 0.80 & 0.52 \\
\hline Cretaceous & 43 & PED_0153 & $-6.00 \mathrm{E}+03$ & $5.43 E+04$ & 1.17 & 1.37 & 1.06 \\
\hline Cretaceous & 37 & PED_0205 & $1.84 \mathrm{E}+04$ & $4.88 \mathrm{E}+04$ & 0.88 & 1.19 & 0.90 \\
\hline Cretaceous & 20 & Zhang_2017 & $-1.13 E+05$ & $6.62 \mathrm{E}+04$ & - & - & - \\
\hline Eocene & 19 & Groehn_2015 & $-9.78 \mathrm{E}+04$ & $-4.26 \mathrm{E}+03$ & - & - & - \\
\hline Eocene & 24 & Groehn_sp_2994 & $1.85 \mathrm{E}+05$ & $1.53 E+04$ & 0.86 & 1.04 & 1.00 \\
\hline Eocene & 25 & Groehn_sp_7639 & $-7.92 \mathrm{E}+03$ & $7.45 \mathrm{E}+03$ & 0.97 & 1.21 & 0.94 \\
\hline Eocene & 27 & Jonas_Damzen & $-6.58 \mathrm{E}+04$ & $9.04 \mathrm{E}+04$ & 0.87 & 1.06 & 0.72 \\
\hline Eocene & 13 & MacLeod_1970 & $1.16 \mathrm{E}+05$ & $1.14 \mathrm{E}+04$ & 1.00 & & 0.98 \\
\hline Eocene & 14 & MacLeod_1970 & $4.53 \mathrm{E}+04$ & $6.14 \mathrm{E}+04$ & 1.00 & & 0.98 \\
\hline Eocene & 26 & Marius_Veta_01 & $-2.26 \mathrm{E}+05$ & $3.43 E+04$ & 0.47 & 0.61 & 0.30 \\
\hline Eocene & 27 & Marius_Veta_02 & $-1.56 \mathrm{E}+05$ & $5.25 \mathrm{E}+04$ & 1.04 & 1.23 & 0.67 \\
\hline Eocene & 28 & Marius_Veta_03 & $-7.40 \mathrm{E}+04$ & $6.88 \mathrm{E}+03$ & 0.51 & 0.65 & 0.40 \\
\hline Eocene & 15 & Weitschat_Wichard_1998 & $-4.41 \mathrm{E}+04$ & $8.72 \mathrm{E}+03$ & 1.11 & 1.33 & 1.09 \\
\hline Modern & 10 & Aspöck_\&_Aspöck_1999 & $-1.31 \mathrm{E}+04$ & $7.66 \mathrm{E}+04$ & 1.80 & 1.98 & 1.64 \\
\hline Modern & 11 & Badano_etal_2017 & $5.91 \mathrm{E}+04$ & $7.06 \mathrm{E}+04$ & 2.00 & 2.39 & 1.71 \\
\hline Modern & 1 & Froggatt_1907 & $-1.28 \mathrm{E}+04$ & $-5.23 E+04$ & - & - & - \\
\hline
\end{tabular}


PALAEO-ELECTRONICA.ORG

\begin{tabular}{llcccccc} 
Modern & 7 & MacLeod_1964 & $-6.00 \mathrm{E}+04$ & $5.03 \mathrm{E}+04$ & 2.48 & 2.88 & 1.98 \\
Modern & 8 & New_1989 & $2.15 \mathrm{E}+04$ & $-2.02 \mathrm{E}+03$ & 1.86 & 2.26 & 1.65 \\
Modern & 9 & New_1991 & $1.12 \mathrm{E}+04$ & $3.18 \mathrm{E}+04$ & 3.17 & 3.67 & 3.02 \\
Modern & 2 & Tillyard_1918_1 & $4.37 \mathrm{E}+04$ & $-1.07 \mathrm{E}+05$ & 0.6 & 0.76 & 0.6 \\
Modern & 3 & Tillyard_1918_2 & $4.69 \mathrm{E}+04$ & $3.63 \mathrm{E}+04$ & 0.54 & 0.57 & 0.68 \\
Modern & 4 & Tillyard_1918_3 & $-6.97 \mathrm{E}+03$ & $3.79 \mathrm{E}+04$ & 1.30 & 1.50 & 1.12 \\
Modern & 5 & Tillyard_1918_4 & $1.83 \mathrm{E}+05$ & $1.88 \mathrm{E}+04$ & 1.80 & 2.10 & 1.90 \\
\hline
\end{tabular}




\section{SUPPLEMENTARY TEXT 1.}

General outcome of the shape analysis. (Available online as zipped download at https://palaeoelectronica.org/content/2020/3113-long-nosed-antlion-diversity.)

[Analysis Information]

Results File : C:IUserslpgpazIDesktopISHAPE\Psycopsiden\Psycopsiden2.pcr

Analyzed NEF File : C:IUserslpgpazIDesktopISHAPEIPsycopsidenIPsycopsiden2.nef

Title of NEF File Data :

Analyzed Date : Sat Aug 03 11:38:29 2019

Method of Analysis : Covariance

Number of Data : 47

Number of Harmonics : 20

Number of Analyzed Harmonics : 20

Constant Coefficient(s) : a1 b1 c1

Number of Principal Components : 77

( = Number of Analyzed Coefficients (NAC) )

Number of Effective Principal Components : 6

( = Number of Principal Components whose proportion is larger than 1 / NAC )

Analyzed Coefficients : d1 a2 b2 c2 d2 a3 b3 c3 d3 a4 b4 c4 d4 a5 b5 c5 d5 a6 b6 c6 d6 a7 b7 c7 d7 a8 b8 c8 d8 a9 b9 c9 d9 a10 b10 c10 d10 a11 b11 c11 d11 a12 b12 c12 d12 a13 b13 c13 d13 a14 b14 c14 d14 a15 b15 c15 d15 a16 b16 c16 d16 a17 b17 c17 d17 a18 b18 c18 d18 a19 b19 c19 d19 a20 b20 c20 d20

[Mean of Coefficients]

a

1

2

3

4

5

6

7

8

9

10 b

9,013001E-001

$-1,142236 \mathrm{E}-002$

$-9,246928 E-004$

3,338180E-002

1,789355E-002

1,971402E-002

2,004014E-002

1,409044E-003

1,155929E-002

$-3,742925 E-003$
C

3,541960E-004

4,049880E-004

$-2,365464 \mathrm{E}-004$

6,621269E-004

$-3,120223 E-004$

1,928378E-004

-1,179402E-004

-4,946780E-004 -5,283721E-004 7,542369E-003

-1,064128E-004 -7,684433E-005 4,968046E-003

-5,443621E-004 1,889746E-005 1,782267E-003 


$\begin{array}{lllll}11 & 2,474630 \mathrm{E}-003 & 2,501617 \mathrm{E}-004 & 1,149081 \mathrm{E}-004 & 3,928757 \mathrm{E}-003 \\ 12 & -3,292831 \mathrm{E}-003 & -1,188024 \mathrm{E}-004 & 1,052184 \mathrm{E}-004 & 6,001994 \mathrm{E}-004 \\ 13 & -1,258874 \mathrm{E}-003 & -1,583003 \mathrm{E}-005 & -1,215376 \mathrm{E}-004 & 1,026173 \mathrm{E}-003 \\ 14 & -8,882003 \mathrm{E}-004 & -1,009216 \mathrm{E}-004 & 9,268205 \mathrm{E}-005 & 1,126052 \mathrm{E}-004 \\ 15 & 5,992307 \mathrm{E}-004 & -3,521711 \mathrm{E}-004 & -1,831116 \mathrm{E}-005 & -2,603924 \mathrm{E}-004 \\ 16 & -3,030715 \mathrm{E}-006 & -1,420960 \mathrm{E}-004 & -1,316949 \mathrm{E}-004 & -3,379506 \mathrm{E}-005 \\ 17 & 1,070093 \mathrm{E}-003 & -3,361517 \mathrm{E}-004 & -2,711440 \mathrm{E}-005 & -2,230399 \mathrm{E}-004 \\ 18 & -4,560399 \mathrm{E}-004 & -1,612551 \mathrm{E}-004 & -1,370525 \mathrm{E}-004 & -4,099025 \mathrm{E}-004 \\ 19 & 4,847169 \mathrm{E}-004 & -5,132764 \mathrm{E}-005 & 6,615035 \mathrm{E}-005 & 3,117016 \mathrm{E}-004 \\ 20 & -5,107569 \mathrm{E}-004 & -5,976346 \mathrm{E}-005 & -4,465082 \mathrm{E}-005 & 8,206074 \mathrm{E}-006\end{array}$

[Std of Coefficients]

$\begin{array}{lllll} & \text { a } & \text { b } & \text { C } & d \\ 1 & \text { Constant } & \text { Constant } & \text { Constant } & 1,141901 \mathrm{E}-001 \\ 2 & 5,962016 \mathrm{E}-002 & 2,564592 \mathrm{E}-003 & 2,696206 \mathrm{E}-003 & 5,639810 \mathrm{E}-002 \\ 3 & 3,142239 \mathrm{E}-002 & 1,565867 \mathrm{E}-003 & 1,876399 \mathrm{E}-003 & 3,025975 \mathrm{E}-002 \\ 4 & 1,977904 \mathrm{E}-002 & 2,084459 \mathrm{E}-003 & 2,074685 \mathrm{E}-003 & 1,928264 \mathrm{E}-002 \\ 5 & 2,012709 \mathrm{E}-002 & 2,582477 \mathrm{E}-003 & 1,960840 \mathrm{E}-003 & 1,815608 \mathrm{E}-002 \\ 6 & 1,511581 \mathrm{E}-002 & 1,988407 \mathrm{E}-003 & 8,727410 \mathrm{E}-004 & 9,767954 \mathrm{E}-003 \\ 7 & 1,334967 \mathrm{E}-002 & 2,762748 \mathrm{E}-003 & 8,759804 \mathrm{E}-004 & 7,839698 \mathrm{E}-003 \\ 8 & 1,147105 \mathrm{E}-002 & 2,335555 \mathrm{E}-003 & 1,856993 \mathrm{E}-003 & 8,649629 \mathrm{E}-003 \\ 9 & 1,045938 \mathrm{E}-002 & 2,711975 \mathrm{E}-003 & 7,112876 \mathrm{E}-004 & 5,471741 \mathrm{E}-003 \\ 10 & 1,026878 \mathrm{E}-002 & 1,454713 \mathrm{E}-003 & 7,430338 \mathrm{E}-004 & 4,039004 \mathrm{E}-003 \\ 11 & 1,095713 \mathrm{E}-002 & 1,501009 \mathrm{E}-003 & 1,498789 \mathrm{E}-003 & 4,415301 \mathrm{E}-003 \\ 12 & 8,249745 \mathrm{E}-003 & 1,877792 \mathrm{E}-003 & 6,140412 \mathrm{E}-004 & 3,624446 \mathrm{E}-003 \\ 13 & 7,368188 \mathrm{E}-003 & 1,104968 \mathrm{E}-003 & 4,306727 \mathrm{E}-004 & 2,555553 \mathrm{E}-003 \\ 14 & 3,670406 \mathrm{E}-003 & 5,956915 \mathrm{E}-004 & 3,134418 \mathrm{E}-004 & 2,599298 \mathrm{E}-003 \\ 15 & 4,439560 \mathrm{E}-003 & 1,417612 \mathrm{E}-003 & 3,361999 \mathrm{E}-004 & 2,672471 \mathrm{E}-003 \\ 16 & 3,747505 \mathrm{E}-003 & 1,038660 \mathrm{E}-003 & 4,364940 \mathrm{E}-004 & 2,135680 \mathrm{E}-003 \\ 17 & 3,001377 \mathrm{E}-003 & 1,606035 \mathrm{E}-003 & 4,772746 \mathrm{E}-004 & 1,823482 \mathrm{E}-003 \\ 18 & 3,115096 \mathrm{E}-003 & 7,963153 \mathrm{E}-004 & 7,094157 \mathrm{E}-004 & 1,603129 \mathrm{E}-003 \\ 19 & 2,789156 \mathrm{E}-003 & 5,956237 \mathrm{E}-004 & 5,536875 \mathrm{E}-004 & 1,026726 \mathrm{E}-003 \\ 20 & 3,188951 \mathrm{E}-003 & 5,211463 \mathrm{E}-004 & 4,693320 \mathrm{E}-004 & 1,334821 \mathrm{E}-003\end{array}$


HAUG ET AL.: LONG-NOSED ANTLION DIVERSITY

[Eigenvalue and Proportion]

\begin{tabular}{|c|c|c|c|c|}
\hline & Eigenvalue & Proportion(\%) & Cumulative(\%) & $>1 / 77$ \\
\hline Prin1 & 1,374158E-002 & 55,6576 & 55,6576 & * \\
\hline Prin2 & 6,630375E-003 & 26,8550 & 82,5126 & * \\
\hline Prin3 & 1,407523E-003 & 5,7009 & 88,2135 & * \\
\hline Prin4 & 8,832404E-004 & 3,5774 & 91,7909 & * \\
\hline Prin5 & 5,795102E-004 & 2,3472 & 94,1381 & * \\
\hline Prin6 & 3,561979E-004 & 1,4427 & 95,5808 & * \\
\hline Prin7 & 3,066356E-004 & 1,2420 & 96,8228 & \\
\hline Prin8 & 1,998735E-004 & 0,8095 & 97,6324 & \\
\hline Prin9 & 1,395009E-004 & 0,5650 & 98,1974 & \\
\hline Prin10 & 1,261851E-004 & 0,5111 & 98,7085 & \\
\hline Prin11 & 7,722640E-005 & 0,3128 & 99,0213 & \\
\hline Prin12 & 4,908225E-005 & 0,1988 & 99,2200 & \\
\hline Prin13 & 4,368390E-005 & 0,1769 & 99,3970 & \\
\hline Prin14 & 3,118802E-005 & 0,1263 & 99,5233 & \\
\hline Prin15 & 2,030702E-005 & 0,0822 & 99,6056 & \\
\hline Prin16 & 1,916525E-005 & 0,0776 & 99,6832 & \\
\hline Prin17 & 1,342779E-005 & 0,0544 & 99,7376 & \\
\hline Prin18 & 1,214732E-005 & 0,0492 & 99,7868 & \\
\hline Prin19 & 9,878194E-006 & 0,0400 & 99,8268 & \\
\hline Prin20 & 8,456684E-006 & 0,0343 & 99,8610 & \\
\hline Prin21 & 7,012797E-006 & 0,0284 & 99,8894 & \\
\hline Prin22 & 4,595290E-006 & 0,0186 & 99,9080 & \\
\hline Prin23 & 3,934891E-006 & 0,0159 & 99,9240 & \\
\hline Prin24 & 3,650210E-006 & 0,0148 & 99,9388 & \\
\hline Prin25 & 2,828082E-006 & 0,0115 & 99,9502 & \\
\hline Prin26 & 2,574916E-006 & 0,0104 & 99,9606 & \\
\hline Prin27 & 2,059027E-006 & 0,0083 & 99,9690 & \\
\hline Prin28 & 1,698327E-006 & 0,0069 & 99,9759 & \\
\hline Prin29 & 1,206911E-006 & 0,0049 & 99,9808 & \\
\hline Prin30 & 7,671337E-007 & 0,0031 & 99,9839 & \\
\hline Prin31 & 6,639683E-007 & 0,0027 & 99,9866 & \\
\hline Prin32 & $6,456122 E-007$ & 0,0026 & 99,9892 & \\
\hline Prin33 & $6,117698 \mathrm{E}-007$ & 0,0025 & 99,9916 & \\
\hline
\end{tabular}




\begin{tabular}{|c|c|c|c|}
\hline Prin34 & 5,751086E-007 & 0,0023 & 99,9940 \\
\hline Prin35 & 3,700404E-007 & 0,0015 & 99,9955 \\
\hline Prin36 & 2,533536E-007 & 0,0010 & 99,9965 \\
\hline Prin37 & 2,336975E-007 & 0,0009 & 99,9974 \\
\hline Prin38 & 1,532594E-007 & 0,0006 & 99,9981 \\
\hline Prin39 & 1,132112E-007 & 0,0005 & 99,9985 \\
\hline Prin40 & 1,019811E-007 & 0,0004 & 99,9989 \\
\hline Prin41 & 8,097672E-008 & 0,0003 & 99,9993 \\
\hline Prin42 & 7,363526E-008 & 0,0003 & 99,9996 \\
\hline Prin43 & 3,779834E-008 & 0,0002 & 99,9997 \\
\hline Prin44 & 3,080417E-008 & 0,0001 & 99,9998 \\
\hline Prin45 & 2,186609E-008 & 0,0001 & 99,9999 \\
\hline Prin46 & 1,704243E-008 & 0,0001 & 100,0000 \\
\hline Prin47 & 1,794093E-019 & 0,0000 & 100,0000 \\
\hline Prin48 & 2,286244E-020 & 0,0000 & 100,0000 \\
\hline Prin49 & $1,436332 E-020$ & 0,0000 & 100,0000 \\
\hline Prin50 & 1,234527E-020 & 0,0000 & 100,0000 \\
\hline Prin51 & 5,841178E-021 & 0,0000 & 100,0000 \\
\hline Prin52 & 3,301462E-021 & 0,0000 & 100,0000 \\
\hline Prin53 & 1,998344E-021 & 0,0000 & 100,0000 \\
\hline Prin54 & $1,350950 E-021$ & 0,0000 & 100,0000 \\
\hline Prin55 & 1,158544E-021 & 0,0000 & 100,0000 \\
\hline Prin56 & 9,942159E-022 & 0,0000 & 100,0000 \\
\hline Prin57 & 6,397532E-022 & 0,0000 & 100,0000 \\
\hline Prin58 & 4,846920E-022 & 0,0000 & 100,0000 \\
\hline Prin59 & 2,086806E-022 & 0,0000 & 100,0000 \\
\hline Prin60 & $9,398104 \mathrm{E}-023$ & 0,0000 & 100,0000 \\
\hline Prin61 & $6,730416 \mathrm{E}-023$ & 0,0000 & 100,0000 \\
\hline Prin62 & -1,054137E-022 & 0,0000 & 100,0000 \\
\hline Prin63 & $-2,266325 E-022$ & 0,0000 & 100,0000 \\
\hline Prin64 & $-2,916995 \mathrm{E}-022$ & 0,0000 & 100,0000 \\
\hline Prin65 & $-6,583730 \mathrm{E}-022$ & 0,0000 & 100,0000 \\
\hline Prin66 & $-1,011585 E-021$ & 0,0000 & 100,0000 \\
\hline Prin67 & $-1,206215 E-021$ & 0,0000 & 100,0000 \\
\hline Prin68 & $-1,384734 \mathrm{E}-021$ & 0,0000 & 100,0000 \\
\hline
\end{tabular}


HAUG ET AL.: LONG-NOSED ANTLION DIVERSITY

$\begin{array}{llll}\text { Prin69 } & -1,508118 \mathrm{E}-021 & 0,0000 & 100,0000 \\ \text { Prin70 } & -2,006845 \mathrm{E}-021 & 0,0000 & 100,0000 \\ \text { Prin71 } & -2,087937 \mathrm{E}-021 & 0,0000 & 100,0000 \\ \text { Prin72 } & -2,840998 \mathrm{E}-021 & 0,0000 & 100,0000 \\ \text { Prin73 } & -2,867573 \mathrm{E}-021 & 0,0000 & 100,0000 \\ \text { Prin74 } & -3,276927 \mathrm{E}-021 & 0,0000 & 100,0000 \\ \text { Prin75 } & -8,104551 \mathrm{E}-021 & 0,0000 & 100,0000 \\ \text { Prin76 } & -1,144573 \mathrm{E}-020 & 0,0000 & 100,0000 \\ \text { Prin77 } & -2,524190 \mathrm{E}-020 & 0,0000 & 100,0000\end{array}$

Total Variance: 2,468950E-002 